\title{
Circulation of Heavy Ions and Their Dynamical Effects in the Magnetosphere: Recent Observations and Models
}

\author{
Elena A. Kronberg • Maha Ashour-Abdalla • Iannis Dandouras • \\ Dominique C. Delcourt • Elena E. Grigorenko • Lynn M. Kistler • Ilya V. Kuzichev • \\ Jing Liao • Romain Maggiolo $\cdot$ Helmi V. Malova $\cdot$ Ksenia G. Orlova • \\ Vahe Peroomian • David R. Shklyar • Yuri Y. Shprits • Daniel T. Welling • \\ Lev M. Zelenyi
}

Received: 29 April 2014 / Accepted: 26 September 2014 / Published online: 22 October 2014

(C) The Author(s) 2014. This article is published with open access at Springerlink.com

\begin{abstract}
Knowledge of the ion composition in the near-Earth's magnetosphere and plasma sheet is essential for the understanding of magnetospheric processes and instabilities. The presence of heavy ions of ionospheric origin in the magnetosphere, in particular oxygen $\left(\mathrm{O}^{+}\right)$, influences the plasma sheet bulk properties, current sheet (CS) thickness and its structure. It affects reconnection rates and the formation of Kelvin-Helmholtz instabilities. This has profound consequences for the global magnetospheric dynamics, including geomagnetic storms and substorm-like events. The formation and demise of the ring current and the radiation belts are also dependent on the presence of heavy ions. In this review we cover recent advances in observations and models of the circulation of heavy ions in the magne-
\end{abstract}

\footnotetext{
E.A. Kronberg (凶)

Max Planck Institute for Solar System Research, Göttingen, 37077, Germany

e-mail: kronberg@mps.mpg.de
}

\section{Ashour-Abdalla · K.G. Orlova · V. Peroomian · Y.Y. Shprits}

Department of Earth Planetary and Space Sciences, University of California, Los Angeles, CA, 90095, USA

\section{Dandouras}

Institut de Recherche en Astrophysique et Planétologie (IRAP), University of Toulouse, UPS-OMP,

UMR 5277, Toulouse, France

I. Dandouras

IRAP, CNRS, Toulouse, France

D.C. Delcourt

Laboratoire de Physique des Plasmas, Palaiseau Cedex, 91128, France

E.E. Grigorenko · I.V. Kuzichev · H.V. Malova · D.R. Shklyar · L.M. Zelenyi

Space Research Institute, Russian Academy of Sciences, Moscow, 117810, Russia

L.M. Kistler · J. Liao

University of New Hampshire, Durham, NH 03824, USA

R. Maggiolo

Institut d'Aeronomie Spatiale de Belgique, Brussels, 1180, Belgium 
tosphere, considering sources, transport, acceleration, bulk properties, and the influence on the magnetospheric dynamics. We identify important open questions and promising avenues for future research.

Keywords Heavy ions · Ion outflow · Plasma sheet · Magnetospheric dynamics · Ion acceleration

\section{List of Acronyms}

AE

Auroral Electrojet

AMIE Assimilative Mapping of Ionospheric Electrodynamics

AMPTE Active Magnetospheric Particle Tracer Explorers

BATS-R-US Block Adaptive Tree Solar wind Roe-type Upwind Scheme

CAMMICE Charge and Mass Magnetospheric Ion Composition Experiment

CHEM Charge Energy Mass experiment

CME Coronal Mass Ejection

CIS Cluster Ion Spectrometry

CODIF COmposition DIstribution Function

CPCP Cross Polar Cap Potential

CS Current Sheet

Dst Disturbance storm time

EMIC ElectroMagnetic Ion Cyclotron

ENA Energetic Neutral Atom

EPIC Energetic Particle and Ion Composition

EUV Extreme Ultraviolet radiation

GOES Geostationary Operational Environmental Satellite

GSE Geocentric Solar Ecliptic

GSM Geocentric Solar Magnetospheric

$\mathrm{H}^{+} \quad$ Hydrogen ion

$\mathrm{He}^{+} \quad$ Helium ion

HENA High-Energy Neutral Atom

IMAGE Imager for Magnetopause-to-Aurora Global Exploration

IMF Interplanetary Magnetic Field

ISEE International Earth-Sun Explorer

LANL Los Alamos National Lab

LFM Lyon-Fedder-Mobarry

LSK Large-Scale Kinetic

MHD MagnetoHydroDynamics

K.G. Orlova

Skobeltsyn Institute of Nuclear Physics, Lomonosov Moscow State University, Moscow 119991, Russia

Y.Y. Shprits

Skolkovo Institute of Science and Technology, Skolkovo 143025, Russia

Y.Y. Shprits

Department of Earth Atmospheric and Planetary Sciences, Massachusetts Institute of Technology,

Cambridge, MA 02139, USA

D.T. Welling

University of Michigan, Ann Arbor, MI 48109, USA 


$\begin{array}{ll}\text { MICS } & \text { Magnetospheric Ion Composition Spectrometer } \\ \text { MLT } & \text { Magnetic Local Time } \\ \text { NENL } & \text { Near-Earth Neutral Line } \\ \mathrm{O}^{+} & \text {Oxygen ion } \\ \text { PSBL } & \text { Plasma Sheet Boundary Layer } \\ \text { PWOM } & \text { Polar Wind Outflow Model } \\ \text { RAPID } & \text { Research with Adaptive Particle Imaging Detectors } \\ \text { R }_{\text {E }} & \text { Earth Radii } \\ \text { SC } & \text { Spacecraft } \\ \text { SSC } & \text { Sudden Storm Commencement } \\ \text { STICS } & \text { Supra-Thermal Ion Composition Spectrometer } \\ \text { TCS } & \text { Thin Current Sheet }\end{array}$

\section{Introduction}

It was a surprising discovery that strongly accelerated ions of ionospheric origin, including helium and oxygen $\left(\mathrm{He}^{+}, \mathrm{O}^{+}\right)$, are observed in the Earth's magnetosphere and in the surrounding solar wind. The ionosphere is rather cold, with the temperature of the ions not exceeding a few $\mathrm{eV}$. How ionospheric ions are energized by several orders of magnitude to escape and populate the magnetosphere is not only interesting in the context of magnetospheric physics but also has possible applications in astrophysical and laboratory plasmas.

Since the pioneering discovery of Shelley et al. (1972), a number of studies have provided evidence of heavy ions (mostly $\mathrm{O}^{+}$) of ionospheric origin throughout the magnetosphere: in the lobes (e.g., Sharp et al. 1981; Candidi et al. 1982, 1984; Seki et al. 1998a, 1998b), in the plasma sheet (e.g., Mukai et al. 1994), and in the ring current (Hamilton et al. 1988). Through transport from the ionosphere into these different magnetospheric regions, the heavy ion populations significantly modify the ambient plasma density and temperature. The contribution of the ionospheric population is highly variable. Therefore, it is important to define which ionospheric sources are responsible for the ion supply into the magnetosphere and what determines their dependence on the geomagnetic and solar conditions. What are the ejection and acceleration mechanisms responsible for ion escape from the ionosphere? How is the transport of ions affected by external conditions?

Knowledge of the ion composition in the near-Earth magnetosphere and plasma sheet is essential for the analysis of magnetospheric processes and related instabilities. Plasma composition determines its mass density, and so it impacts fundamental plasma properties such as the Alfvén speed and the plasma pressure. As the presence of heavy ions in the plasma sheet changes the magnitude of the Alfvén speed, it could affect the reconnection rate. In the low-latitude flanks, these ions modify the threshold for the Kelvin-Helmholtz instabilities that are important drivers of global magnetospheric dynamics. Also the presence of $\mathrm{O}^{+}$ions has been identified as a possible factor influencing the current sheet (CS) stability with respect to tearing perturbations. The exact role of heavy ions in the reconnection rate, in the formation of multiple islands in the magnetotail, and in the structure of magnetic separatrices is still highly debated. Because their Larmor radii are much larger than those of protons, $\mathrm{O}^{+}$ions exhibit nonadiabatic behavior throughout most of the distant magnetotail and they may thus influence the tail CS structure and pressure balance. The presence of these ions can lead to the thickening of CSs and play a role in the formation of the double-humped current density that has now been reported by a variety of spacecraft (SC). 
Heavy ions can be effectively energized in the magnetotail by inductive electric fields during substorm dipolarizations, by electric fields near X-lines, or through magnetic turbulence. Heavy ions can also be energized due to the duskward drift along the dawn-dusk electric field, in the course of their convection from the distant tail towards the Earth. Therefore, they may contribute to substorm-related plasma processes in the distant magnetotail and also influence the dynamics of middle and inner magnetotail regions. It is still unclear which energization mechanism is dominant.

Ultimately, these $\mathrm{O}^{+}$ions may be convected into the innermost magnetosphere, where they feed the ring current populations. The contribution to the innermost populations is especially important during geomagnetic storms. The ring current changes at distances of 3-6 Earth Radii $\left(\mathrm{R}_{\mathrm{E}}\right)$ during geomagnetic storms are responsible for the well documented disturbances of the geomagnetic field measured by the Disturbance storm time (Dst) index. The changes in the geomagnetic field are proportional to the changes in the plasma pressure (or equivalently, the plasma energy density) and variations in this parameter define the growth and decay phases of the ring current. Several studies have shown that, during magnetic storms, the presence of ionospheric $\mathrm{O}^{+}$ions leads to significant plasma pressure enhancements in the inner magnetosphere, while a decrease of the $\mathrm{O}^{+}$contribution is associated with a fast decay of the ring current. Changes in the ring current and outer radiation belts are of the foremost importance for space weather studies, and adequate modeling of these regions of space must thus account for the contribution of these heavy ions of ionospheric origin.

While a number of questions on the role of these ions are still open (Sect. 7), the focus of this paper is to review recent findings on the sources (Sect. 2), transport and acceleration (Sect. 3), bulk properties (Sect. 4), losses (Sect. 5) and the impact on the magnetospheric dynamics (Sect. 6) to help establish a comprehensive view of heavy ions in the Earth's magnetosphere.

\section{Sources}

There are two primary sources for the magnetospheric plasma: the solar wind and the ionosphere. The solar wind consists predominantly of protons $\left(\mathrm{H}^{+}\right)$. The abundance of $\mathrm{He}^{++}$is usually in the range of $3 \%$ to $6 \%$ (Neugebauer 1981; Aellig et al. 2001; Kasper et al. 2007), although wide variations, with values as high as $30 \%$, are sometimes observed (e.g. Borrini et al. 1982, and references therein). Other heavy ions constitute $<0.1 \%$ of the total (e.g. Gloeckler and Geiss 1989). Thus, except in rare cases, the solar wind is not an important source of heavy ions. The solar wind enters the magnetosphere predominantly through magnetic reconnection, which can occur across the dayside magnetosphere during southward IMF (Interplanetary Magnetic Field), and tailward of the high latitude cusp during northward IMF. The plasma escaping from the ionosphere also has a $\mathrm{H}^{+}$component, but contains a significant and highly variable contribution from heavy ion species. The heavy ions that are able to escape into the magnetosphere reflect the composition of the topside ionosphere: $\mathrm{He}^{+}$, $\mathrm{N}^{+}, \mathrm{O}^{+}$, and the molecular ions $\mathrm{NO}^{+}$and $\mathrm{O}_{2}^{+}$have all been observed (e.g. Yau et al. 1991; Klecker et al. 1986). However, the dominant heavy ion present in the magnetosphere is $\mathrm{O}^{+}$. The heavy ion content of the magnetosphere will depend on the flux of the ionospheric outflow, the composition of the ionospheric outflow, and the mix of solar wind and ionospheric plasma at a particular time.

The energy input into the ionosphere that controls the outflow comes from three sources: solar EUV (Extreme Ultraviolet radiation), electromagnetic energy from reconnection at the 


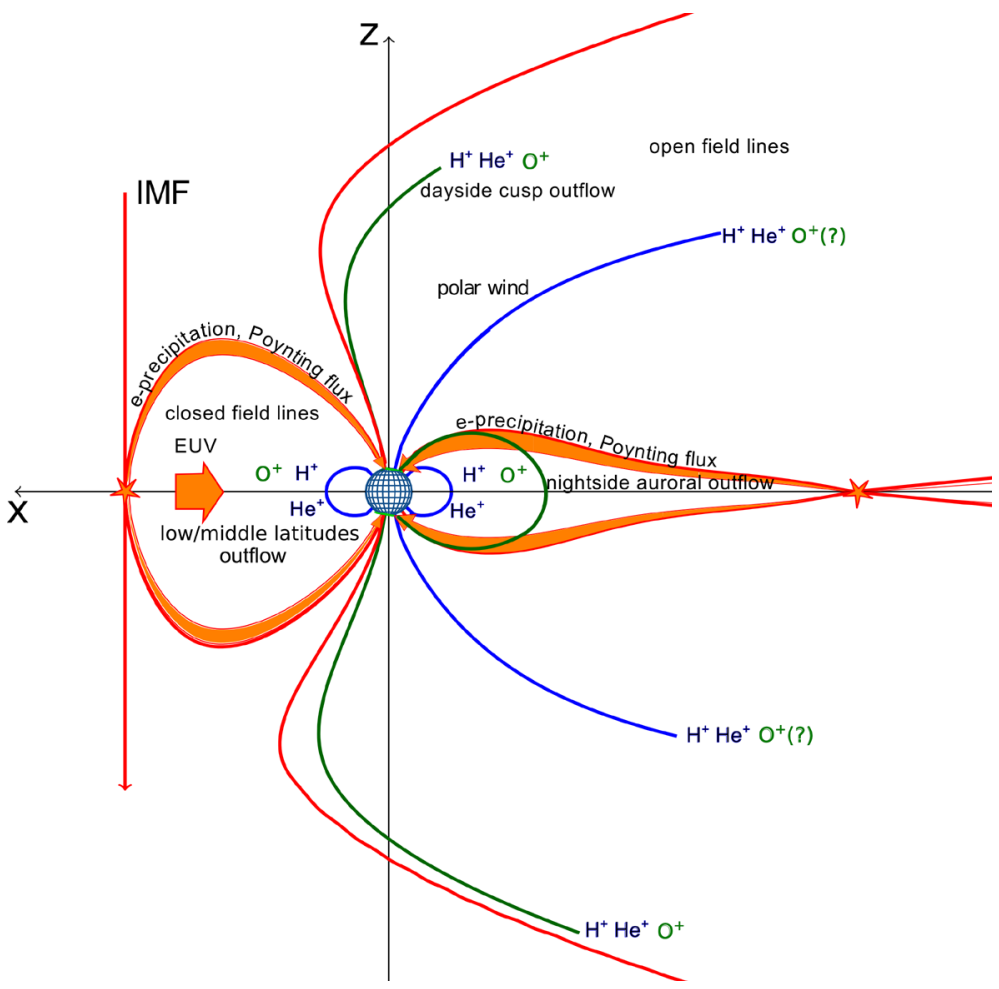

Sketch 1 Main sources of heavy ions and corresponding trajectories of outflowing ionospheric ions: polar cap (polar wind), auroral region subdivided into dayside cusp and the nighsight auroral region and low/middle latitudes. The green-colored trajectories represent sources for which the content of oxygen is significant. The blue-colored trajectories indicate sources with negligible amounts of oxygen. The red-colored lines are the magnetic fields. The lines are drawn using particle tracing model from D. Delcourt. The orange-colored arrows show the energy inputs into the ionosphere

magnetopause that creates a downward Poynting flux, and electron precipitation, as shown in Sketch 1. The solar EUV controls the overall ionization, heating and molecular dissociation rates of the neutral atmosphere. The EUV input changes with solar cycle, solar activity, and season, as well as time of day. Changes in the EUV affect the ionospheric and atmospheric densities, composition, and scale height. In general, the $\mathrm{H}^{+}$density increases with increasing EUV input, but the scale height is not strongly affected (Yau et al. 1985). For O ${ }^{+}$, both the density and scale height increase with EUV input, and so a seasonal and a solar cycle effect are observed, as well as short term changes with solar activity (Yau et al. 1985; Cully et al. 2003). The Poynting flux and electron precipitation input are driven by changes in the solar wind and IMF. The Poynting flux results in ionospheric heating through Joule dissipation. The higher thermal temperature increases the scale height of the ionospheric ions. At higher altitudes, wave-particle interactions accelerate the ions further, driving them into the magnetosphere. In the subsections below we discuss the outflow in different regions. The main regions of ionospheric escape include the polar region, which is subdivided into polar cap and auroral region, and the region at low/middle latitudes, see Sketch 1 . 


\subsection{Polar Region}

\subsubsection{Polar Cap}

Polar Wind The low-energy ions escaping over the polar cap are called the polar wind, see Sketch 1. The polar wind was first postulated by Axford (1968) as an analogy to the solar wind. As the concept of the open magnetosphere became accepted, Axford (1968) recognized that the polar cap field lines would be open to the magnetotail lobes. They hypothesized that the radial pressure gradient would cause the high density ionospheric plasma to expand along these open field lines to the empty lobes. The classical mechanism of polar wind escape assumes that the ionosphere is in hydrostatic equilibrium, with the gravitational force balanced by the pressure gradient. The electrons would have a higher scale height than the ions due to their smaller masses. However, this charge separation generates an "ambipolar electric field" that brings up the ions. Because the dominant ion in the ionosphere is $\mathrm{O}^{+}$, the electric field which balances the gravitational force on $\mathrm{O}^{+}$would be strong enough to drive the lighter ions, $\mathrm{H}^{+}$and $\mathrm{He}^{+}$, up the field lines.

Observations confirm that there is a steady ion outflow over the polar cap, with a velocity increasing with altitude, reaching about $12 \mathrm{~km} / \mathrm{s}$ for $\mathrm{H}^{+}$(see review by Yau et al. 2007). Surprisingly the outflow contains $\mathrm{O}^{+}$, as well as $\mathrm{H}^{+}$and $\mathrm{He}^{+}$, in contrast to the classical picture. Observations from Akebono (Abe et al. 1993; Cully et al. 2003) and Polar (e.g. Su et al. 1998) show the presence of $\mathrm{O}^{+}$ions above the polar caps, especially during stormtime and solar-maximum (Lotko 2007). It is not clear if these $\mathrm{O}^{+}$ions actually belong to the polar wind proper and are further accelerated by additional mechanisms or if they correspond to the thermal part of cusp and/or auroral outflows (Chandler 1995, Su et al. 1998). More realistic 3D time dependent models have been developed that give reasonable agreement with the observations (Schunk and Sojka 1989, 1997; Schunk 2007). The more realistic models do not assume hydrostatic equilibrium, and include time dependence, with the flux tubes convecting over the polar cap, while the outflow occurs.

Due to their very low energies that are comparable to the SC potential in the polar cap and lobe $(<\sim 40 \mathrm{eV})$, the cold ionospheric ions are usually invisible to plasma instruments without SC potential control. The TIDE experiment onboard the Polar satellite provided accurate measurements at altitudes around $8 \mathrm{R}_{\mathrm{E}}$ (Su et al. 1998). Numerical simulations using measurements from TIDE have also been performed to supplement these measurements and provide density estimates between a few $R_{E}$ altitudes up to $10 \mathrm{~s}$ of $R_{\mathrm{E}}$ (Huddleston et al. 2005). Cully et al. (2003) made an extensive study of low energy (1-70 eV) $\mathrm{O}^{+}$and $\mathrm{H}^{+}$outflow using measurements from the Akebono satellite at altitudes between 2000 and $10000 \mathrm{~km}$. They reported a net flux increase rate of the same order of magnitude from low to high geomagnetic activity levels and from low to high solar EUV flux (monitored by the $\mathrm{Kp}$ and F10.7 indecies, respectively). The increases were a factor of $\sim 5$ for $\mathrm{H}^{+}$and of more than one order of magnitude for $\mathrm{O}^{+}$.

Polar Cap Ion Beams Above the polar ionosphere (it is still controversial if the magnetic topology closed or open) and during prolonged periods of northward IMF, Cluster revealed the presence of upflowing ion beams consisting of $\mathrm{O}^{+}$and $\mathrm{H}^{+}$ions locally accelerated by field-aligned, quasi-static electric fields to energies of typically hundreds of eVs (Maggiolo et al. 2006). They are probably associated with polar cap arcs (Maggiolo et al. 2012). It is an intermittent source of $\mathrm{O}^{+}$ions active only during prolonged periods of northward IMF and the total outflow flux associated with polar cap ion beams is low compared to other sources. However, it may provide a source of $\mathrm{O}^{+}$ions to the far tail regions because of the significant field aligned acceleration and low convection electric field during periods of northward IMF (Maggiolo et al. 2011). 


\subsubsection{Auroral Region}

The auroral oval is a major source of the ionospheric plasma that reaches the magnetosphere. Although outflow can be observed at all locations along the oval, there are two dominant regions: a relatively narrow region close to local noon, identified as the dayside cusp, and a broader region centered around midnight, the nightside auroral region. An extended statistical study of energetic outflow $(0.01-17 \mathrm{keV})$ of the full oval based on measurements from the DE-1 SC (Yau et al. 1988) reveals that energetic $\mathrm{O}^{+}$outflows strongly depend on geomagnetic activity measured by the Kp index (up to a factor of 20 from low to high geomagnetic activity during solar maximum) while the corresponding increase of $\mathrm{H}^{+}$ion outflow is about a factor of $\sim 4$. Solar EUV flux is associated with an increase of the $\mathrm{O}^{+}$flux by a factor of $\sim 5$. These orders of magnitude have been further confirmed by other studies (see the review by Yau and André 1997).

Dayside Cusp The dayside cusp region is a site for the precipitation of soft $(\sim 100 \mathrm{eV})$ electrons, as the magnetosheath plasma has direct access along open field lines. This precipitation can heat the ambient plasma directly. It also enhances the ionization, which increases the electron density. The increased temperature raises the electron scale height which amplifies the ambipolar electric field, bringing ions to higher altitudes as well. Joule heating due to reconnection at the dayside also causes ionospheric upwelling in this region. At higher altitudes $(>1000 \mathrm{~km})$ a variety of waves are excited which can accelerate ions through gyroresonant interactions (see review by Andre and Yau 1997). The ions are accelerated predominantly perpendicular to the magnetic field, and then move up the field due to the mirror force. This multi-step process is summarized by Strangeway et al. (2005). They used FAST data to identify correlations between the input energy functions and the outflow flux to determine the importance of the different mechanisms, and found that they all contributed, and were all to some extent correlated.

The cusp outflow population has a significant $\mathrm{O}^{+}$component with an energy range from a few eV to a few $\mathrm{keV}$. The total flux is mainly controlled by ionospheric upflow at low altitudes (Nilsson et al. 2006) which is modulated by the inflow of magnetosheath plasma into the cusp (Lennartsson et al. 2004) and by the solar illumination level (Peterson et al. 2006). The further acceleration of ions into the high altitude cusp region will be discussed in Sect. 3.2.

Nightside Auroral Region Nightside auroral outflows occur on closed field lines (see an example of ion trajectory in Sketch 1), close to the open/closed field-line boundary or so called plasma sheet boundary layer (PSBL). They are particularly intense on magnetic field lines connected to the tail regions, where energy is released during active periods (Andersson et al. 2004). The ions can be accelerated to energies up to a few tens of keVs by either quasistatic electric fields associated with inverted V's or wave-particle interactions (Ergun et al. 1998). The dominant source of the nightside auroral outflow is ion conics driven by waves at the plasma sheet boundary layer (Tung et al. 2001). Wilson et al. (2004) examined how the nightside auroral outflow varied with time relative to substorm onset time for substorms of different intensities. They found that regardless of intensity, the outflow increased by about a factor of two at onset time. However, the more intense substorms had a significantly higher outflow rate, both before and after substorm onset, indicating that overall activity level has a greater impact than the substorm itself. 


\subsection{Low/Middle Latitudes}

There is some direct entry from the ionosphere into the inner magnetosphere. At very low energies $(\sim 1 \mathrm{eV})$, this is the plasmasphere. The plasmasphere results from essentially the same processes as the polar wind, but because the ions at low latitudes are upflowing on closed field lines and on closed drift paths, they can accumulate in the inner magnetosphere, creating a very dense cold plasma region (see an example of ion trajectory in Sketch 1). The $\mathrm{He}^{+} / \mathrm{H}^{+}$ratio in the plasmasphere is typically 0.2 (Horwitz et al. 1990). The $\mathrm{O}^{+}$density is significantly below $\mathrm{He}^{+}$but highly variable (Horwitz et al. 1990). A narrow region just inside the plasmapause, termed the " $\mathrm{O}^{+}$torus", can have $\mathrm{O}^{+}$densities two orders of magnitude higher than further in Roberts et al. (1987). The location of the plasmapause changes with geomagnetic activity (Kp index) and plumes of dense plasma from the plasmasphere are observed in the dusk sector, moving to the magnetopause. In addition, the plasmaspheric wind, an outflow from boundaries of the plasmasphere, whose presence was confirmed by Dandouras (2013), also supplies the inner magnetosphere with $\mathrm{H}^{+}$and $\mathrm{He}^{+}$.

In the sub-keV range, the low-latitude source may be also important. A recent study by Yamauchi et al. (2013) reviewed the variety of ion signatures observed in the sub-keV range. One common feature is a "wedge-like" dispersion signature. This signature could be due to drift from a cold population in the plasma sheet (Ebihara et al. 2001). However, the drift signatures were often mixed with new upflowing ions, indicating that low latitude upflow (an interval from the low-altitude ionosphere to the plasmasphere) is also a source (Giang et al. 2009). Short bursts of low energy $(<100 \mathrm{eV})$ field aligned ions is another indication of low latitude outflow Yamauchi et al. (2013).

\subsection{Sources and Global Models}

Translating the multitude of acceleration mechanisms into an ionospheric source of plasma in global-scale numerical magnetosphere models is key to investigating the impact of this population on magnetospheric dynamics. Typically, this involves adjusting an inner boundary or initial condition such that outflow manifests in the code results. Efforts to include outflow in large scale models has increased precipitously over the past decade, and now a multitude of models include these effects with varying degrees of complexity.

The simplest method to include outflow in large scale models is to simply prescribe outflow properties for a time, region, or population of interest. This was first done in a 2D kinetic particle tracing model by Horwitz (1984); ionospheric $\mathrm{O}_{2}^{+}, \mathrm{O}^{+}, \mathrm{He}^{+}$, and $\mathrm{H}^{+}$of prescribed initial energies were seeded at a geocentric radius of $1.3 \mathrm{R}_{\mathrm{E}}$. This methodology was subsequently expanded to 3D by Sauvaud and Delcourt (1987) and Delcourt et al. (1989); outflow properties were selected to represent average observed conditions. Similarly, early simulations of $\mathrm{O}^{+}$by the Large Scale Kinetic (LSK) model launched particles with set energies, pitch angles, and spatial distributions (Peroomian and Ashour-Abdalla 1996). Huddleston et al. (2005), in an attempt to bind their launch particle distributions to observations more completely and realistically, used SC-potentialcorrected fluxes observed from Polar-TIDE to create a spatially-dependent statistical picture of outflow characteristics at an altitude of $5000 \mathrm{~km}$. More recently, global multifluid magnetohydrodynamic (MHD) codes have used prescribed constant outflows to investigate their impacts on global configurations (Wiltberger et al. 2010; Garcia et al. 2010; Yu and Ridley 2013). This approach is still useful despite limited resemblance to the complex, time-dependent real world outflows. 
Advanced techniques have been developed in an effort to introduce causality between magnetospheric activity and ionospheric outflow. This was accomplished in LSK simulations by tying the statistical weight of dayside-launched $\mathrm{O}^{+}$to upstream solar wind dynamic pressure (Peroomian et al. 2006) via the empirical relationship developed by Pollock et al. (1990) and Moore et al. (1999). The empirical relationship of Strangeway et al. (2005), relating precipitating electron flux and poynting flux to $\mathrm{O}^{+}$outflow, has been leveraged heavily to drive causally driven outflow. It has been used to set the spatial distribution and intensity of storm time $\mathrm{O}^{+}$sources in the LSK (Peroomian et al. 2011a) and incorporated into the multifluid version of the Lyon-Fedder-Mobarry (LFM) global MHD code (Brambles et al. 2010; Damiano et al. 2010). This allows global simulation results to affect the location and rate of outflowing $\mathrm{O}^{+}$in real time.

A series of studies beginning with Moore et al. (2007) and leading to Fok et al. (2011), use inner-boundary results from the single fluid version of LFM as inputs to the Strangeway et al. (2005) relationship, but to initiate $\mathrm{O}^{+}$in a global particle tracing model. Eschewing empirical relationships in favor of a first-principles-based approach, the Block Adaptive Tree Solar wind Roe-type Upwind Scheme (BATS-R-US) MHD model has been two-way coupled to the Polar Wind Outflow Model (PWOM) (Glocer et al. 2009a, 2009b). This model solves a horizontal distribution of vertical 1-D fluid "pipes" to get a spatial outflow distribution of $\mathrm{O}^{+}, \mathrm{He}^{+}$, and $\mathrm{H}^{+}$at the MHD inner boundary. All of these approaches allow, in some form or another, magnetospheric dynamics to dictate outflow activity.

Interestingly, the use of simple, static inner boundary conditions in global MHD codes acts as an ionospheric source of magnetospheric plasma by itself. Though noted by Siscoe et al. (2001) and later more deeply explored by Walker et al. (2003) and Welling and Ridley (2010), it was Winglee (1998) that first leveraged this behavior in a global multifluid code to include heavy ion outflow. It was subsequently shown that even when the mass density inner boundary conditions are constant, the resulting outflow away from the boundary is quite dynamic (Winglee 2002; Winglee et al. 2008) and correlates strongly with cross polar cap potential (CPCP) and solar wind dynamic pressure (Welling and Liemohn 2014). The dynamic nature of these outflows, in spite of their static sources, implies that global fluid models are able to capture some fraction of the high latitude outflow acceleration. Even when not noted, this source occurs in many different MHD simulations.

\section{Transport and Acceleration of $\mathrm{O}^{+}$}

In this section we consider the transport and acceleration of heavy ions circulating from the ionosphere through different regions: lobes, plasma sheet and inner magnetosphere. A summary of this ion circulation is presented in Sketch 2.

\subsection{Lobes}

\subsubsection{Convection and Velocity Filter Effect}

The transport of the heated cusp ions in the lobes effectively separates ions of different energies, a phenomenon known as the velocity filter effect. The ion motion is a combination of the parallel motion along the magnetic field and convective motion perpendicular to it. Due to the presence of the dawn-dusk electric field, the convection brings ions towards the neutral sheet with velocity $V=E \times B / B^{2}$, see Sketch 2 . The region where the ions reach the plasma sheet is determined by the ratio of their velocity along the magnetic field lines 


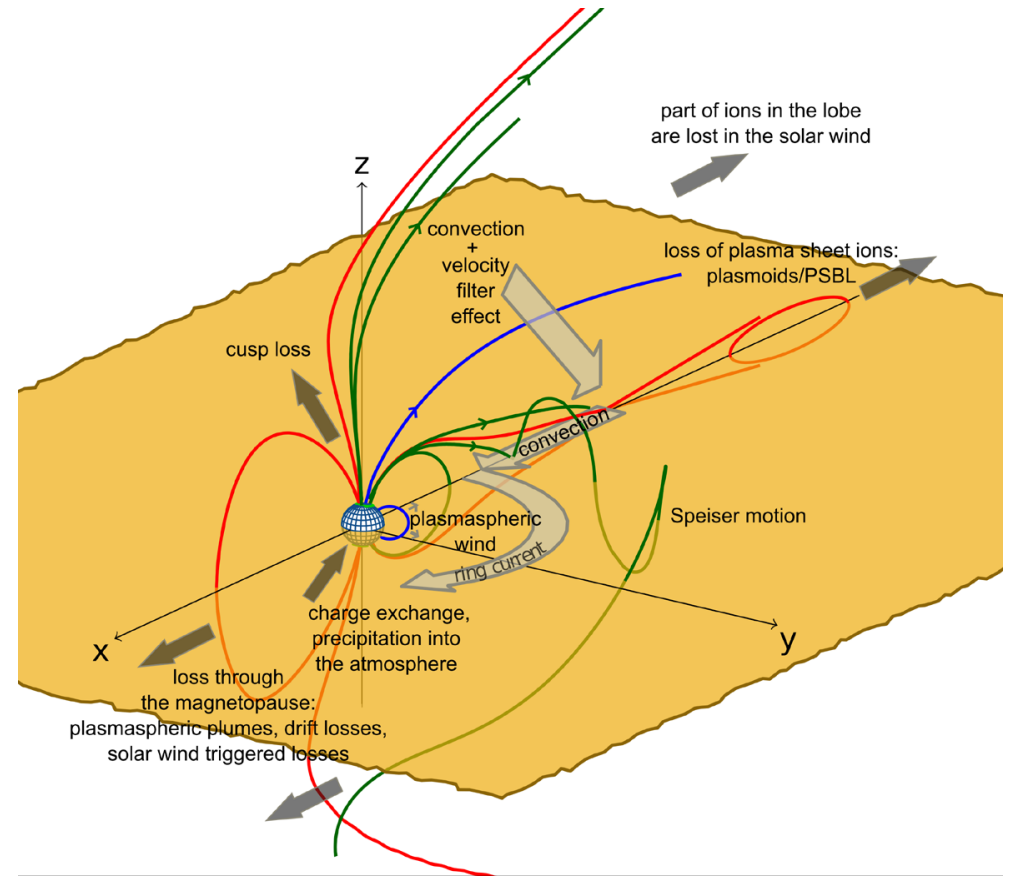

Sketch 2 Circulation of heavy ions in the magnetosphere. Green and blue lines represent the ion trajectories from the dayside cusp, the polar cap, the nightside auroral region and from low/middle latitudes, in the same format as in Sketch 1. Light gray arrows indicate direction of ion transport. A fraction of the ions are trapped in the magnetosphere. The rest are lost through the processes indicated by dark gray arrows

and the convection velocity. Particles with higher speed along the field can travel farther down the tail (e.g., Seki et al. 1998a, 1998b), while slower ones move towards the central plasma sheet. The heated cusp distributions are folded into cold beams in the lobes due to the mirror force. As a result of the velocity filter effect, the beams observed in the polar cap and tail lobes often have mono-energetic distributions (Liao et al. 2010). During transport into the lobes, electric field modulations may also affect the $\mathrm{O}^{+}$trajectories. Such modulations may consist of Alfvèn waves propagating in the lobes (Sauvaud et al. 2004), convection pulses propagating at low velocity in the lobes and possibly triggered by IMF $B_{z}$ turnings (Maggiolo et al. 2006) or by dipolarization fronts associated with substorms (Sauvaud et al. 2012).

\subsubsection{Asymmetry in Particle Paths}

A statistical study of the $\mathrm{O}^{+}$paths from the cusp to the magnetotail using Cluster observations by Cluster Ion Spectrometry (CIS)/Composition Distribution Function (CODIF) (see Rème et al. 2001 for the instrument description) reveals that occurrence frequency of $\mathrm{O}^{+}$ion beams detection in the tail lobes is fairly high, even during quiet times (Liao et al. 2010), see Fig. 1 . The probability of observing $\mathrm{O}^{+}$is even higher during storm recovery phase and it maximizes during storm main phase. Solar wind pressure and IMF strength have the best correlation with the $\mathrm{O}^{+}$occurrence rate. Also, an overall asymmetry was found in the ion paths whereby $\mathrm{O}^{+}$are preferentially transported into the north-dawn and south-dusk sectors. This path asymmetry is mainly controlled by IMF $\mathrm{B}_{\mathrm{y}}$. When IMF $\mathrm{B}_{\mathrm{y}}$ is positive, $\mathrm{O}^{+}$flowing 


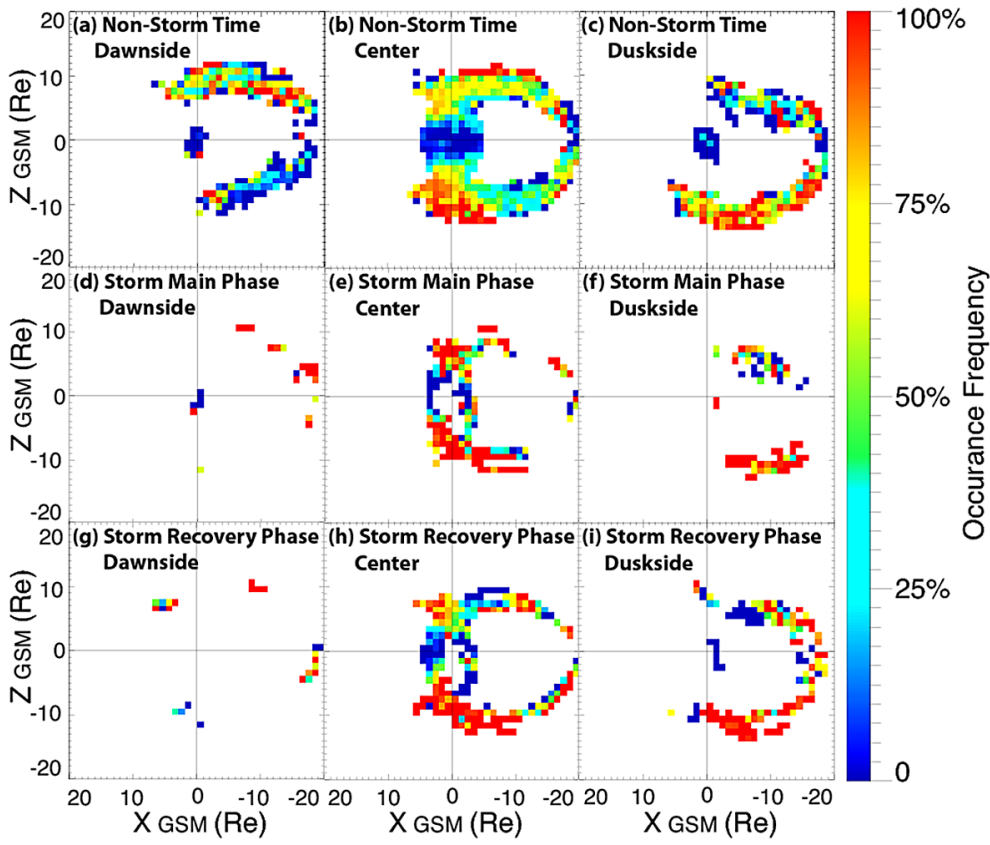

Fig. 1 Occurrence frequency of streaming $\mathrm{O}^{+}$in the lobe and polar cap projected into the GSM (Geocentric Solar Magnetospheric) system $\mathrm{X}-\mathrm{Z}$ plane for three different storm states (from top to bottom) and $\mathrm{Y}_{\mathrm{GSM}}$ directions (from left to right), from Liao et al. (2010)

out from the northern cusp streams into the dawn side tail lobe, while $\mathrm{O}^{+}$from the southern hemisphere are observed on the dusk side. The reversed asymmetry is not obtained unless the negative IMF $B_{y}$ is very strong $(<-3 \mathrm{nT})$. The ion path configuration also varies during solar cycle, as is illustrated in Fig. 2 taken from Liao et al. (2012). The transport paths gradually move upward and sunward during the solar declining phase (viz., from 2001 to 2008), which would be consistent with a reduced convection velocity. This tends to move ions further down the tail rather than into the near-Earth plasma sheet.

\subsection{3 $\mathrm{O}^{+}$Acceleration in the Lobes}

The $\mathrm{O}^{+}$ions from the cusp form an important source for the storm-time plasma sheet (e.g., Kistler et al. 2010a). The average $\mathrm{O}^{+}$energies recorded in the cusp source region are significantly lower than those in the plasma sheet, and it is thus of primary importance to investigate acceleration mechanisms along the ion paths to understand the overall $\mathrm{O}^{+}$transport. The polar orbit of the Cluster SC is ideally suited to examine these ion paths from the cusp to the plasma sheet, and to track ion velocity changes. However, because of the velocity filter effect, ions with higher velocities reach the tail further down, even in the absence of an ion acceleration mechanism. This velocity filter effect must thus be taken into account when investigating velocity changes from SC data.

The lobe properties suggest that the most probable acceleration mechanism for $\mathrm{O}^{+}$in this region is centrifugal acceleration. Although weak, it can lead to a substantial velocity increase if it operates over a long time. Nilsson et al. (2010) estimated that the average acceleration value in the near-Earth magnetotail is about $5 \mathrm{~m} \mathrm{~s}^{-2}$. This results in a velocity 

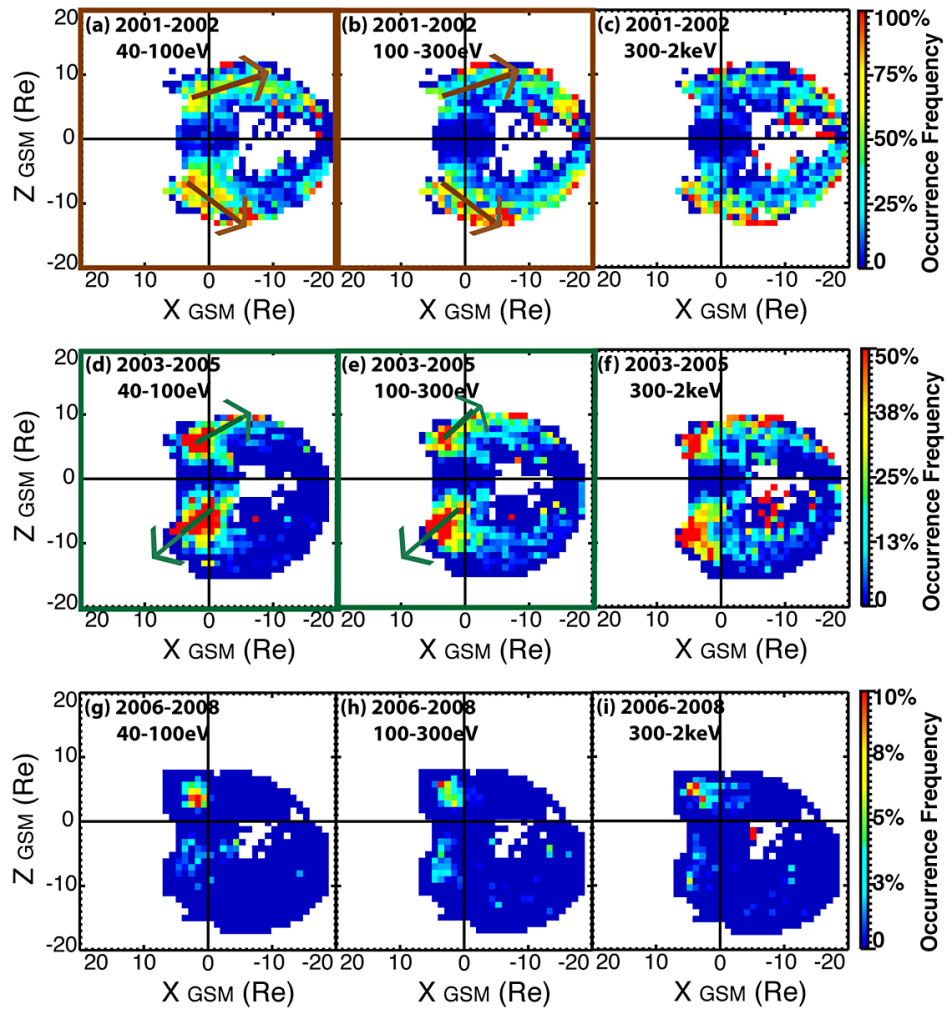

(j) Comparison of the Transport Path

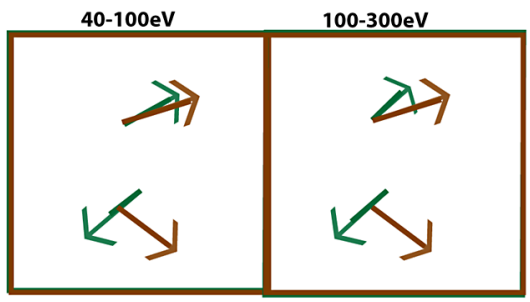

Fig. 2 Occurrence frequency of streaming $\mathrm{O}^{+}$within different energy ranges (viz., from left to right, 40-100 eV, 100-300 eV, $300 \mathrm{eV}-2 \mathrm{keV}$ ) during non-storm times at solar maximum (2001-2002; top panels), transition time (2003-2005; middle panels), and solar minimum (2006-2008; bottom panels). Arrows overplotted in panels a-b (in brown) and d-e (in green) show the observed paths (i.e., where occurrence frequencies are the highest). These different arrows are compared in panel j. Taken from Liao et al. (2012)

increases up to $20 \mathrm{~km} \mathrm{~s}^{-1}$ in the $5-19 \mathrm{R}_{\mathrm{E}}$ interval. The average velocity increase observed in the cold $\mathrm{H}^{+}$population is $15 \mathrm{~km} / \mathrm{s}$, with a $95 \%$ confidence interval from 0 to $20 \mathrm{~km} / \mathrm{s}$ (e.g., Engwall et al. 2009a, 2009b). While the observations are consistent with centrifugal acceleration, the velocity increase may simply be caused by the velocity filter effect. The observations do clearly show that the bulk population is not being accelerated to plasma sheet energies in the lobe.

To separate the velocity filter effect from true acceleration, Liao (2011) compared the normalized distribution functions of the lobe $\mathrm{O}^{+}$with the initial distribution functions ob- 
served in the cusp. While the cusp distribution is dispersed in the tail due to the velocity filter effect, phase space density is conserved, according to Liouville's theorem. Thus each lobe beam distribution represents a velocity slice of the cusp distribution. By comparing the accumulated distributions from the lobe beams with the cusp distribution, one can determine if acceleration has occurred. Figure 3 shows an example from a case study. Figure 3 a displays the $\mathrm{H}^{+}$and $\mathrm{O}^{+}$ion energy spectra for a time period when the Cluster $\mathrm{SC}$ go over the cusp into the polar cap and lobe, and into the plasma sheet. The black line indicates when Cluster was passing the cusp, and the colored lines indicate time periods when lobe beams are observed. Figure $3 \mathrm{~b}$ compares the normalized distribution functions of each of the lobe beam observations with the cusp outflow. To first order, it was found that the lobe beams fall within the envelope defined by the cusp outflow, implying no significant acceleration. Note, that acceleration of the order of $20 \mathrm{~km} / \mathrm{s}(\sim 40 \mathrm{eV})$ is too small to be detected. Because the cusp outflow can be changing with time, a statistical study was conducted to determine if this result is true in general. The statistical study showed that during non-storm times, most of the energetic $\mathrm{O}^{+}$observed in the lobes are well under the upper envelope of the observed initial distributions, indicating that no strong acceleration is at work and that the observed flows are predominantly due to the velocity filter effect. In contrast, during storm times, part of the streaming $\mathrm{O}^{+}$populations (viz., from $500 \mathrm{eV}$ up to $2 \mathrm{keV}$ ) are found above the upper envelope of the outflow distributions. In the PSBL, the distributions are above the upper envelope of the outflow distributions both during storm times and during non-storm times. This suggests that some acceleration is at work in the direction perpendicular to the magnetic field in the boundary layer, with $\mathrm{O}^{+}$ions being transported into the plasma sheet by a strong electric field, on the order of $20 \mathrm{mV} / \mathrm{m}$.

\subsubsection{Ion Transport to the Distant Tail}

Haaland et al. (2012) combined measurements of ion velocity and density from Cluster (Engwall et al. 2009b) with convection electric field measurements in the lobes (Haaland et al. 2008,2009 ) to quantify the recirculation of cold upflowing ions. The recirculation is directly controlled by the convection electric field. That is, during southward IMF periods, convection is strong and most of the cold ions reach the plasma sheet and are recirculated inside the magnetosphere while during northward IMF, characterized by stagnant convection, most of these ions escape down the tail, ultimately entering the solar wind.

$\mathrm{O}^{+}$ions have been observed as far down the tail as $200 \mathrm{R}_{\mathrm{E}}$ in the deep lobe/mantle region (e.g., Mukai et al. 1994; Baker et al. 1996a; Seki et al. 1996, 1998a, 1998b). A key observational characteristics of these distant tail beams is that they are observed in mantlelike plasma simultaneously with $\mathrm{H}^{+}$and $\mathrm{He}^{++}$of solar wind origin. All ion species flow at approximately the same velocity. Their occurrence frequency is highest during active times. In addition, $\mathrm{He}^{+}$is sometimes observed but with a density that seems anti-correlated with the $\mathrm{O}^{+}$density. For cusp outflow, they determined that the outflow would have to be further accelerated by another $\sim 3 \mathrm{keV}$ from the distributions observed at FAST altitudes $(\sim 4000 \mathrm{~km})$ in order to explain the observations.

New information from Cluster may shed light on this issue. Bouhram et al. (2004) and Nilsson et al. (2006) have shown that the acceleration of ions in the cusp is not limited to low altitudes. It continues into the high altitude cusp, where strong transverse heating may energize the ions to $>10 \mathrm{keV}$. The degree of acceleration for a particular ion population depends on the altitude at which it convects out of the cusp. Ions that convect into the polar cap at lower altitudes are not heated to such high energies, and so the $\mathrm{O}^{+}$beams 


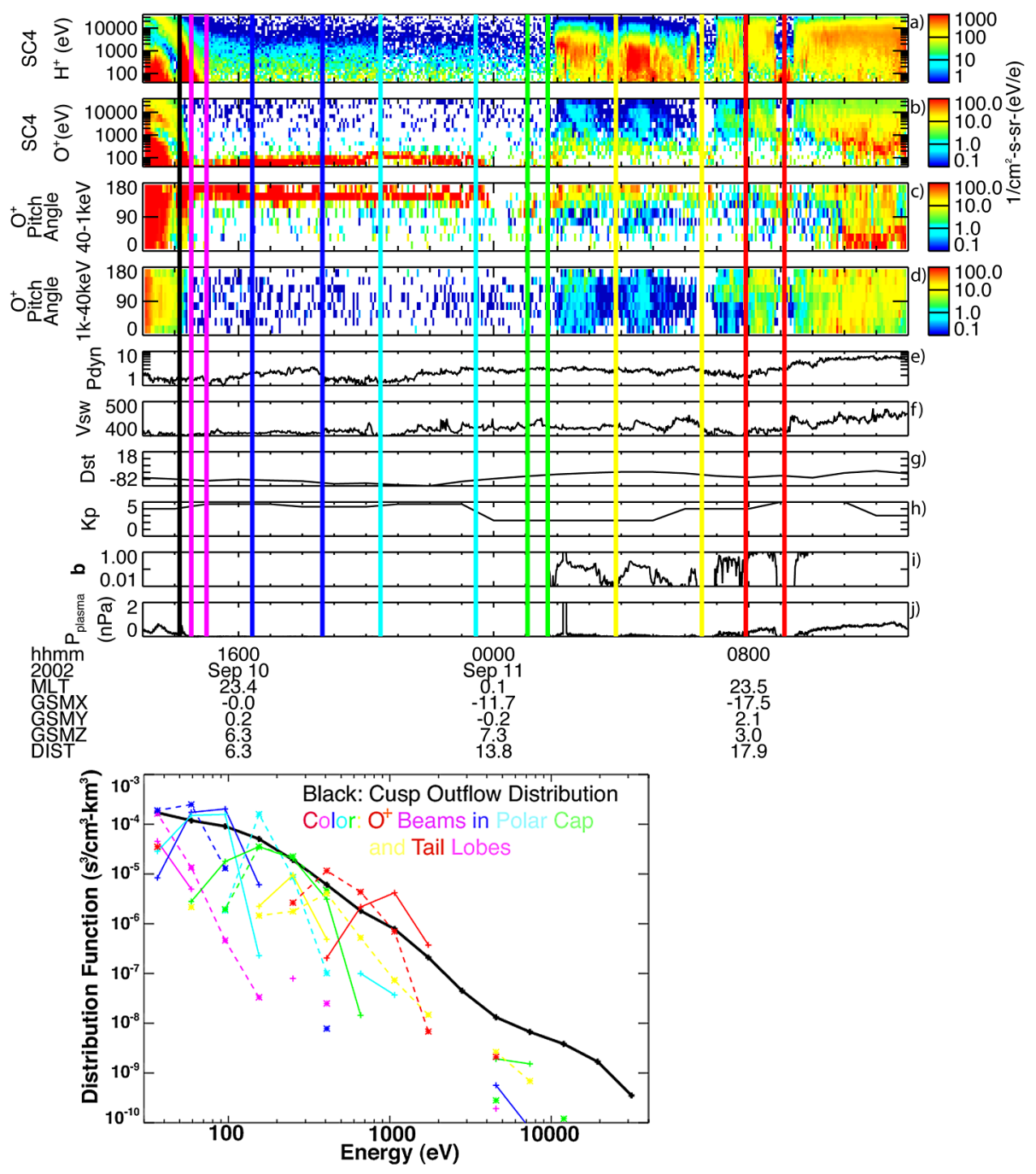

Fig. 3 (a) One day plot of CIS/CODIF Cluster data and external conditions. Cutting lines show the time of cusp pass (in black) and typical $\mathrm{O}^{+}$beams observed in polar cap and tail lobes (in colors). Panels from top to bottom: $\mathrm{H}^{+}$and $\mathrm{O}^{+}$energy spectra, $\mathrm{O}^{+}$pitch angle spectra within energy range between $40 \mathrm{eV}-1 \mathrm{keV}$ and $1 \mathrm{keV}-40 \mathrm{keV}$, solar wind pressure and velocity, Dst and $\mathrm{Kp}$ indexes, plasma beta and plasma pressure. (b) Distribution function VS energy plot for $\mathrm{O}^{+}$outflow at cusp and $\mathrm{O}^{+}$beams in polar cap and tail lobes. Normalized to $1000 \mathrm{~km}$. Color lines correspond to the cuts in panel (a). Taken from Liao (2011)

normally observed over the polar cap and in the lobes by Cluster have energies of $<1 \mathrm{keV}$. But acceleration in the high-altitude region extends the energy range of the ionospheric ion source up to $10 \mathrm{keV}$. The parallel bulk velocity of $\mathrm{O}^{+}$and $\mathrm{H}^{+}$are usually within the same range while the thermal velocity of $\mathrm{O}^{+}$is always much lower than that of $\mathrm{H}^{+}$(Nilsson et al. 2013). These new measurements show that the additional acceleration required to be consistent with the tail observations does in fact occur. In addition, the energetic $\mathrm{O}^{+}$in this region is mixed with the solar wind origin $\mathrm{H}^{+}$from the magnetosheath, consistent with 
the beams that are observed in the tail. Thus it seems that the high altitude cusp provides a likely source for the deep-tail beams. The high energy $\mathrm{O}^{+}(\sim 10 \mathrm{keV})$ beams are also occasionally observed by Cluster in the near-Earth $\left(<19 \mathrm{R}_{\mathrm{E}}\right)$ lobe when a shock compresses the magnetosphere (Zhang et al. 2011b), bringing in the populations that are close to the magnetopause.

In addition, to the $\mathrm{O}^{+}$beams present in the lobe/mantle region, Kistler et al. (2010b) observed the presence of $\mathrm{O}^{+}$ions in the distant $\left(\sim 200 \mathrm{R}_{\mathrm{E}}\right)$ plasma sheet. These ions are most likely ultimately from the cusp, but it is difficult to determine at which distance they moved from the lobe into the plasma sheet. If the ions enter the plasma sheet tailward of the near-Earth neutral line (NENL), then they will be swept tailward when reconnection occurs and a plasmoid forms, as shown in Sketch 2.

\subsection{Plasma Sheet}

\subsubsection{Simulating the Ion History}

The acceleration of ionospheric ions and their transport into the plasma sheet and ring current have been investigated by particle tracing calculations for a number of years (Green and Horwitz 1986; Sauvaud and Delcourt 1987; Delcourt et al. 1989, 1990; Cladis and Francis 1992; Peroomian 1994; Peroomian and Ashour-Abdalla 1995, 1996; Moore and Delcourt 1995; Moore et al. 2005; Ebihara et al. 2006; Yau et al. 2012). More recently, Peroomian et al. (2006, 2007, 2011a, 2011b) have investigated the access and energization of ionospheric ions to the magnetotail during geomagnetic storms by using LSK particle tracing simulation using time-dependent electric and magnetic fields of individual storm events.

For example Peroomian et al. (2006) performed a LSK particle tracing simulation of the 24-25 September 1998 geomagnetic storm driven by Coronal Mass Ejection (CME). This study was carried out by first running an MHD simulation of the event using upstream data from the WIND SC. The time-dependent electric and magnetic fields from the MHD simulation were then used to launch $\mathrm{O}^{+}$ions from the topside ionosphere, with an outflow rate determined from the Moore et al. (1999) data correlating $\mathrm{O}^{+}$outflow with variations in solar wind dynamic pressure. Figure 4a shows the energy density in the ring current (black curve) and equatorial plasma sheet (red curve) obtained from the LSK simulations for this event. Figure $4 \mathrm{~b}$ shows the solar wind dynamic pressure, which increases abruptly with the arrival of the interplanetary shock and remains elevated for the next three hours. Figure 4a shows a rapid increase in energy density in both the plasma sheet and ring current almost immediately after the sudden storm commencement (SSC). Peroomian et al. (2006) computed average flight times of 60-80 minutes for ionospheric ions prior to storm onset, indicating that the rapid increase seen in Fig. $4 \mathrm{a}$ is due to $\mathrm{O}^{+}$ions that were already in the lobes at storm onset. Figures $4 \mathrm{c}-4 \mathrm{f}$ show results in the ring current for two additional CMEdriven storms. For these simulations, Peroomian et al. (2011a, 2011b) used the Strangeway et al. (2005) formulae relating downward Poynting flux and electron precipitation into the ionosphere as proxies for $\mathrm{O}^{+}$outflow. The blue curves in Figs. $4 \mathrm{c}$ and $4 \mathrm{e}$ show the energy density of $\mathrm{O}^{+}$ions in the nightside ring current for the two storms. These results illustrate that the arrival and energization of $\mathrm{O}^{+}$in the near-Earth magnetotail occurs rapidly after storm onset, and does not lag due to the long flight times from the dayside and nightside $\mathrm{O}^{+}$ sources.

For the 17 April 2002 storm, Peroomian et al. (2011a) examined the "fate" of ions found in the near-Earth plasma sheet. They followed the orbits of ions found in a "seed" region 

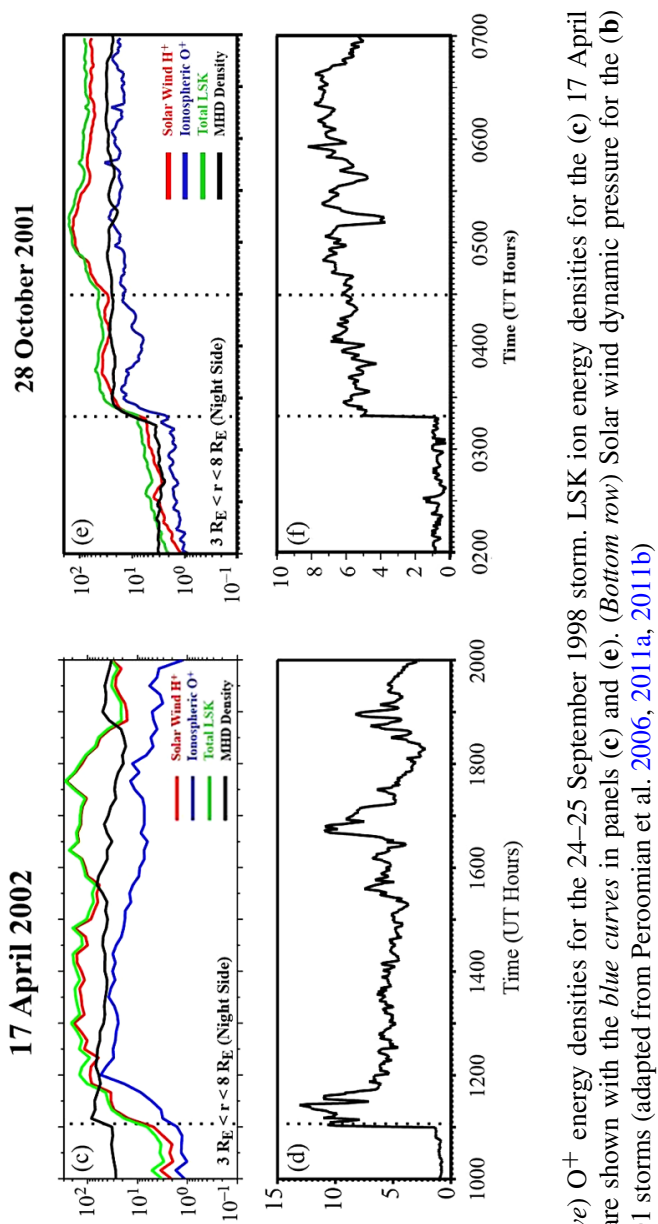

مे 뭉 웡 की กิ ㄱ. . .

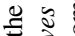
홍 幽 可

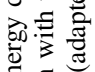
ए to 䒛 0ิ

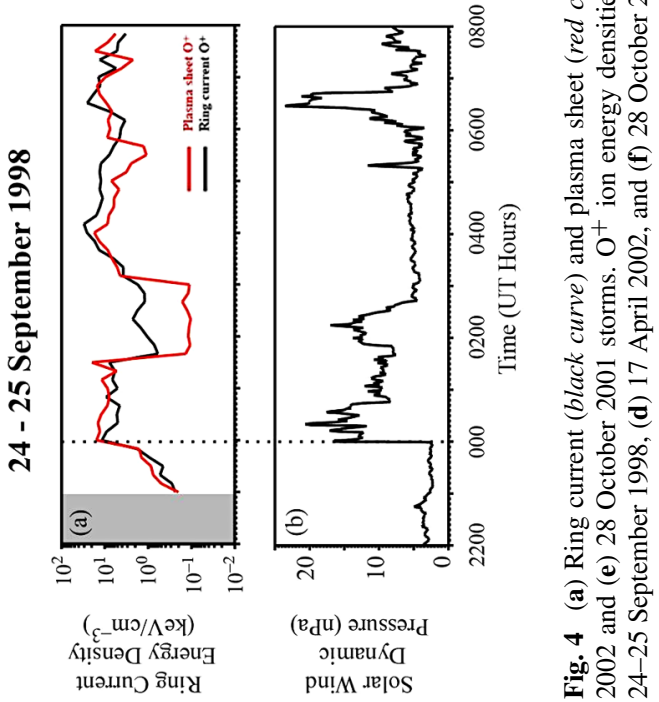



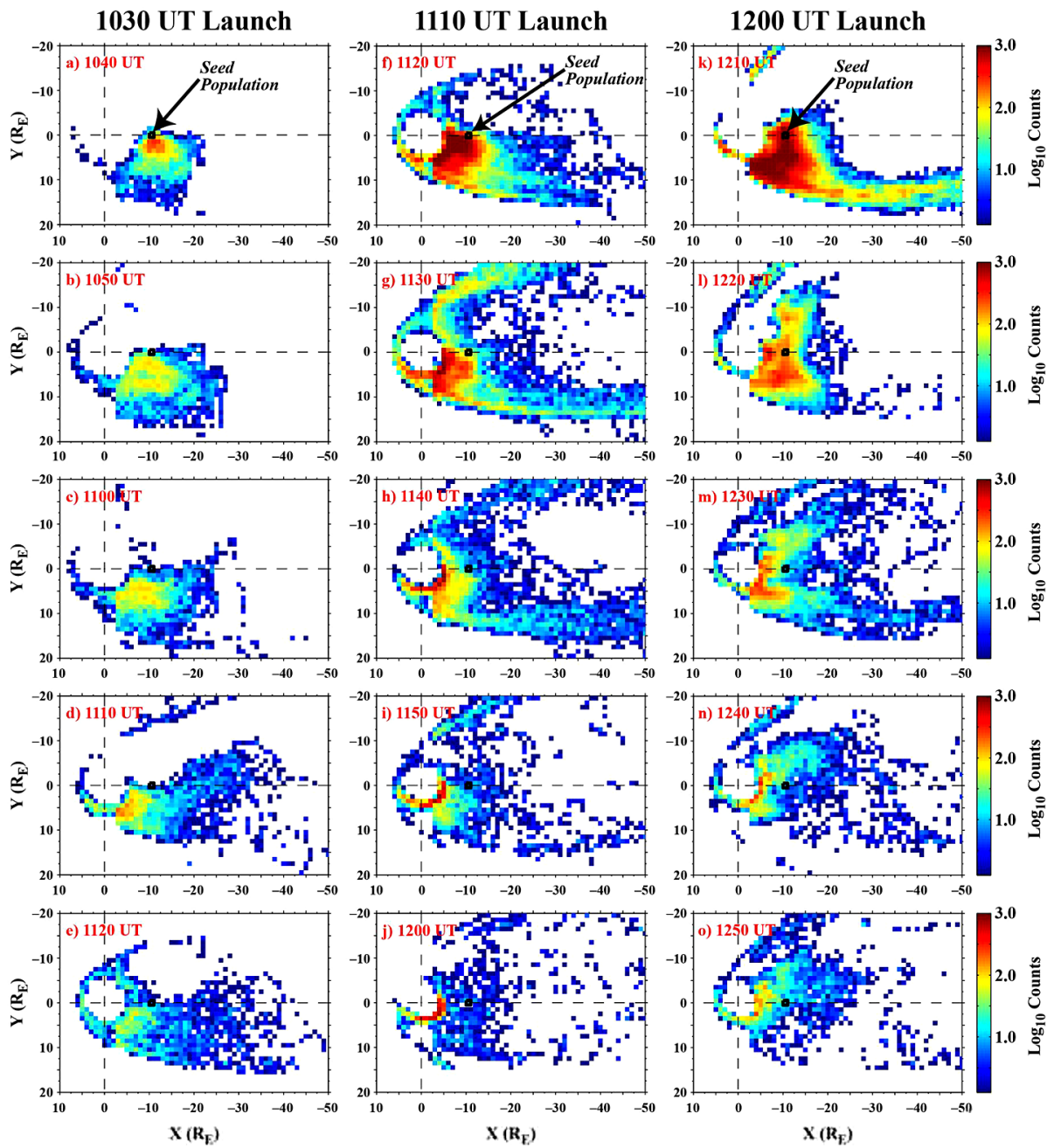

Fig. 5 Equatorial crossings of (left-hand column) 1030 UT seed ions, (middle column) 1110 UT seed ions, and (right-hand column) 1200 UT seed ions during five subsequent 10-minute periods. The seed region is shown with a black box, and the color scale, indicating $\log _{10}$ of counts in each $1 \mathrm{R}_{\mathrm{E}} \times 1 \mathrm{R}_{\mathrm{E}}$ bin, is shown on the right of each row (from Peroomian et al. 2011a)

delineated by $-11 \mathrm{R}_{\mathrm{E}}<x<-10 \mathrm{R}_{\mathrm{E}}$ and $|y|<0.5 \mathrm{R}_{\mathrm{E}}$ in the equatorial plane prior to the SSC, at 1030 UT (left-hand column of Fig. 5), during the initial impact of the interplanetary shock at 1110 UT (middle column of Fig. 5), and 50 minutes after the initiation of the SSC, at 1200 UT (right-hand column of Fig. 5). The left-hand column of Fig. 5 shows that $\mathrm{O}^{+}$ions convecting Earthward are caught by the SSC and are injected into and trapped in the ring current as a result (e.g. Fig. 5e, see also Sketch 2 for an illustration). A much larger fraction of $\mathrm{O}^{+}$ions in the seed region at 1110 UT is trapped in the ring current, creating a "full" ring current within 15 minutes of storm onset. This shows that $\mathrm{O}^{+}$ions rapidly enter the near-Earth tail. Many of these ions remain trapped for several hours. The 
amount of ions in the seed region increases by a factor of almost 20 between 1030 UT and 1200 UT.

\subsection{2 $\mathrm{O}^{+}$Acceleration in the Plasma Sheet}

While there is a correlation between strong $\mathrm{O}^{+}$outflows from the ionosphere and ion flux increases in the plasma sheet, as shown in Sect. 4.2, additional acceleration is necessary to explain the high energies that are observed (from tens of $\mathrm{keV}$ up to hundreds of $\mathrm{keV}$ ). Because of large Larmor radii and cyclotron periods, acceleration of $\mathrm{O}^{+}$ions in the magnetotail plasma sheet usually operates in the non-adiabatic limit, characterized by means of the $\kappa$ parameter, defined as the square root of the ratio of the minimum curvature radius of magnetic field line to the maximum particle gyroradius (Büchner and Zelenyi 1989). In the distant magnetotail (earthward of the distant X-line) or during substorm stretching of the inner tail, particle dynamics is essentially quasi-adiabatic $(\kappa<1)$. Transient and quasi-trapped ions are "de-magnetized" near the CS center (see the green trajectory in Sketch 2) and accelerated by the large scale convection electric field (e.g., Shabansky 1971; Lyons and Speiser 1982). Zelenyi and Zogin (1988) estimated the net energy gain realized during earthward $E \times B$ transport as:

$$
\Delta W=2 m_{i} c^{2} E_{y}^{2} / B_{z}^{2}(x)
$$

where $m_{i}$ is the ion mass, $E_{y}$, the large scale convection electric field, and $c$, the speed of light. Using test particle simulations, Ashour-Abdalla et al. (1994) showed that the energy gain realized by protons may be as high as a factor of 50. For heavy ions, this energy gain may be even higher because of their larger mass.

This acceleration may also be due to the inductive electric fields that are generated during various transient processes such as the formation of magnetic X-line, dipolarization fronts (e.g., Sharma et al. 2008; Runov et al. 2009, and references therein), plasmoids (e.g., Zong et al. 2004, and references therein) and electromagnetic turbulence (e.g., Zimbardo et al. 2010, and references therein).

Observations of $\mathrm{O}^{+}$Energization During Substorms A notable feature of the expansion phase of substorms in the inner terrestrial magnetotail is the relaxation of magnetic field lines from a stretched configuration to a more dipolar one. During such dynamical events, $\mathrm{O}^{+}$ions of ionospheric origin may be subject to prominent energization up to the hundreds of keV range (e.g., Ipavich et al. 1984; Mitchell et al. 2003; Keika et al. 2010). Repeated enhancements of the energetic $\mathrm{O}^{+}$content in conjunction with repeated intensifications of auroral features were seen in Energetic Neutral Atom (ENA) measurements by Mitchell et al. (2003). Some energization processes thus appear to be at work in the inner plasma sheet that affect pre-existing $\mathrm{O}^{+}$ions but not protons as indicated by the absence of similar changes in the energetic hydrogen content (see, e.g., Mitchell et al. 2003; Ohtani et al. 2005; Nosé et al. 2010). Evidence of a mass-dependent energization in the $\sim 10-210 \mathrm{keV} / \mathrm{e}$ range during substorms in the near-Earth plasma sheet were also reported by e.g. Möbius et al. (1987) and Nosé et al. (2000). Kistler et al. (1990) showed that the spectral changes in the near-Earth region $\left(7-9 R_{E}\right)$ were the same as those further down the tail (10-19 $\left.R_{E}\right)$ indicating that the same process occurred in both locations.

Mass Selective Ion Energization Due to Impulsive Induced Electric Fields A possible mechanism to explain this mass selective ion energization is a short-lived nonadiabatic heating under the effect of the electric field induced by the time-varying magnetic field. 

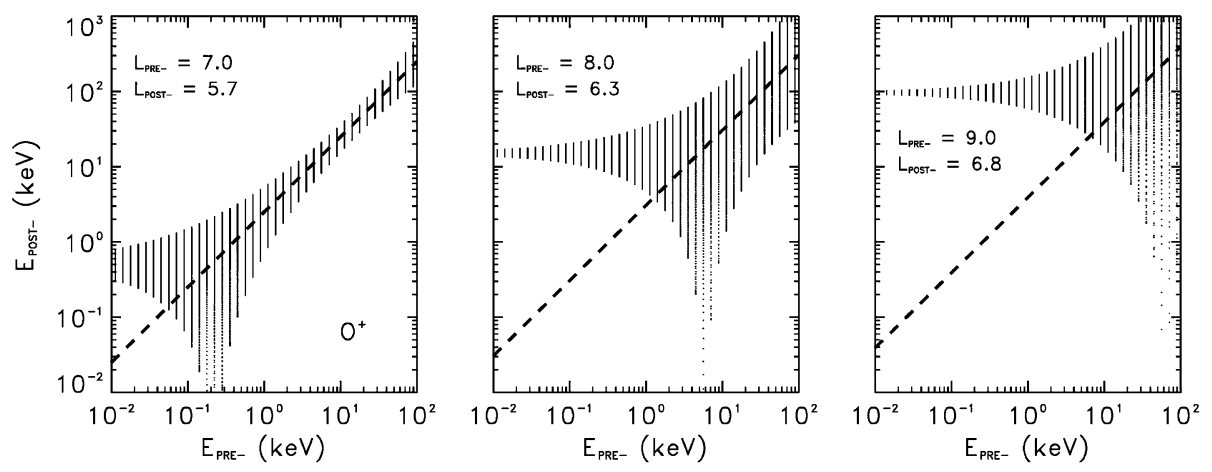

Fig. 6 Post-dipolarization energy versus initial energy for equatorially mirroring $\mathrm{O}^{+}$launched from different initial geodistances: (from left to right) $\mathrm{L}=7, \mathrm{~L}=8$, and $\mathrm{L}=9$. In each panel, the various dots correspond to distinct initial gyrophases whereas the dashed line shows the final energy expected in the case of adiabatic (betatron-type) energization. Taken from Delcourt (2002)

As demonstrated by Delcourt et al. (1990), heavy ions such as $\mathrm{O}^{+}$that have gyration periods comparable to the dipolarization time scale (several tens of seconds) are most affected by this non-adiabatic heating while protons with smaller gyro-periods may be transported adiabatically. As an example, Fig. 6 shows the post-dipolarization energy computed for equatorial $\mathrm{O}^{+}$assuming a one-minute model dipolarization of the inner magnetosphere. It is apparent from this figure that $\mathrm{O}^{+}$ions with low initial energies are systematically energized up to a range that gradually increases with geodistance (from left to right). In particular, in the right panel of Fig. 6, low-energy $\mathrm{O}^{+}$initialized at $9 \mathrm{R}_{\mathrm{E}}$ are energized up to $\sim 100 \mathrm{keV}$ while being transported down to $\sim 6.8 \mathrm{R}_{\mathrm{E}}$, an energization that significantly exceeds that expected from the large scale convection electric field alone. This non-adiabatic behavior at low initial energies contrast with that obtained for $\mathrm{O}^{+}$with large initial energies that experience a betatron-type energization (viz., in proportion to the magnetic field change). In-situ measurements (e.g., Hamilton et al. 1988; Daglis and Axford 1996) reveal a dramatic increase of the $\mathrm{O}^{+}$content of the ring current during magnetic storms, and the above non-adiabatic heating due to inductive electric fields may provide a mechanism for the production of such energetic populations (e.g. Fok et al. 2006; Jones et al. 2006). Still, a recent statistical study of Geotail data by Ono et al. (2009) showed that at times, the $\mathrm{H}^{+}$spectra can harden more significantly than $\mathrm{O}^{+}$. In this latter case, fluctuations of the dipolarizing field lines on time scales comparable to the $\mathrm{H}^{+}$gyroperiod may be responsible for the high proton energization.

Acceleration of $\mathrm{O}^{+}$Ions in the Reconnection Region The mechanism of particle acceleration near X-lines and in the region of magnetic reconnection may lead to an energy gain from several hundreds of $\mathrm{eV}$ up to the $\mathrm{MeV}$ range (e.g., Zelenyi et al. 1984). Observations of energetic $\mathrm{O}^{+}$bursts accelerated earthward and tailward of the NENL during substorm events were reported by Zong et al. (1998). $\mathrm{O}^{+}$acceleration across the potential drop in the reconnection region was shown by Wygant et al. (2005). Effective acceleration of heavy ions in the vicinity of the near-Earth X-line, up to energies higher than $\sim 140 \mathrm{keV}$ was statistically demonstrated by Luo et al. (2014).

Tailward energetic $\mathrm{O}^{+}$streams (and other heavy ions) in association with the passage of plasmoids or flux ropes during substorms or pseudo-breakups were reported by Christon et al. (1994); Jacquey et al. (1994); Wilken et al. (1995). A series of tailward moving 
Fig. 7 Schematic diagram of the plasmoid with high $\mathrm{O}^{+}$ abundance detected in the distant tail. Adapted from Zong et al. (1997)

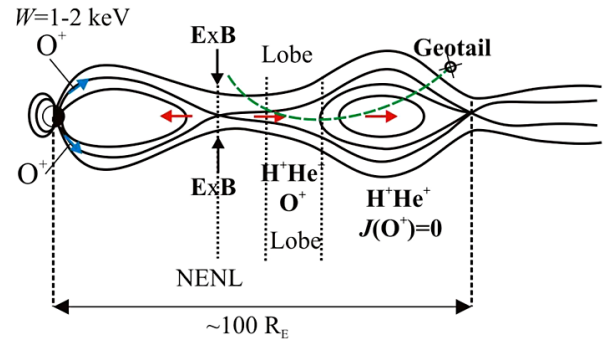

plasmoids related to the formation of a near-Earth magnetic X-line was studied by Zong et al. (1997). It was shown that an $\mathrm{O}^{+}$burst developed in the largest of the plasmoids that exhibited both $\mathrm{B}_{\mathrm{Y}}$ and $\mathrm{B}_{\mathrm{Z}}$ bipolar magnetic field signatures. As apparent from Fig. 7, the ionospheric $\mathrm{O}^{+}$ions are likely accelerated up to high energies in the reconnection region and, as a result, travel downtail in the narrow post-plasmoid plasma sheet. The $\mathrm{O}^{+}$ions reach the distant tail $\sim 25$ minutes after the energetic protons, which can be explained by the slower motion of the ionospheric $\mathrm{O}^{+}$before it becomes a part of acceleration process. It should also be noted here that the $\mathrm{O}^{+}$beams are highly collimated in the tailward direction (e.g., Wilken et al. 1995; Zong et al. 1997, 1998) and that they are observed both in the central plasma sheet and in PSBL (e.g., Jacquey et al. 1994).

The acceleration of $\mathrm{O}^{+}$ions using test particle orbits in model fields obtained from MHD simulations of plasmoid formation and inner tail dipolarization was studied by Birn et al. (2004). It was shown that the duskward electric field at the NENL has a pronounced although localized effect on $\mathrm{O}^{+}$ions, leading to the formation of a narrow beam of duskward flux. This effect was not as pronounced for $\mathrm{H}^{+}$ions, since the influence of spatial and temporal nonadiabaticity are much more pronounced for heavy ions than for light ones (e.g., Delcourt and Sauvaud 1994). Therefore, $\mathrm{O}^{+}$may provide a better indicator of the NENL presence. A close relationship between tailward energetic $\mathrm{O}^{+}$beams and the passage of an O-line was also found by Birn et al. (2004).

Turbulence In particular, in the far tail where the value of the normal component of the magnetic field is close to zero and magnetic turbulence is strong, heavy ions may be subject to Fermi-type acceleration via stochastic motion in the turbulent electromagnetic fields (e.g., Milovanov and Zelenyi 2002). This process leads to characteristic high-energy tails in the particle distribution functions with energy gains of several orders of magnitude. Ion interaction with moving vortical magnetic "bubbles" may lead to mass selective energization as well. Oscillating 3-D magnetic bubbles may prevent $\mathrm{H}^{+}$ions from reaching the center of the CS where acceleration is maximum (e.g., Zelenyi et al. 2008b; Artemyev et al. 2009). In contrast, due to their inertia, heavy ions are less affected by magnetic bubbles and can reach the region of vanishing magnetic field where they can be significantly accelerated. From a general viewpoint, both magnetic turbulence and magnetic bubbles form efficient energization processes that distinctly affect $\mathrm{H}^{+}$and $\mathrm{O}^{+}$populations in the terrestrial magnetotail.

\subsection{Inner Magnetosphere}

\subsubsection{Ring Current}

The energetic population in the inner magnetosphere, at ring current energies from $\sim 10-100 \mathrm{keV}$, comes dominantly from the nightside plasma sheet. It is mainly $E \times B$ 
drift transport and impulsive injections from the near-Earth plasma sheet to the inner magnetosphere (Ganushkina et al. 2005). There has been a recent suggestion that the thermal $\mathrm{O}^{+}$torus can be accelerated by nonadiabatic mechanisms to ring current energies (Nosé et al. 2010, 2011). Nosé et al. (2014), showed that the magnetic fluctuations associated with dipolarizations inside $6.6 \mathrm{R}_{\mathrm{E}}$ have a frequency close to the $\mathrm{O}^{+}$ gyrofrequency, and can preferentially accelerate the $\mathrm{O}^{+}$to $5-10 \mathrm{keV}$. The population from 1-10 keV can also drift in from the nightside plasma sheet, so the importance of the energization is not clear. The inner magnetosphere ion energy spectra in this energy range often show multiple energy bands (or "nose" structures) in all the major species, $\mathrm{H}^{+}, \mathrm{He}^{+}$and $\mathrm{O}^{+}$, sometimes down to L-values less than 2 (Vallat et al. 2007; Dandouras et al. 2009). These features are due to the interplay between the $E \times B$ and gradient-curvature drifts on the ions convecting in from the plasma sheet. However the formation of these features is sensitive to the electric field and its time variation, and some details of the formation are still not clear.

\subsubsection{Low-Altitude Magnetosphere}

Some contribution to ion energization in the low-altitude magnetosphere is made by lightning. The effect of lightning-induced emission on ion dynamics above thunderstorm cells has been discussed by several authors (see, e.g., Gurnett and Brice 1966; Bell et al. 1993). Recently, a new mechanism of ion energization due to interaction with lightning-induced emission has been considered (Shklyar and Kuzichev 2014). A part of the electromagnetic energy induced by lightning in the ELF frequency band penetrates into the low-altitude magnetosphere and starts propagating there as slow ion cyclotron waves (see, e.g., Shklyar et al. 2012, and references therein). A feature of these waves is that they propagate almost along the geomagnetic field lines, and they have resonance at the gyrofrequency of each sort of ions at which the wave refractive index $N=k c / \omega$ goes to infinity. Since these waves propagate along the field line from the upper ionosphere towards lower latitudes, and since the ion gyrofrequency decreases along the wave paths, some waves get stuck in the region where their frequency approaches the ion gyrofrequency. Then an electromagnetic wave packet in which the wave frequency is close to the local ion gyrofrequency is formed. A strong waveparticle interaction then takes place and leads to wave energy absorption by suprathermal ions with the corresponding non-diffusive energization of the latter. Since lightning strokes occur incessantly over the globe, the above mechanism constitutes a continual means of ion energization in the near-Earth space. It operates in the low-altitude magnetosphere at the heights up to (1500-2000) km, involving $\mathrm{H}^{+}$ions with energies from few $\mathrm{eV}$ up to hundreds $\mathrm{eV}$, and $\mathrm{O}^{+}$ions with energies from hundreds $\mathrm{eV}$ up to tens of $\mathrm{keV}$.

\section{Bulk Properties}

\subsection{Lobe}

A method combining a density estimate from the SC electric potential and a velocity estimate from the "wake" effect behind the SC has recently been applied to Cluster observations to determine the prevalence of cold ions in the lobe at geocentric distances between 5 and 19.6 $\mathrm{R}_{\mathrm{E}}$ (Engwall et al. 2009a, 2009b). A statistical study performed with this method reveals that low energy ions dominate the lobe plasma, both in terms of flux and density with a net overall upflow of about $10^{26}$ ions/s (Engwall et al. 2009a). This study also found weak 


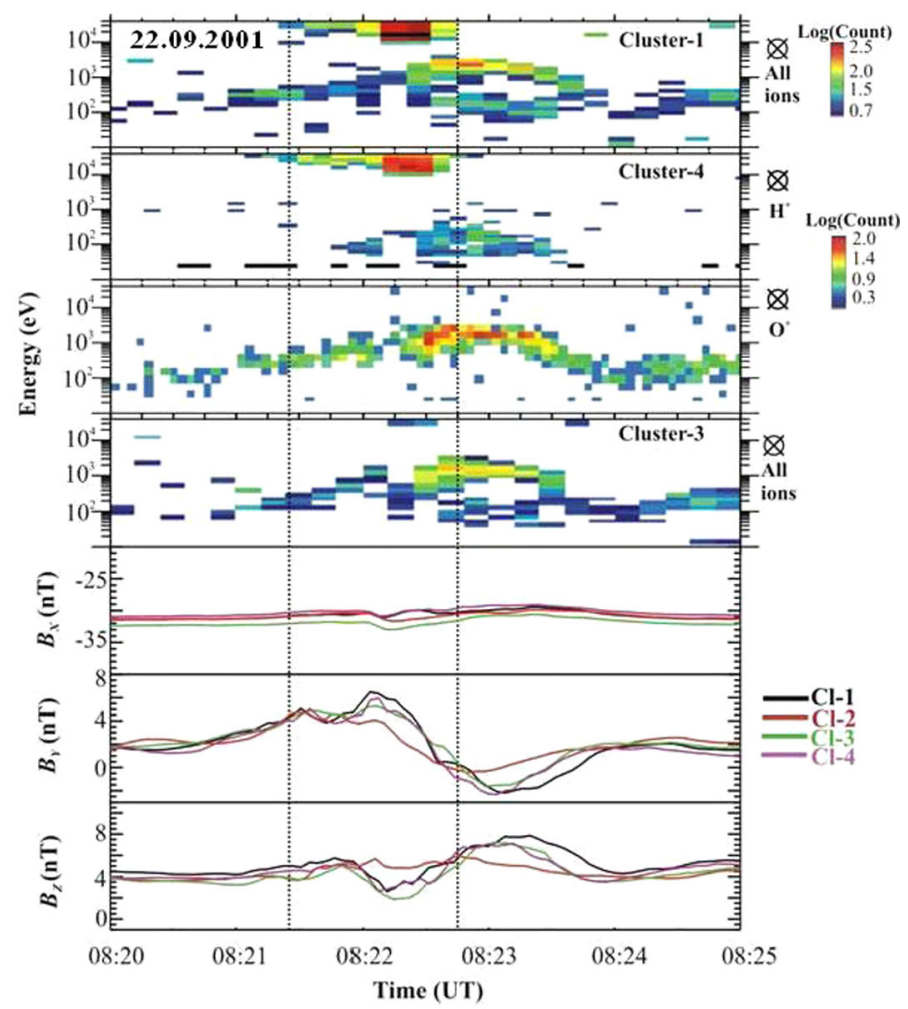

Fig. 8 Cluster observations of a transient energization of ionospheric ions near PSBL, at $[18,6.5,-1] \mathrm{R}_{\mathrm{E}}$ in Geocentric Solar Ecliptic (GSE). From top to bottom: ion energy-time spectrograms (all species); $\mathrm{H}^{+}$ and $\mathrm{O}^{+}$ions; three components of the magnetic field measured by the different Cluster SC. The transient excursion into PSBL is marked by dashed lines. Taken from Grigorenko et al. (2010)

flux variations from low to high magnetic activity and from low to high solar EUV flux, with a net change by about a factor of $3 / 4$. They also found that the main effect of enhanced magnetic activity and/or southward IMF $B_{z}$ is to increase the size of the magnetospheric lobes (i.e., of the region of open magnetic flux).

When electric field variations are intense enough, these cold ionospheric ions may become visible to particle detectors even in the absence of SC potential control. A number of studies support the presence of low energy ion populations in the lobe and PSBL (e.g., Mukai et al. 1994; Hirahara et al. 1996; Sauvaud et al. 2004; Zelenyi et al. 2004a; Keiling et al. 2006; Grigorenko et al. 2010). Near the PS boundary, the energy of ionospheric ions can temporarily increase up to a few keVs in the course of large-scale wavy perturbations such as those due to Kelvin-Helmholtz instabilities that develop in the PSBL in the presence of large velocity shear with magnetosheath flow (Grigorenko et al. 2010), see Fig. 8.

Because $\mathrm{O}^{+}$ions at the same velocity have 16 times the energy of $\mathrm{H}^{+}$, the $\mathrm{O}^{+}$ions that are on the same trajectories as the lobe $\mathrm{H}^{+}$, due to the velocity filter effect, are more likely to have energies above the SC potential and are visible to standard plasma instrumentation. These $\mathrm{O}^{+}$beams in the lobe have been observed by many SC, including ISEE 1 and 2 (Orsini et al. 1990), Polar (Elliot et al. 2001), and Cluster (Liao et al. 2010). Figure 9 shows 
Fig. 9 Properties of low energy streaming $\mathrm{O}^{+}$ions and $\mathrm{H}^{+}$ions in the lobes. Panels (a)-(h) show $\mathrm{O}^{+}$properties for nonstorm and storm times: density, total bulk velocity, outward flux and temperature. Panels (i)-(l) show $\mathrm{H}^{+}$properties (from Engwall et al. 2009b): density, total ion flow velocity, outward $\mathrm{H}^{+}$flux and the magnetic field aligned velocity away from the Earth. The vertical lines show median values
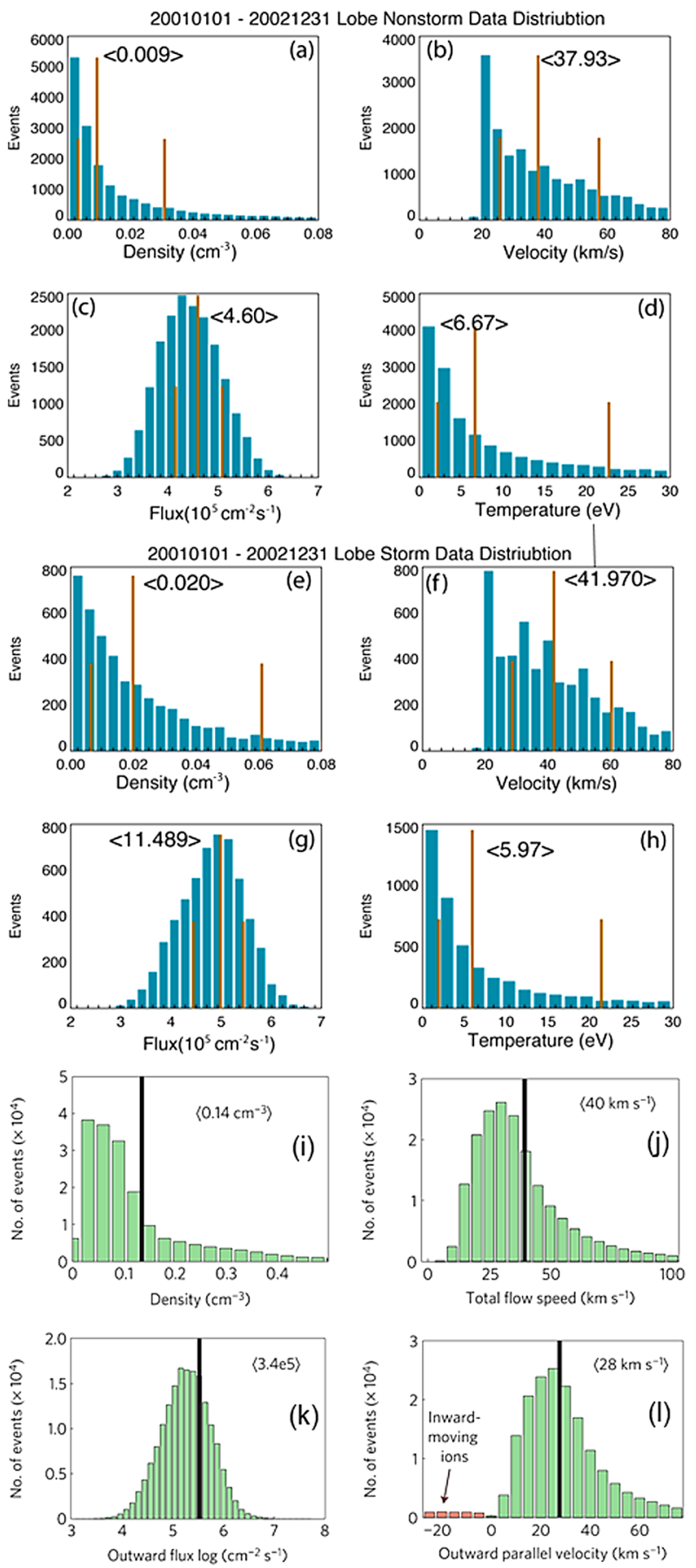

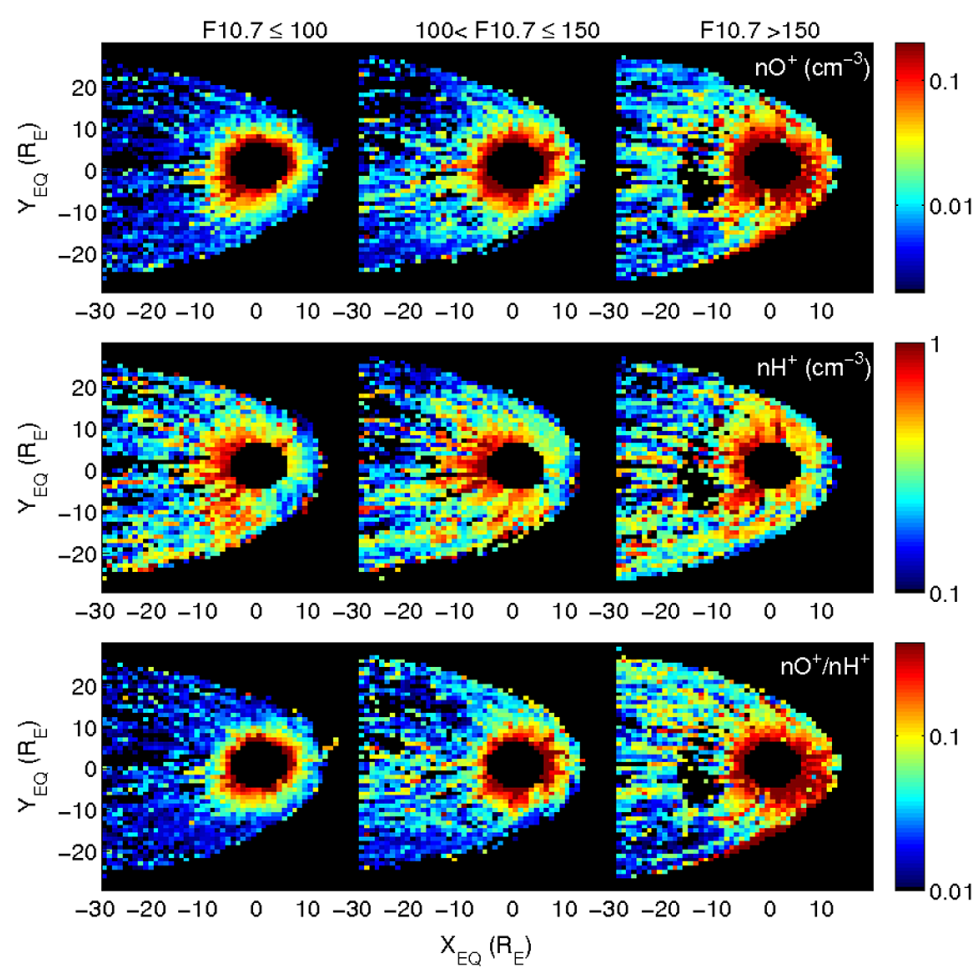

Fig. $10 \mathrm{O}^{+}$density, $\mathrm{H}^{+}$density and $\mathrm{O}^{+} / \mathrm{H}^{+}$density ratio in the magnetospheric equatorial plane at $1 \times 1 \mathrm{R}_{\mathrm{E}}$ resolution for three ranges of solar EUV level (represented by the F10.7 index), from Maggiolo and Kistler (2014)

a comparison between density and velocity of hidden populations (mainly $\mathrm{H}^{+}$) (Engwall et al. 2009a) and streaming $\mathrm{O}^{+}$ions in the lobes (Liao et al. 2010; Liao 2011), both from the Cluster SC. The $\mathrm{O}^{+}$can only be observed down to the low energy limit of the dataset $(40 \mathrm{eV}$, which corresponds to $22 \mathrm{~km} / \mathrm{s}$ for $\mathrm{O}^{+}$), but over the common velocity range, the $\mathrm{H}^{+}$and $\mathrm{O}^{+}$ have a similar distribution. This suggests that the $\mathrm{H}^{+}$and $\mathrm{O}^{+}$are from the same source, the cusp outflow observed as cold beams due to the velocity filter effect.

\subsection{Plasma Sheet}

Solar and Geomagnetic Activity Dependence Statistical evidence for the influence of the solar EUV irradiance (F10.7 index) on the $\mathrm{O}^{+}$ion density in the plasma sheet was provided by Young et al. (1982), Lennartsson and Shelley (1986), Lennartsson (1989), Denton et al. (2005), Nosé et al. (2009), Mouikis et al. (2010), Ohtani et al. (2011) and Maggiolo and Kistler (2014). The instruments, observation periods, regions, energy ranges and species investigated in these studies and those in Sect. 4.3 are summarized in Table 1. They showed that the average $\mathrm{O}^{+}$ion density strongly increases with solar EUV flux, see Fig. 10.

Extensive studies of the mid-tail plasma sheet composition as a function of geomagnetic activity (Kp-index) revealed that during quiet periods, the plasma sheet material is predominantly of solar wind origin while for active periods the ionospheric component can represent up to half of the plasma sheet material (Peterson et al. 1981; Sharp et al. 1982; 


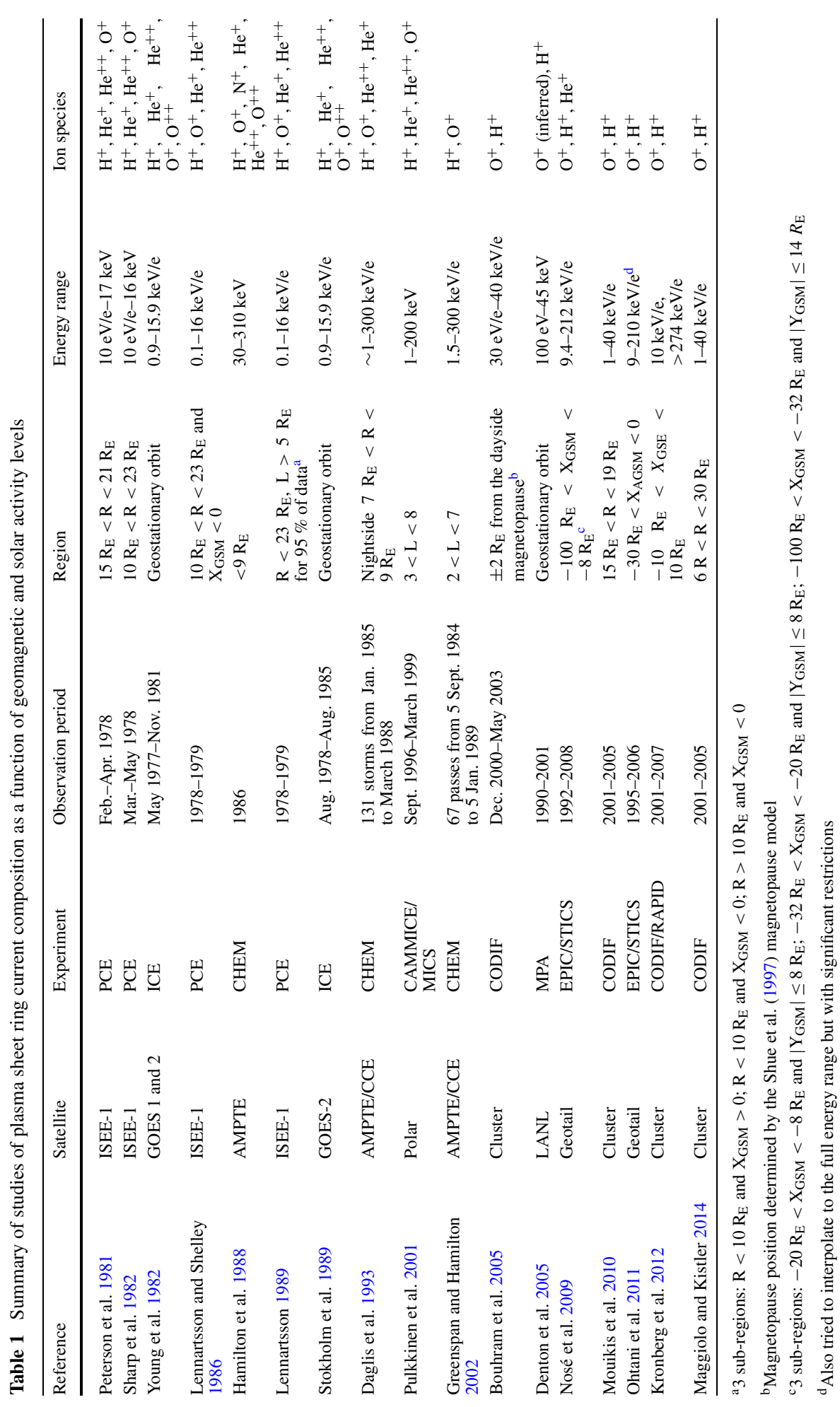



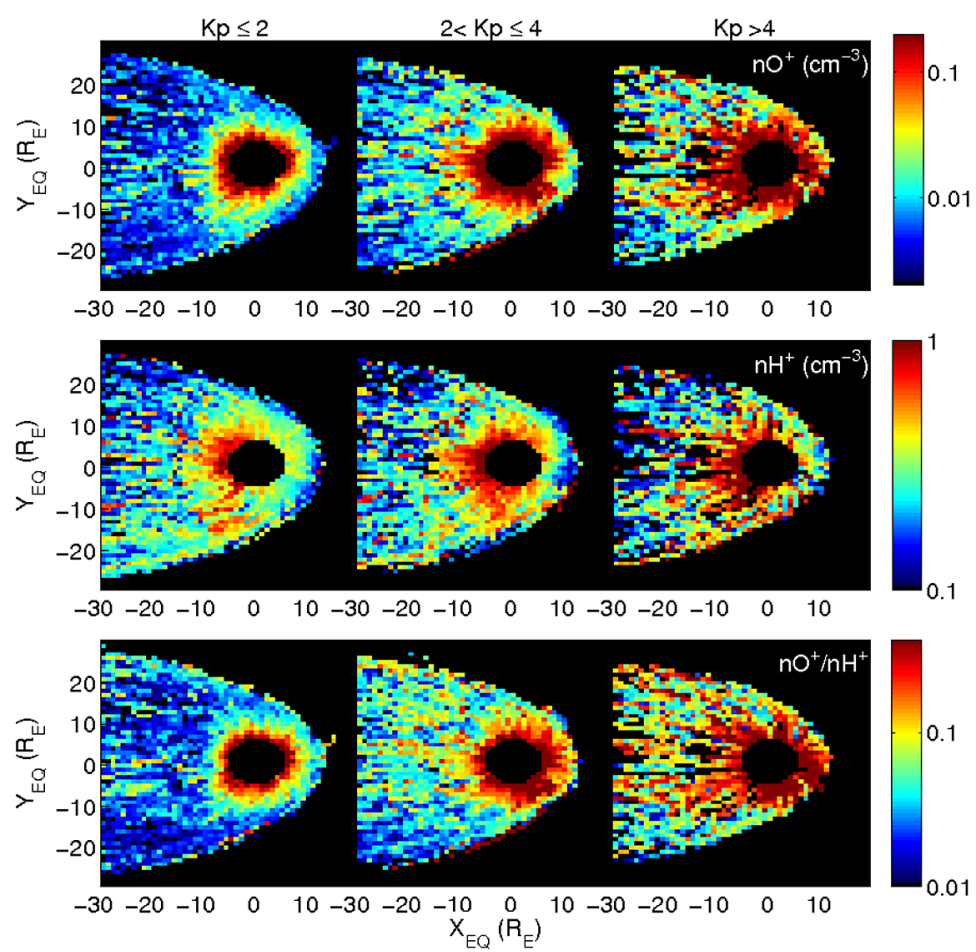

Fig. $11 \mathrm{O}^{+}$density, $\mathrm{H}^{+}$density and $\mathrm{O}^{+} / \mathrm{H}^{+}$density ratio in the magnetospheric equatorial plane for three ranges of geomagnetic activity (represented by the Kp index), from Maggiolo and Kistler (2014)

Denton et al. 2005; Nosé et al. 2009; Mouikis et al. 2010; Maggiolo and Kistler 2014), as illustrated in Fig. 11. Lennartsson and Shelley (1986) showed that the average $\mathrm{O}^{+} / \mathrm{H}^{+}$ density ratio increases approximately in proportion with the Auroral Electrojet (AE) index. Modulation of the $\mathrm{O}^{+}$density and energy by geomagnetic activity monitored by the Sym-H index was shown by Ohtani et al. (2011). The $\mathrm{O}^{+}$density just inward of the magnetopause in the magnetospheric boundary layer also displays a significant exponential increase with geomagnetic activity indicated by the Dst index (Bouhram et al. 2005).

The behavior of $\sim 10 \mathrm{keV}$ and $>274 \mathrm{keV} \mathrm{O}^{+}$and $\mathrm{H}^{+}$ions in the near-Earth magnetosphere was compared by Kronberg et al. (2012). The study focuses on the $\mathrm{O}^{+}$and $\mathrm{H}^{+}$ abundance response to geomagnetic activity (Dst and $\mathrm{AE}$ indecies) and solar wind conditions in the near-Earth region (at geocentric distances lower than $10 \mathrm{R}_{\mathrm{E}}$ ). Kronberg et al. (2012) suggest that the strong correlation between the $\mathrm{O}^{+}, \mathrm{H}^{+}$and $\mathrm{O}^{+} / \mathrm{H}^{+}$flux ratio with solar wind parameters shows that energy input to the magnetosphere and effective energization of energetic ions are connected. This study reveals that the increase rate of the flux of $>274 \mathrm{keV} \mathrm{O}^{+}$between quiet and disturbed times is similar to the increase rate of ionospheric ion outflow. It indicates that, in addition to more effective acceleration, enhanced ion outflow also contributes to the energetic ion intensity increase during active periods. Kronberg et al. (2012) showed that the $\mathrm{O}^{+} / \mathrm{H}^{+}$intensity at energies above $274 \mathrm{keV}$ is between 0.5 and 1 and is much higher than the ratio at $\sim 10 \mathrm{keV}$ which may result from a more efficient heating of $\mathrm{O}^{+}$ions than of $\mathrm{H}^{+}$ions. 
Density In the mid tail region $\left(\sim 15-20 \mathrm{R}_{\mathrm{E}}\right)$, functional forms describing the $\mathrm{O}^{+}, \mathrm{H}^{+}$density and $\mathrm{O}^{+} / \mathrm{H}^{+}$density ratio variation as a function of $\mathrm{Kp}$ and $\mathrm{F} 10.7$ were recently provided in an extensive statistical study by Maggiolo and Kistler (2014) and are in agreement with Young et al. (1982), Mouikis et al. (2010), Ohtani et al. (2011). These trends indicate that the mid tail $\mathrm{O}^{+}$density is more sensitive to geomagnetic activity than to solar EUV flux. From low to high geomagnetic activity the $\mathrm{O}^{+}$density increases by a factor of $\sim 10$ at solar minimum and of $\sim 31$ at solar maximum while from low to high solar EUV flux it increases by a factor of $\sim 3.5$. Typical $\mathrm{O}^{+}$densities in this region during quiet periods ranges from $\sim 0.005 \mathrm{~cm}^{-3}$ (low F10.7) to $\sim 0.02 \mathrm{~cm}^{-3}$ (high F10.7) corresponding to a $\mathrm{O}^{+} / \mathrm{H}^{+}$density ratio between $\sim 0.02$ and 0.05 . The highest average $\mathrm{O}^{+}$density is observed during active periods close to solar cycle maximum and approaches $0.1 \mathrm{~cm}^{-3}$ representing between one third and one half of the $\mathrm{H}^{+}$density. An empirical relation describing the $\mathrm{O}^{+} / \mathrm{H}^{+}$flux ratio as a function of F10.7 shows similar average values to those derived by Nosé et al. (2009) but with a much harder slope. The average $\mathrm{O}^{+}$density from the Lennartsson (1989) empirical formula is about 3 times higher than the estimate by Maggiolo and Kistler (2014), but displays a similar increase rate with F10.7. Lennartsson and Shelley (1986) obtained an empirical function describing the $\mathrm{O}^{+} / \mathrm{H}^{+}$density ratio variation as a function of Kp corresponding to an average ratio about 2 times higher than the one estimated from Maggiolo and Kistler (2014) observations but with a similar increase rate.

Empirical formulas at lower geocentric distances $\left(7-8 R_{E}\right)$ were also recently provided by Maggiolo and Kistler (2014). In contrast to the mid tail regions, in the near-Earth regions the effect of geomagnetic activity and of solar EUV flux are of the same order of magnitude. The $\mathrm{O}^{+}$density increases by about one order of magnitude from low to high geomagnetic activity level (with no clear modulation by solar activity) and by a factor of $\sim 7$ from low to high solar EUV during quiet periods. Typical $\mathrm{O}^{+}$densities in this region during quiet periods ranges from $\sim 0.02 \mathrm{~cm}^{-3}$ (low F10.7) to $\sim 0.3 \mathrm{~cm}^{-3}$ (high F10.7) corresponding to a $\mathrm{O}^{+} / \mathrm{H}^{+}$ density ratio between $\sim 0.08$ and 0.5 . The highest average $\mathrm{O}^{+}$density is observed during active periods close to solar cycle maximum and approaches $1 \mathrm{~cm}^{-3}$ which is just slightly lower than the average $\mathrm{H}^{+}$density. Empirical formulas at geocentric distances derived by Young et al. (1982) and Stokholm et al. (1989) are relatively similar to the Maggiolo and Kistler (2014) formulas.

Despite a clear correlation of the $\mathrm{O}^{+}$ion number and energy density with solar and geomagnetic activity, average trends are not sufficient to predict precisely the plasma sheet composition. Indeed, the density of all plasma sheet species has a large variance, and for similar geomagnetic and solar activity levels, a wide range of densities and composition can be observed. This variability explains why $\mathrm{O}^{+}$can be the most abundant ion during specific periods in the midnight sector (Lennartsson and Shelley 1986; Kistler et al. 2005), in the near-Earth regions (e.g. Maggiolo and Kistler 2014) or in the dayside magnetosphere (Bouhram et al. 2005) while if we consider the average plasma sheet composition $\mathrm{H}^{+}$is the dominant species (in number density) for all geomagnetic and solar activity level except at low geocentric distances near geostationary orbit (Young et al. 1982).

$\mathrm{O}^{+}$Energy The typical $\mathrm{O}^{+}$energy in the plasma sheet has been estimated to be around 3-4 keV both in the dayside magnetosphere (Bouhram et al. 2005) and in the tail plasma sheet (Lennartsson and Shelley 1986; Lennartsson 1989). Ohtani et al. (2011) provide much higher estimates of the $\mathrm{O}^{+}$energy (up to $10-20 \mathrm{keV}$ ) but from the extrapolation of high energy measurements, which as conceded by the authors may be associated with some errors. Lennartsson and Shelley (1986) found no variation of the $\mathrm{O}^{+}$average energy with geomagnetic activity using AE index contrary to Ohtani et al. (2011) who reported a positive correlation between the $\mathrm{O}^{+}$energy and the Sym-H index. Both Lennartsson (1989) and 
Ohtani et al. (2011) reported observations indicating a decrease of the $\mathrm{O}^{+}$average energy with increasing solar EUV flux. Lennartsson (1989) estimated that the $\mathrm{O}^{+}$decreases from $\sim 4-5 \mathrm{keV}$ for low F10.7 to $\sim 2-3 \mathrm{keV}$ for high F10.7 and showed that this energy decrease is weaker at high geocentric distances than at low geocentric distances. Ohtani et al. (2011) reported that in contrast to $\mathrm{H}^{+}$, the $\mathrm{O}^{+}$average energy is decreasing toward Earth.

Spatial Dependencies There is a consensus on the increase of the $\mathrm{O}^{+}$density and $\mathrm{O}^{+} / \mathrm{H}^{+}$ density ratio toward the Earth (Lennartsson and Shelley 1986; Ohtani et al. 2011; Maggiolo and Kistler 2014). As shown by Lennartsson and Shelley (1986) and Maggiolo and Kistler (2014) this increase is steeper at low geocentric distances (below 10-15 $R_{E}$ ) than farther out, where the $\mathrm{O}^{+}$density and $\mathrm{O}^{+} / \mathrm{H}^{+}$density ratio shows few changes with geocentric distances. Both Ohtani et al. (2011) and Maggiolo and Kistler (2014) density profiles for various solar activity levels show that the $\mathrm{O}^{+}$density and $\mathrm{O}^{+} / \mathrm{H}^{+}$density ratio increase toward Earth becomes more pronounced as solar activity increases. This should result from the higher $\mathrm{O}^{+}$density increase with increasing solar EUV flux at low geocentric distances compared to high geocentric distances.

This increase of the $\mathrm{O}^{+} / \mathrm{H}^{+}$density ratio made Lennartsson and Shelley (1986), Mouikis et al. (2010) and Maggiolo and Kistler (2014) suggest that there is a direct entry of $\mathrm{O}^{+}$ions in the plasma sheet at low geocentric distances. Other observations have been proposed as additional evidence of the direct entry of $\mathrm{O}^{+}$ions in the near-Earth region like the decrease of the $\mathrm{O}^{+}$average energy toward Earth (Ohtani et al. 2011) or the different dependence on Kp and F10.7 in the near-Earth region compared to the mid tail (Maggiolo and Kistler 2014).

There is, however, no unanimity on the existence of a cross tail asymmetry of the $\mathrm{O}^{+}$ ion density. A higher $\mathrm{O}^{+}$density in the central plasma sheet around $\mathrm{Y}_{\mathrm{GSM}} \sim 0$ compared to the flanks were shown by Lennartsson and Shelley (1986). In contrast, observations by Mouikis et al. (2010) and Maggiolo and Kistler (2014) found no evidence for a significant cross tail asymmetry and observations by Ohtani et al. (2011) showed a decrease of the $\mathrm{O}^{+}$ energy toward dusk but no significant $\mathrm{O}^{+}$density variation. This diversity may be result from the different energy ranges included in the different studies (for instance Lennartsson and Shelley 1986 considered energies below $1 \mathrm{keV}$ ) or from the data selection method (see discussion in Mouikis et al. 2010). At the magnetopause, Bouhram et al. (2005) showed a strong dawn dusk asymmetry in the average $\mathrm{O}^{+}$density below $40 \mathrm{keV}$ which is higher in the dusk side (on average $0.053 \mathrm{~cm}^{-3}$ which represents on average $30 \%$ of the mass density) than in the dawn side $\left(0.014 \mathrm{~cm}^{-3}\right.$, corresponding to only $3 \%$ of the mass density). For energies above $274 \mathrm{keV}$ higher fluxes are observed on the duskside and interpreted it as being the result of significant loss of energetic ions in the dayside, as illustrated in Fig. 14.

Other Ion Species $\quad$ In this section we deliberately focused on $\mathrm{O}^{+}$ions because, $\mathrm{H}^{+}$and $\mathrm{O}^{+}$ ions are normally the main contributors to the plasma sheet mass density. Among the most recent studies, only Nosé et al. (2009) addresses the issue of other minor species, $\mathrm{He}^{++}$, $\mathrm{He}^{+}, \mathrm{O}^{++}$which represent just small fractions of the plasma sheet number density both close to Earth (see Young et al. 1982; Stokholm et al. 1989) and at larger geocentric distance (see Lennartsson and Shelley 1986; Lennartsson 1989; Nosé et al. 2009). However, in the ring current these species can have a more significant contribution as shown by Polar observation which indicates that the $\mathrm{He}^{+}$flux is typically comparable to or higher than the $\mathrm{O}^{+}$flux (Pulkkinen et al. 2001). Minor species are also modulated by solar and geomagnetic activity. $\mathrm{He}^{+}$and $\mathrm{O}^{++}$ions predominantely originate from the ionosphere and display variations as with solar and geomagnetic activity that are similar to $\mathrm{O}^{+}$ions, although their density increase with increasing solar and geomagnetic activity is less pronounced than for 
$\mathrm{O}^{+}$(Lennartsson and Shelley 1986; Stokholm et al. 1989; Nosé et al. 2009). $\mathrm{He}^{++}$ions, which predominantely originate from the solar wind, display a different behavior. Significant $\mathrm{He}^{++}$density increase (by a factor of 3) with solar activity was reported by Lennartsson (1989) who suggested that it could be related to changes in the solar wind composition. In contrast Young et al. (1982), Stokholm et al. (1989), and Nosé et al. (2009) did not find significant $\mathrm{He}^{++}$density changes related to solar activity level. $\mathrm{He}^{++}$density variation with geomagnetic activity is also weak. Lennartsson and Shelley (1986) reported a slight decrease of the $\mathrm{He}^{++}$density in the tail plasma sheet when geomagnetic activity increases while Young et al. (1982) reported a slight increase of its density at geostationary orbit. $\mathrm{N}^{+}$ ions are also present in the magnetosphere, particularly during strong geomagnetic storms (Hamilton et al. 1988), and can be the third most abundant species, after $\mathrm{O}^{+}$. However, many of the instruments do not distinguish $\mathrm{N}^{+}$and $\mathrm{O}^{+}$because of their similar mass, and for these instruments $\mathrm{N}^{+}$is included in the $\mathrm{O}^{+}$ions.

\subsection{Ring Current}

Composition measurements of the energetic ring current showed that $\mathrm{O}^{+}$energy density is well correlated with the $\mathrm{AE}$ index, indicating an increased contribution of $\mathrm{O}^{+}$ions to the ring current during substorms (Daglis 1993). Functional forms describing the $\mathrm{O}^{+}$energy density variation as a function of the AE index can be found in Daglis and Axford (1994). Greenspan and Hamilton (2002) analyzed the contribution of different species to the ring current energy near magnetic storm maximum and its modulation by solar EUV flux, and also provided functional forms describing the $\mathrm{O}^{+}$energy density and $\mathrm{O}^{+} / \mathrm{H}^{+}$density variation as a function of F10.7 and Dst. They observed that, in addition to geomagnetic activity, increased solar EUV flux was also enhancing the $\mathrm{O}^{+}$contribution to the ring current. During storm periods, Greenspan and Hamilton (2002) showed that for $94 \%$ of the events the $\mathrm{O}^{+}$ energy density was lower than the $\mathrm{H}^{+}$energy density and that most of the time ( $72 \%$ of the storms) the $\mathrm{O}^{+}$contributes to less than $23 \%$ of the ring current energy.

Considering both storm time and non-storm time periods, Pulkkinen et al. (2001) studied the $\mathrm{O}^{+}$contribution to the ring current and its modulation by geomagnetic (the Dst and Kp indicies) and solar activity: the $\mathrm{O}^{+}$energy density increases by a factor of $\sim 5$ from solar minimum to solar maximum, ranging from a few percent to $\sim 10 \%$ of the ring current energy. They demonstrated clear changes of the ring current composition and intensity with solar cycle.

\subsection{Bulk Properties and Global Models}

The observations discussed in Sect. 4.2 have focused on the dependence of the plasma sheet bulk properties on EUV and geomagnetic activity. Global models help to predict bulk properties for different solar wind conditions (e.g., the IMF orientation).

During steady state conditions, global models analyzing the fate of ionospheric outflows paint a simple, IMF-dependent picture of plasma sheet conditions (e.g. Winglee 1998, 2000; Welling and Ridley 2010). During northward IMF orientations, light and heavy ionospheric ions are relegated to the plasmasphere and lobes with little delivery to the plasma sheet. During southward conditions, the plasma of ionospheric origin is more or less relegated to the central plasma sheet. Figure 12 demonstrates this behavior from two independent models. The top two frames show multi-fluid results during northward IMF (left) and southward IMF (right). The pink contour indicates the density geopause, the region of near-Earth outer space where ionospheric populations dominate. The lower frames show similar results from 

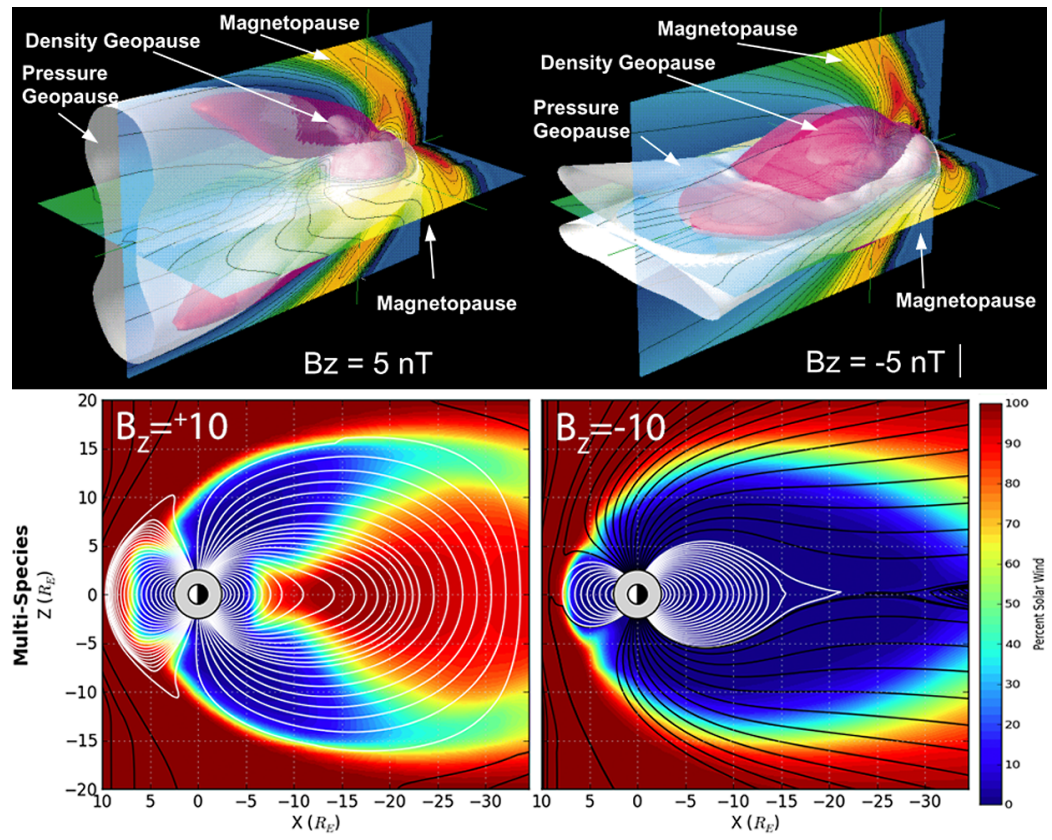

Fig. 12 Fate of outflowing ionospheric populations as identified using a multi-fluid model (upper frames; adapted from Winglee 2000) and a single fluid, multi-species MHD model (bottom frames; recreated from Welling and Ridley 2010)

a single fluid, multi-species MHD simulation. The contours show the percentage of plasma originating from the solar wind, blue indicates a ionospheric-dominated plasma. Both results show similar patterns: during northward IMF, high latitude outflow escapes downtail via the lobes (left frames). However, during southward IMF configurations, a portion of the outflowing populations are captured on reconnecting field lines and gain access to the central plasma sheet and inner magnetosphere. This distinct transport pattern for southward and northward IMF is in agreement with the transport pattern inferred from satellite measurements by Liao et al. (2010) (see Sect. 3.1.2).

Ions captured on closed field lines are heated as they pass near the nightside magnetic $\mathrm{X}$-line and then transported adiabatically as they advect Earthward (Huddleston et al. 2005; Welling and Ridley 2010; Yu and Ridley 2013). This behavior is contingent on the source region and initial velocity of the ionospheric population. In agreement with observations (e.g. Nilsson et al. 2012 and references in Sect. 3), modeling results suggest that fast moving cusp outflow may escape downtail and do not contribute significantly to the central plasma sheet, while slow moving cusp outflow populations are captured effectively (e.g., Brambles et al. 2010; Wiltberger et al. 2010). The amount of adiabatic heating from the inward transport is a function of distance from the Earth where the plasma is deposited into the tail. If the population falls into the central plasma sheet near the X-line, it will experience the maximum amount of adiabatic heating possible. Closer to the Earth, this mechanism is less effective.

During dynamic periods and storm times, this simple picture breaks. Storm time simulations of real events yield plasma sheet details that are difficult to categorize. For example, Winglee et al. (2005) demonstrated that plasma temperature, peak density, and relative 


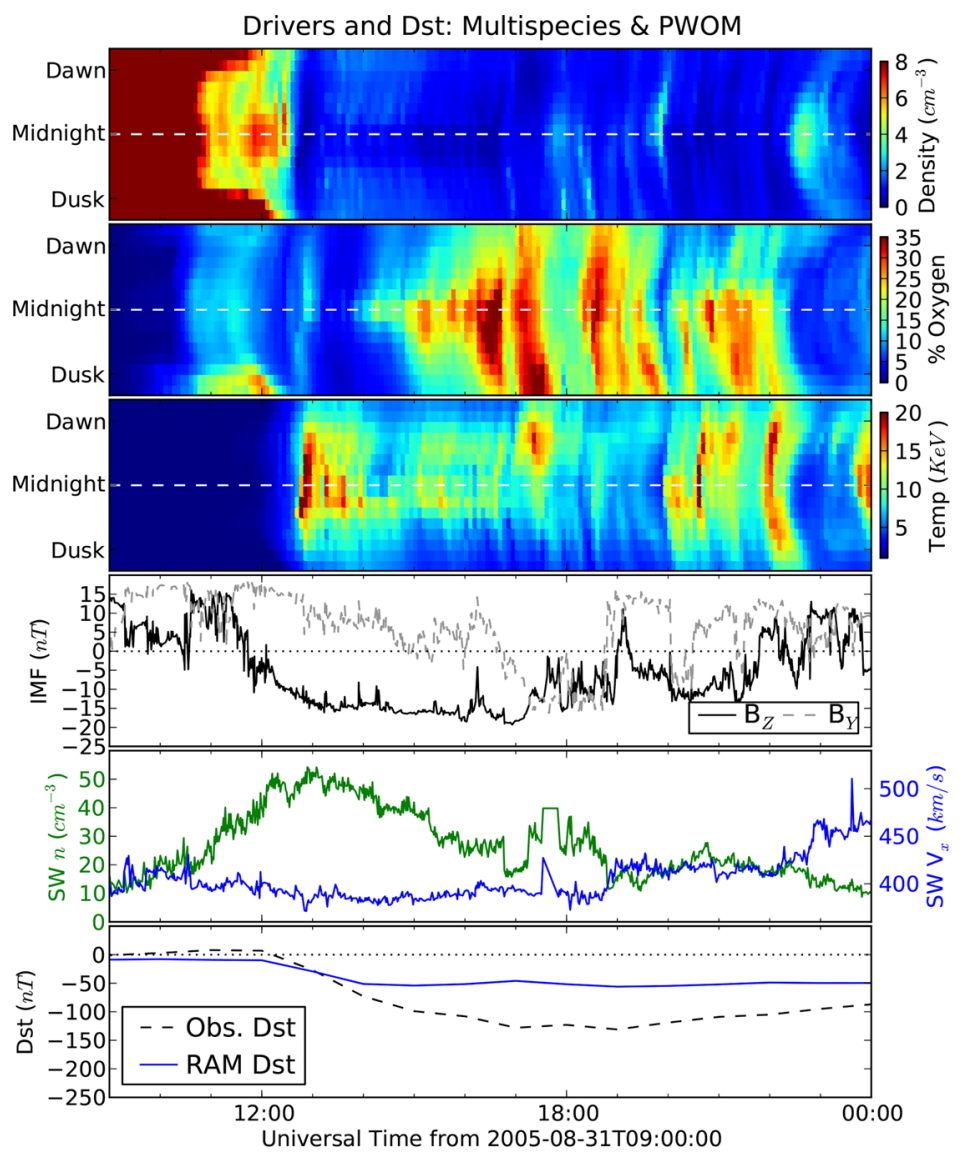

Fig. 13 Plasma conditions about different magnetic local times at a radius of $6.6 \mathrm{R}_{\mathrm{E}}$ (top three frames), the associated upstream IMF and solar wind drivers (fourth and fifth from the top), and resulting Dst index for a multi-model simulation of the 31 August 2005 moderate storm (Welling et al. 2011)

contribution of $\mathrm{O}^{+}$for a single storm can vary wildly not only in time, but with the composition of the ionospheric source. Furthermore, two subsequent substorm events modeled by Winglee and Harnett (2011) demonstrated how two events separated by only a few hours can show completely different patterns of composition and species-specific energy density. The implication is that $\mathrm{O}^{+}$patterns in the active plasma sheet are a function of the solar wind and IMF conditions, outflow behavior, and magnetospheric preconditioning. This high complexity and variability of the plasma sheet $\mathrm{O}^{+}$component indicated by models is clearly supported by the high variability of the $\mathrm{O}^{+}$density reported by observations (see Sect. 4.2).

An example of this variability is illustrated by Welling et al. (2011), who used multispecies MHD and the PWOM to drive a ring current model. The top three panels of Fig. 13 show the variation in universal time ( $x$-axis) and magnetic local time ( $y$-axis) of the plasma sheet total density (top), the percentage of $\mathrm{O}^{+}$by number (second from top), and the plasma temperature (third from top) at a geocentric distance of about $6.6 \mathrm{R}_{\mathrm{E}}$. This distance corresponds to the spatial interface between the ring current model and the MHD plasma sheet. The upstream IMF and plasma conditions are shown in the next two frames. The resulting ring current energy density, summarized by the Dst index, is shown in the bottom frame. The 
peak $\mathrm{O}^{+}$contribution shifts in local time as a function of IMF $\mathrm{B}_{\mathrm{Y}}$, positive $\mathrm{B}_{\mathrm{y}}$ pushing the stronger $\mathrm{O}^{+}$concentrations toward the duskside, negative toward the dawnside. In the final few hours of the simulation, a substorm event manifests as an injection of dense, low- $\mathrm{O}^{+}$ content plasma. The intricacy of the plasma sheet is reflective of other studies and plays a role in the formation of the ring current for this storm.

Larger scale plasma sheet properties during a real-world event were explored by Winglee et al. (2005). The extreme 17 April 2002 event was investigated using different inner boundary $\mathrm{O}^{+}$concentrations. Again, a dynamic, complex picture of tail dynamics was produced, but interesting global features arose. Light ions yielded more symmetric patterns in density and temperature than heavy ions. $\mathrm{O}^{+}$density and temperature peaks showed a duskward preference; the strength of this asymmetry changed with the strength of the $\mathrm{O}^{+}$outflow. Specifically, as ionospheric $\mathrm{O}^{+}$concentrations increased, $\mathrm{O}^{+}$temperature in the magnetotail became more uniform in local time.

Comparing numerical investigations of bulk plasma sheet heavy ion characteristics to statistical, observationally-based studies is difficult. For simple, steady-state studies (e.g. Winglee 1998, 2000; Welling and Ridley 2010), the global codes appear to be in qualitative agreement with observations that show little or no asymmetry (e.g., Mouikis et al. 2010; Ohtani et al. 2011; Maggiolo and Kistler 2014). Further, numerical studies show that $\mathrm{O}^{+}$ concentrations increase with activity, again in agreement with observations. This result is ubiquitous independent of the outflow model used. The duskward asymmetries found in Winglee et al. (2005) and Fok et al. (2006) appear in agreement with some of the statistical studies (e.g., Bouhram et al. 2005; Ohtani et al. 2011) but not others. An example of comparison of Cluster/RAPID observations during quiet and disturbed geomagnetic times with the distribution of the $\mathrm{O}^{+}$pressures in the near-Earth magnetosphere before a substorm onset and during a substorm expansion phase in simulations by Fok et al. (2006) is shown in Fig. 14. They both show dawn-dusk asymmetry in the near-Earth magnetosphere. The time dynamics shown in numerical case studies demonstrate the difficulty in making such comparisons. Still, studies that include comparisons with in-situ measurements (e.g., Glocer et al. 2009a, 2009b; Winglee and Harnett 2011) show that large scale patterns are qualitatively captured, but achieving quantitative agreement with observed $\mathrm{O}^{+}$and $\mathrm{H}^{+}$plasma properties is difficult. There is currently little accounting for discrepancies between observations and models.

\section{Losses}

Seki et al. (2001) proposed that ions leave the magnetosphere through four routes: (1) tailward ion beams in the lobe/mantle region, (2) tailward plasma flows in the nightside plasma sheet, (3) energetic particle drift to the dayside magnetopause (energetic ring current particles and dayside plasma sheet) and (4) cold plasma drift to the dayside magnetopause (plasmaspheric plumes). The estimated total $\mathrm{O}^{+}$loss rate through these four routes is about $\sim 5 \cdot 10^{24} \mathrm{~s}^{-1}$. Later studies, e.g. by Echer et al. (2008), estimated that the loss of $\mathrm{O}^{+}$through the plasma sheet boundary layer of the magnetotail alone can be about $\sim 4 \cdot 10^{24} \mathrm{~s}^{-1}$, suggesting a much higher total loss rate. The acceleration in the cusp region can lead to escape at the dayside magnetopause, and is also a source for the ions in route (1), as discussed in Sect. 3.1.4. Therein, a significant fraction of cusp ions are sufficiently accelerated to escape through the magnetopause with a total escape flux of $\sim 7 \cdot 10^{24} \mathrm{~s}^{-1}$ (Slapak et al. 2012, 2013). Possible processes responsible for the loss at the dayside are reconnection with the northward directed IMF (Kasahara et al. 2008) or 

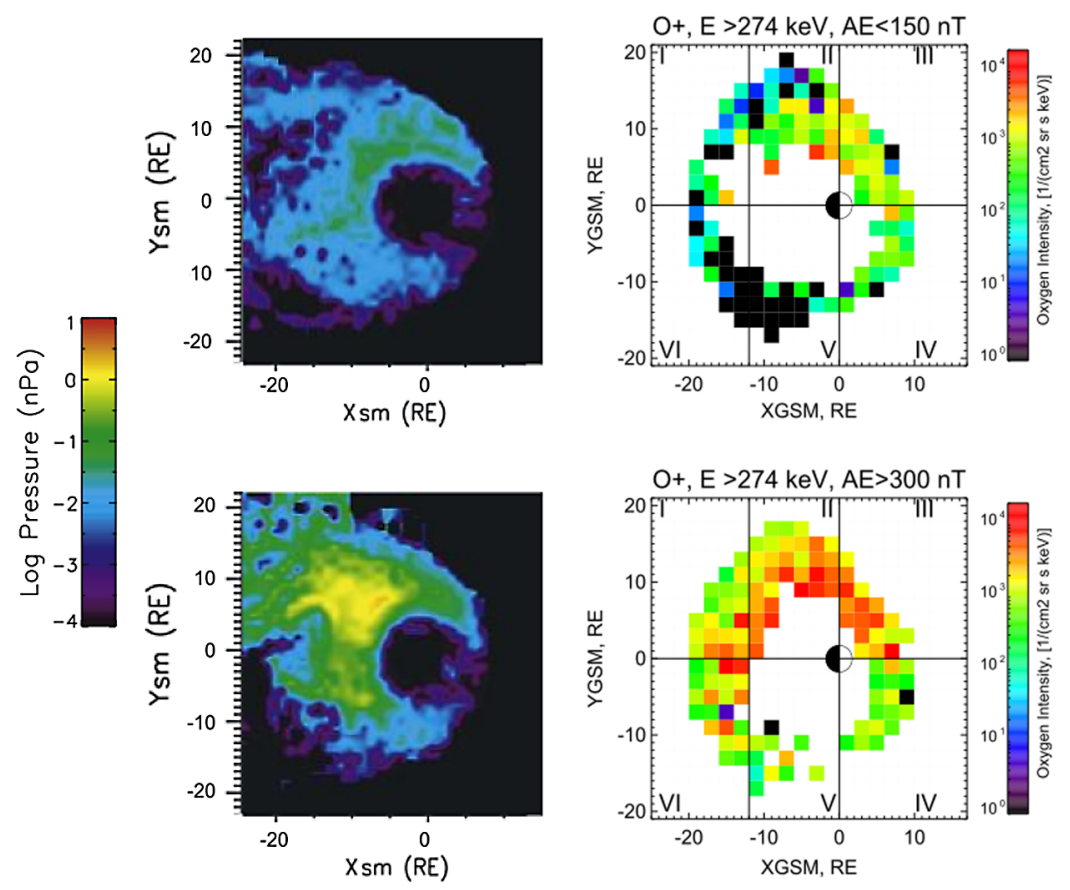

Fig. 14 Comparison of the simulations of $\mathrm{O}^{+}$pressure in $\mathrm{X}-\mathrm{Y}$ plane before a substorm onset (top) and during a substorm (bottom) from Fok et al. (2006) with observations of $\mathrm{O}^{+}$intensity at $>274 \mathrm{keV}$ measured by Cluster/RAPID in the plasma sheet at $\mathrm{AE}<150 \mathrm{nT}$ and $\mathrm{AE}>300 \mathrm{nT}$, respectively

the southward directed IMF (Zong et al. 2001), drift losses (mainly triggered by the solar wind dynamic pressure which changes the magnetopause shape; this is also applicable to the nightside plasma sheet) and due to the interaction with Pc 5 waves when the ion kinetic energy drops below the level required to overcome the convection potential, wherefore the ion is lost at the dayside magnetopause by sunward drift (Li et al. 1993; Yang et al. 2011). Supermagnetosonic plasma streams can lead to the escape of $\mathrm{O}^{+}$from the magnetosphere (Savin et al. 2014). Also, the interaction with CIRs leads to the escape of ions through the whole magnetosphere (Kronberg et al. 2011; Wei et al. 2012). The interaction of the magnetosphere with the solar wind disturbances thus plays an important role in triggering the $\mathrm{O}^{+}$escape (Moore and Horwitz 2007).

Ions can also be lost internally in the magnetosphere, through charge exchange with neutral hydrogen at the geocorona or precipitation into the atmosphere facilitated through wave-particle interactions (Kistler et al. 1989; Jordanova et al. 1996). The relation of these processes to the ring current decay is discussed in more detail in Sect. 6.5. A summary of the loss processes is shown in Sketch 2.

\section{Effects of Heavy Ions on Magnetospheric Dynamics}

An important aim of this review is to summarize how heavy ions influence the dynamics of the magnetosphere. 


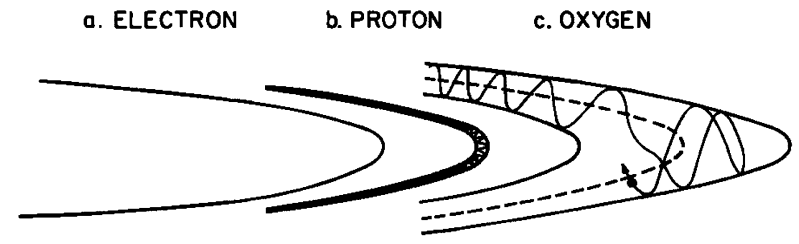

Fig. 15 Schematic illustration of the motion of thermal electron and ion in the vicinity of a quasi-neutral sheet as is the case in the Earth's magnetotail. The relative gyroradii of different particle species and realistic values of the normal field component $\mathrm{B}_{\mathrm{Z}}$ (as shown) imply that electrons are gyrotropic (a), while heavy ion motion becomes non-gyrotropic (c). Taken from Baker et al. (1982)

\subsection{Influence on the Structure and Dynamics of the Magnetotail}

\subsubsection{Quasi-adiabatic Heavy Ion Motion and Its Influence on the Thin Current Sheet Structure}

Southward reversals of the IMF lead to effective reconnection of magnetic field lines at the dayside magnetopause and to the consequent growth of magnetic flux in the magnetospheric lobes together with an increase of the cross-tail electric field (Dungey 1963; Axford 1969). As a result, the thickness of the CS can decrease from several Earth radii down to $\sim 250$ to $2000 \mathrm{~km}$, comparable to a few proton gyroradii (Fairfield 1984; McPherron et al. 1987; Lui et al. 1992; Sergeev et al. 1993; Sanny et al. 1994; Pulkkinen et al. 1994). Such a thin CS (TCS) has metastable properties, i.e., it can be stable during relatively long time periods from several minutes to 2 hours, but then may be spontaneously destroyed due to plasma instabilities (e.g. tearing perturbation) with the appearance of accelerated and thermalized plasma beams (Lui et al. 1992; Sergeev et al. 1993; Baker et al. 1996b; Runov et al. 2005). Most likely TCS play a key role in the development of substorm disturbances, and can play a role of a trigger that switches the magnetic energy loading during relatively slow magnetotail thinning to the fast energy unloading that occurs at the onset and expansion phases of these disturbances (Mozer 1971; Coroniti 1985). The relative contribution of $\mathrm{O}^{+}$ ions to the current across the magnetotail was estimated theoretically as no more than $30 \%$ (Zelenyi et al. 2006). This estimate is consistent with that of Kistler et al. (2005) from Cluster observations of $\mathrm{O}^{+}$content in the magnetotail during substorms.

The behavior of electrons and ions with realistic thermal velocities in a realistic magnetic field configuration in the magnetotail TCS is illustrated in Fig. 15. Because of their very small gyroradii, thermal electrons remain adiabatic, and move in a helical manner throughout the quasi-neutral sheet during their bounce motion (Fig. 15a). On the other hand, thermal ions have much larger gyroradii, and for sufficiently small field line radius of curvature and sufficiently large gyroradii (Figs. 15b, 15c), ions become unmagnetized near the neutral sheet. This unmagnetized ion motion is different from that in relatively thick current configurations (with thicknesses much larger than the ion gyroradius) where most of plasma particles are magnetized. In the TCS, protons and heavy ions travel along quasi-adiabatic orbits (Büchner and Zelenyi 1989, see also Sect. 3.2.2), but their contributions to the balance, structure, and dynamics of the CS can be different (Zelenyi et al. 2006). In the following, we briefly discuss the contribution of heavy ions to the structure and dynamics of TCS.

Using a self-consistent quasi-adiabatic model of a TCS (Sitnov et al. 2000; Zelenyi et al. 2000, 2006), it was shown that a cross-tail TCS has a multi-scale embedded structure like a "matryoshka doll," with several levels of embedding. Thus, a very narrow electron sheet is embedded within a proton sheet, itself embedded inside an even thicker sheet of ionospheric 

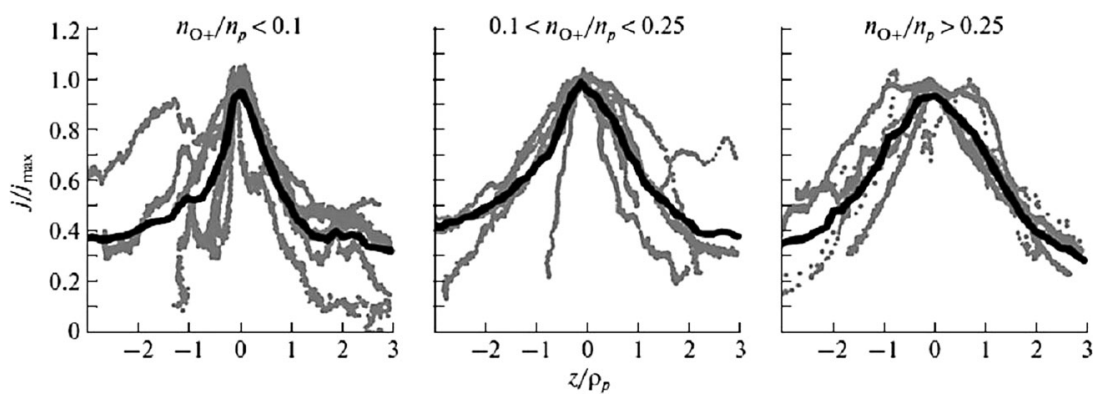

Fig. 16 Current density profiles in magnetotail TCS (grey lines) with different ratios of $\mathrm{O}^{+}$to $\mathrm{H}^{+}$densities, $n_{\mathrm{O}^{+}} / n_{\mathrm{H}^{+}}$. One can see the general thickening of the average (black line) profiles of the CS in proportion to the relative $\mathrm{O}^{+}$density. From Zelenyi et al. (2011)

$\mathrm{O}^{+}$ions. This whole configuration can also be embedded inside a thicker plasma sheet. This TCS embedding property was confirmed by Cluster observations in the magnetotail (Sergeev et al. 1993; Cai et al. 2008; Petrukovich et al. 2011). Cluster observations revealed that CS profiles of TCS might be very different from the usual bell-shaped profiles, and instead become triple- or double-humped (i.e., bifurcated) (e.g. Ashour-Abdalla et al. 1994; Hoshino et al. 1996; Runov et al. 2006; Nakamura et al. 2006). In the frame of the quasiadiabatic model (Zelenyi et al. 2004b), this feature was explained by different partial contributions from electron curvature currents and transient and quasi-trapped ions, depending upon parameters of the field configuration and plasma streams in TCS (Zelenyi et al. 2002; Malova et al. 2013). Generally, the presence of $\mathrm{O}^{+}$ions in the magnetotail leads to thickening of TCS as is illustrated in Fig. 16 from Zelenyi et al. (2011), where several current density profiles of TCS and average profiles with the presence of different relative amount of $\mathrm{O}^{+}$to $\mathrm{H}^{+}$ions are shown. The reason for this thickening is the quasi-adiabatic motion of $\mathrm{O}^{+}$ions with large Larmor radii. However, Liu et al. (2014), showed that during reconnection events, the current sheet thickness is equal to the $\mathrm{H}^{+}$Larmor radius, even when there is significant $\mathrm{O}^{+}$present. Thus the proton scale still dominates the current profile during reconnection.

Birn et al. (2004) suggested that the effects of spatial and temporal nonadiabaticity and nongyrotropy of ion quasi-adiabatic motion are much more pronounced for heavy ions than for light ions and electrons in the magnetotail CS. Using test particle simulations, Dalena et al. (2010) investigated the dynamics of $\mathrm{H}^{+}$and $\mathrm{O}^{+}$ions in the magnetotail CS, both in the presence and in the absence of magnetic turbulence. They showed that, in contrast to protons, quasi-adiabatic $\mathrm{O}^{+}$ions are able to support a bifurcated CS in the absence of magnetic fluctuations. According to the model of Zelenyi et al. (2002), this can be due to the so-called "meandering" motion of heavy ions in the magnetotail. Cai et al. (2008) compared Cluster data of proton TCS and bifurcated $\mathrm{O}^{+}$-rich TCS with two maxima of current density. These authors showed that the embedded proton TCS exhibits a pressure anisotropy with $p_{\|}>p_{\perp}$, while a bifurcated TCS with $\mathrm{O}^{+}$ions exhibits a pressure anisotropy mainly with $p_{\perp}>p_{\|}$ and nongyrotropy, except near the edges where $p_{\|}>p_{\perp}$ is the necessary marginal firehose stability condition. Cai et al. (2008) proposed that the bifurcation of CS profile is due to scattering of quasi-trapped $\mathrm{O}^{+}$ions in the magnetotail. This result is in good qualitative agreement with theoretical investigations by Zelenyi et al. (2002) and Malova et al. (2013). 


\subsection{2 $\mathrm{O}^{+}$and Magnetotail Instability}

One of the key questions concerning $\mathrm{O}^{+}$ions in the magnetosphere is their role in substorm triggering (e.g. Baker et al. 1982; Cladis and Francis 1992). Today there is still no clear answer to this question. The energy principle for tearing mode applied to the well-known Harris model confirms CS instability (Coppi et al. 1966). However, inclusion of a small but finite normal component $\mathrm{B}_{\mathrm{z}}$ in this model leads to the stability of such CSs (Lembege and Pellat 1982). This paradox led to a long lasting controversy about the mechanism of substorm triggering (e.g., Coroniti 1985). Particularly, using results of MHD models of a "thick" CS by Schindler (1974), Baker et al. (1982) examined a possible role of ionospheric heavy ions in the development of plasma sheet instabilities. In particular, they evaluated a possible influence of ionospheric $\mathrm{O}^{+}$on the growth rates of the collisionless ion tearing mode in the near-Earth quasi-neutral sheet region. These authors showed that asymmetries in the distribution of enhanced $\mathrm{O}^{+}$density may delineate plasma sheet regions where the tearing mode growth rate is increased and the instability threshold is lowered. Since the growth rate of a linear ion tearing instability is $\gamma=(\pi)^{1 / 2} \times V_{\mathrm{th}} \times\left(\rho_{i} / 2 L_{\mathrm{Z}}\right)^{3 / 2} / L_{\mathrm{Z}}$, (where $V_{\text {th }}$ is the ion thermal velocity, $L_{Z}$ is the characteristic half-thickness of the CS, and $\rho_{i}$ is the characteristic ion gyroradius), then for a given CS thickness $L_{\mathrm{Z}}$, the larger the characteristic ion gyroradius, the larger the tearing mode growth rate. The qualitative estimate of the growth rate of the linear ion tearing mode using statistical models of the dusk-dawn and earthward-tailward distributions of $\mathrm{O}^{+}$results in a location of maximum ion tearing growth rate in the range $\mathrm{X}_{\mathrm{GSM}} \sim-10$ to $-15 \mathrm{R}_{\mathrm{E}}$ and $\mathrm{Y}_{\mathrm{GSM}} \sim 5 \mathrm{R}_{\mathrm{E}}$, which could be the most likely region where substorms are triggered. There is however no clear observational evidence for this. As discussed in Sect. 4.2, there does not seem to be a significant dawn-dusk asymmetry in the $\mathrm{O}^{+}$densities in the plasma sheet (Mouikis et al. 2010; Maggiolo and Kistler 2014). A dawn-dusk asymmetry is observed in the location of substorm onset, (e.g., Frey et al. 2004), but a relation between this and the location of $\mathrm{O}^{+}$in the tail seems unlikely.

Liu et al. (2013) approached the question by examining how the degree of magnetic flux loading during a substorm correlates with the amount of $\mathrm{O}^{+}$in the plasma sheet. The hypothesis was that if $\mathrm{O}^{+}$makes the tail more unstable to reconnection, then there should be less magnetic flux loading before onset occurs when more $\mathrm{O}^{+}$is present. To determine the amount of loading, they measured the total pressure change in the magnetotail, normalized by the solar wind pressure and by the distance down the tail. They found that in fact the amount of loading was greater when there was more $\mathrm{O}^{+}$, indicating that, if anything, the $\mathrm{O}^{+}$ was making it harder to trigger substorm onset.

It was hypothesized that the ion nonadiabatic behavior could lead to an ion tearing mode instability with the concomitant growth of neutral line structures (Schindler 1974). The analysis of quasi-adiabatic TCS in proton-electron plasma (Zelenyi et al. 2008a) practically resolved the controversy about magnetotail instability and showed that the regions of TCS instability represent narrow gaps in parameter space of the current sheet, separated by wide stable regions. Thus, the natural metastability property of TCS could be explained in the frame of a quasi-adiabatic CS model.

\subsubsection{Influence of Heavy Ions on the Reconnection Process}

Another important question concerns the influence of heavy ions on the reconnection process. There is clear observational evidence for the presence of $\mathrm{O}^{+}$ions in some reconnection events (e.g. Kistler et al. 2005; Wygant et al. 2005). Hesse and Birn (2004) using threespecies full particle simulations with periodic boundary conditions concluded that the $\mathrm{O}^{+}$ 
component of the ion population has very little effect on the reconnection process. However, these authors warned against the generality of their result due to the use of a small simulation box. On the other hand, Shay and Swisdak (2004) used a three-fluid reconnection simulation with periodic boundary conditions and concluded that besides the usual two scales associated with collisionless two-fluid reconnection ("light" whistler and "light" Alfvèn), there are two additional larger scales, namely the "heavy whistler" and the "heavy Alfvèn" scales. The length scale that is associated with the "heavy whistler" produces a large-scale quadrupole out-of-plane magnetic field structure, whereas the one associated with the "heavy Alfvèn" wave can slow the reconnection rate.

Karimabadi et al. (2011) performed a kinetic study of collisionless reconnection in threespecies plasma using a combination of linear Vlasov theory and non-driven and driven 2D full particle simulations. They examined the effects of heavy ions on the linear growth rate, onset, peak reconnection rate and overall structure of the reconnection layer. They showed that one of the critical factor is the so-called "flushing effect", which is that as reconnection proceeds, plasma is brought in from the lobe, while the initial population of current carriers is ejected from the system. Thus, the lobe plasma becomes dominant in the system and the lobe ions carry most of the ion current. This provides a natural explanation of Cluster observations (Kistler et al. 2005; Wygant et al. 2005) which have shown that during stormtime substorms, the $\mathrm{O}^{+}$number density in the plasma sheet close to the reconnection X-line in the Earth's magnetotail can become comparable to, or even higher, than the corresponding $\mathrm{H}^{+}$number density, so that $\mathrm{O}^{+}$ions carry most of the particle pressure. It was revealed that the presence of $\mathrm{O}^{+}$ions in the lobe can significantly change the evolution and the resulting structure of the reconnection region on the nonlinear stage of the reconnection process. Namely, the presence of $\mathrm{O}^{+}$ions in the lobe (i) reduces the number and repetition frequency of secondary islands, (ii) broadens and intensifies the quadrupole out-of-plane magnetic structure, (iii) slows down the coalescence process, and (iv) modifies the composition of current carriers in the CS.

To determine if a difference in reconnection rate was evident in global substorm parameters, Liu et al. (2013) tested whether the unloading rate correlated with the amount of $\mathrm{O}^{+}$ in the plasma sheet. They found that in fact there was faster unloading when there was more $\mathrm{O}^{+}$. This is counter to the theoretical expectation of a decrease in reconnection rate, based on changes of the Alfvèn speed, and may be a result of the structural changes in the reconnection that occur when $\mathrm{O}^{+}$is present, identified by Karimabadi et al. (2011).

Reconnection effects in self consistent global models are considered in Sect. 6.2.

\subsection{Heavy Ions in Self Consistent Global Models}

Global MHD simulations have demonstrated that heavy ion outflow has a profound effect on plasma sheet and tail geometry. Because the additional mass density provided by heavy ion outflow can feed inner magnetosphere pressure build up, tail stretching due to force balance is often seen. Glocer et al. (2009a, 2009b) quantified how effective this pressure increase can be by comparing the observed geosynchronous magnetic field inclination angle against simulation prediction with and without $\mathrm{O}^{+}$outflow. The results were stark; outflow changed the result from a near-dipole field to one with significant stretching that matched observed quantities. Brambles et al. (2010) found similar behavior using cusp outflow driven by the Strangeway et al. (2005) empirical relationship, but only in the case where the outflow was not fast enough to escape down tail. Garcia et al. (2010) showed similar effects when nightside auroral outflow was prescribed. 
Reconnection The effects of heavy ions on reconnection have been observed in global MHD simulations, with cusp outflow appearing to be the prime culprit. In ideal MHD, reconnection is a function of numerical dissipation, which is proportional to the local Alfvèn speed. As such, a higher mass density is expected to slow reconnection rates and force changes in tail geometry and dynamics. Wiltberger et al. (2010), when prescribing a fast $(50 \mathrm{~km} / \mathrm{s}) \mathrm{O}^{+}$population originating from the cusp region, found that the $\mathrm{O}^{+}$would escape downtail and the X-line would be pushed Earthward of its previous position. Brambles et al. (2010) observed similar behavior and credited the move in the reconnection line to the magnetosphere's response to a lower local reconnection rate at the original X-line position. Yu and Ridley (2013) found a different response: instead of pushing the X-line Earthward, the plasma sheet underwent a large scale reconfiguration resulting in a longer tail capable of capturing the bulk of the cusp outflow. These responses change even more drastically when the static outflows of the above studies are replaced by causally driven outflow, as was done by Brambles et al. (2011). The result of this study was that the magnetosphere fell into a sawtooth-oscillation mode, discussed in detail below. All of the above features depend not only on the presence of an $\mathrm{O}^{+}$, population but also on its initial velocity and density as it escapes the ionosphere.

It is important to note that reconnection effects are not limited to the nightside. Yu and Ridley (2013), again leveraging global multi-fluid MHD with prescribed outflow, found that portions of heavy ion outflow arriving at the dayside magnetopause clearly affected dayside reconnection dynamics. Using prescribed cusp and nightside auroral outflow, this effect was quantified using the Cassak-Shay formula for reconnection rate (Cassak and Shay 2007) and by integrating the reconnection electric field across the X-line to get a total dawn-dusk potential drop. Nightside auroral outflow reduced the reconnection rate by approximately $8 \%$ via mass-loading the reconnection site. The cusp region outflow reduced the dayside rate further $(\sim 12 \%)$ not only due to localized mass loading, but also via a reduction in the dayside terrestrial field strength resulting from partial ring current and tail current intensification. A similar result was found in roundabout fashion in an earlier, single-fluid MHD investigation of reconnection rates (Borovsky et al. 2008). High mass density near the inner boundary (arising from the de facto-type outflow mechanisms) convected sunward at the start of the simulation, creating a pseudo-plasmaspheric plume. Upon arriving at the dayside magnetopause, the pseudo plume reduced the local reconnection rate (as determined by the Cassak-Shay formula) by a factor of 2 . This result is consistent with observational work correlating periods where plumes are observed with indicators of solar wind-magnetosphere energy coupling (e.g., OMNI $-v B_{Z}$, AE indices, etc.) (Borovsky and Denton 2006). Despite this recent progress, the relationship between heavy ion outflow and dayside reconnection dynamics remains poorly understood.

Cross Polar Cap Potential An effect observed ubiquitously in global simulations is a reduction in the cross polar cap potential when a slow, dense source of $\mathrm{O}^{+}$is included. This feature, not to be confused with the saturation of the CPCP at high levels of solar wind driving, is profound in its implications on how ionospheric outflow participates and perhaps even regulates global dynamics. Figure 17, taken from Winglee (2002), demonstrates this effect for the 24 September 2013 storm event. As $\mathrm{O}^{+}$concentration is increased from negligible values ( $5 \%$, black line) to the dominant ion species (50 to $100 \%$, red-dashed and light blue lines), the CPCP is reduced by nearly $100 \mathrm{kV}$. The lower CPCP values are more in-line with the values derived from the observation-driven Assimilative Mapping of Ionospheric Electrodynamics (AMIE, Lu et al. 1996) technique (red diamonds). The net result is far slower convection speeds in the plasma sheet and ring current regions. 
Fig. 17 Cross polar cap potential from several different global, multifluid simulations of the magnetosphere (thin colored lines) against values derived from AMIE (red diamonds). From Winglee (2002)
Cross-Polar Cap Potential - Variable O Concentration

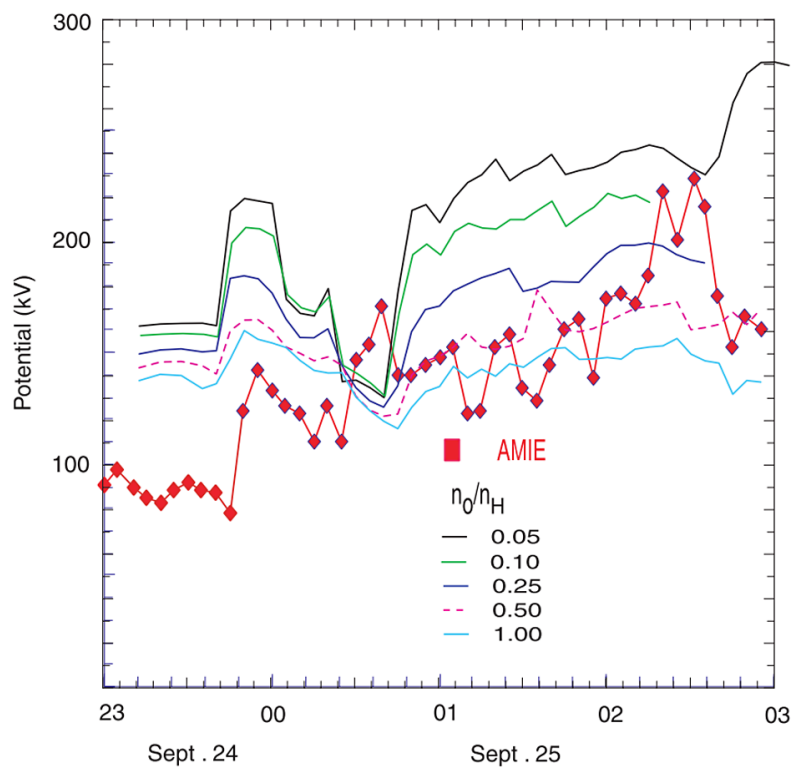

The mechanisms responsible for outflow-related CPCP reduction are poorly understood. Winglee (2002) postulated that the increase in mass density along flux tubes lowered the distributed velocity given the same solar energy input, thus lowering the overall electric potential. Glocer et al. (2009a) suggested that the increase in mass density near the MHD inner boundary was altering field-aligned-current strength through an Ohm's law-type relationship. Wiltberger et al. (2010) went one step further, noting that the increased mass density towards the inner boundary changes the electron precipitation pattern in the LFM model, raising conductance and lowering electric potential. Brambles et al. (2010) noted that as outflow fuels the ring current, the magnetosphere expands, especially at the flanks, leading to the CPCP reduction. Lopez et al. (2010) described the physical mechanisms behind this: as the magnetosphere becomes a blunter obstacle to the solar wind, the solar wind flow has to traverse a greater distance across a wider magnetosheath and hence experiences a greater deflection due to magnetosheath forces. This reduces the geoeffective lengtha scale length indicative of the amount of solar wind flow potential that is applied to the magnetosphere (Burke et al. 1999). While Lopez et al. (2010) used this dynamic to help explain CPCP saturation, Brambles et al. (2010) found it applicable to the present case of non-saturated CPCP reductions when polar wind-like outflow is included in global simulations. Garcia et al. (2010) presented supporting evidence in simulations that used the LFM with prescribed outflow relegated to the nightside ionosphere only. In each of the above studies, comparisons with observations of CPCP is sometimes improved, sometimes degraded by outflow-related reductions. While the explanation put forth by Brambles et al. (2010) was tested and rejected by Welling and Zaharia (2012), all other explanations remain untested. The issue of how heavy ion outflow impacts CPCP currently remains unresolved.

Ring Current The above impacts on the plasma sheet and global magnetosphere, as modeled by global MHD codes, map directly to the ring current. This is typically characterized 

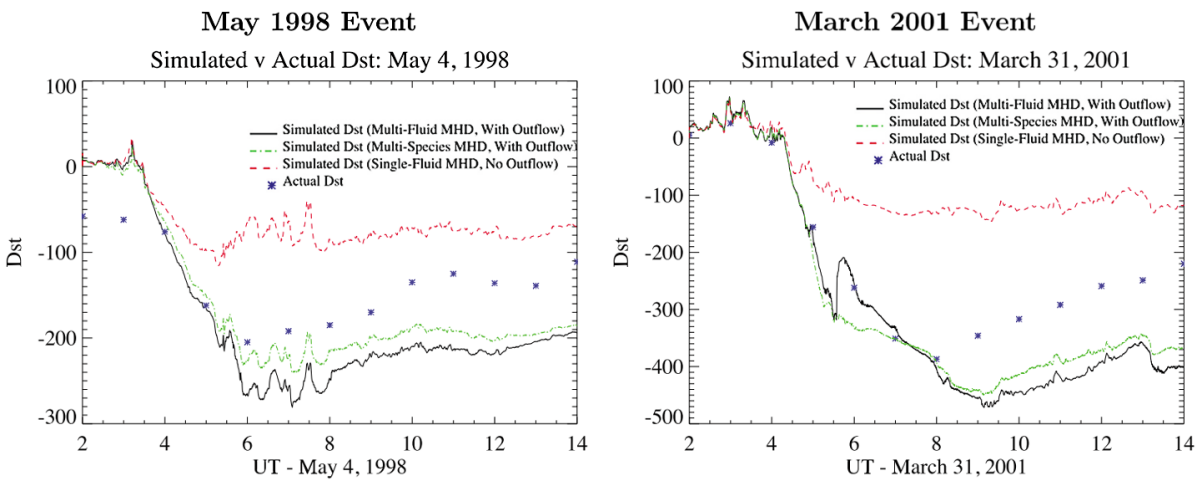

Fig. 18 Dst index as derived from global MHD simulations of two strong storm events without ionospheric outflow (red lines) and with. Single fluid, multi-species MHD (green lines) and full multi-fluid (black lines) were used. Hourly observed Dst is shown as blue asterisks (Glocer et al. 2009b)

as an appropriate source (e.g., one that is sufficiently captured into the central plasma sheet) feeding the ring current with an abundance of $\mathrm{H}^{+}$and $\mathrm{O}^{+}$not otherwise available. It results in greater ring current energy density, often demonstrated through a much lower resulting Dst index. Figure 18 demonstrates this quantitatively; the difference between simulated Dst when outflow is and is not included is several hundred $\mathrm{nT}$ for each of the events.

This characterization neglects how heavy ions indirectly affect ring current development through their strong influence on plasma sheet dynamics. Though the increase of ring current $\mathrm{H}^{+}$and $\mathrm{O}^{+}$enhances inner magnetospheric plasma pressure, this pressure stretches the geomagnetic field significantly, therefore increasing gradient-curvature drift speeds (e.g., Zaharia et al. 2006; Jordanova et al. 2010). Additionally, if MHD predictions of reduced CPCP values resulting from $\mathrm{O}^{+}$outflow are correct, the $E \times B$ drift of fresh plasma will be greatly diminished. Welling et al. (2011) demonstrated that these two factors caused weak Earthward penetration of plasma into the ring current. Warmer populations, especially those entering duskward of local midnight, could gradient-curvature drift out of the code domain without being captured. The total result was a ring current that was significantly weaker than that when no outflow was included in the model. Though this result is likely an extreme case, it demonstrates how the effects of heavy ion outflow are complex and non-linear. Other, less critical plasma sheet characteristics, such as spatial asymmetries in density and composition, also contribute to these effects (Welling et al. 2011), as discussed in Sect. 4.4.

Fok et al. (2011) demonstrated how necessary the heavy ion component can be for storm time ring current development. This study follows the approach of Moore et al. (2007) by using single fluid LFM to track entry of solar wind material to the inner magnetosphere as well as produce inputs to the Strangeway et al. (2005) empirical relationship. The resulting $\mathrm{O}^{+}$fluxes are used to seed a global kinetic model, which creates heavy ion distributions at the outer edge of the inner magnetosphere. The two populations are fed into the Comprehensive Ring Current Model (CRCM) (Fok et al. 2001), where their contribution to the ring current energy can be monitored. This approach was applied to the 20 November 2003 super storm. Their initial simulation generated a reasonable reproduction of observed Dst and solar wind plasma was the main pressure carrier. However, if plasma sheet fluxes were adjusted to match Geotail observations, $\mathrm{O}^{+}$became the dominant pressure carrier and the timing, magnitude, and structure of the resulting Dst curve strongly matched observations. 


\subsection{Influence on Substorm Dynamics}

The two processes by which heavy ions may impact substorm dynamics are through affecting the triggering of reconnection and affecting the reconnection rate. These have been discussed in Sects. 6.1.3 and 6.2. In addition, substorms may have an impact on heavy ions through preferential energization associated with reconnection and dipolarization. This is discussed in Sect. 3.2.2. Finally, substorms may increase the amount of heavy ions in the magnetosphere through enhanced outflow from the auroral region feeding the plasma sheet. Here we first discuss statistical changes in heavy ions observed during substorms, and then show the results of substorm simulations that include heavy ions.

Daglis and Axford (1994), showed that $\mathrm{O}^{+}$energy density in the near-Earth $\left(\sim 9 \mathrm{R}_{\mathrm{E}}\right)$ plasma sheet is significantly enhanced at substorm onset, with the bulk of the enhancement occurring above $17 \mathrm{keV}$. Using Cluster/CODIF data, Kistler et al. (2006) performed statistical studies of the changes of ion composition in the energy range $40 \mathrm{eV}-40 \mathrm{keV}$ during storm intervals and nonstorm substorms in the vicinity of Cluster apogee $\left(X \sim-19 \mathrm{R}_{\mathrm{E}}\right)$. They found that there is significantly more $\mathrm{O}^{+}$in the plasma sheet during storm-times than during non-storm times. However, in contrast to the near-Earth plasma sheet ( $X \sim-8$ to $-9 R_{E}$ ), no significant changes in the ion composition were observed near the Cluster apogee during non-storm substorms. There are composition changes during storm-time substorms. Sauvaud et al. (2004), showed an example in which ions were massively injected into the $\sim-19 \mathrm{R}_{\mathrm{E}}$ tail during a storm-time substorms from the nightside ionosphere. In that case, a single $\mathrm{O}^{+}$injection was able to account for over $80 \%$ of the $\mathrm{O}^{+}$population of the midtail plasma sheet during storm time. However, statistically, Kistler et al. (2006) found that while the $\mathrm{O}^{+} / \mathrm{H}^{+}$ratio does increase at substorm onset, the change is mainly due to a decrease in the $\mathrm{H}^{+}$. The $\mathrm{H}^{+}$density and pressure decrease over the whole energy range at substorm onset, while the decrease of $\mathrm{O}^{+}$density and pressure is less and the $\mathrm{O}^{+}$temperature increases. The fact that more $\mathrm{O}^{+}$ions are left after substorm onset indicates that either $\mathrm{O}^{+}$ are more quickly replenished from the lobes and/or that the more energetic $\mathrm{O}^{+}$, due to their large gyroradii, are not depleted when the field reconfigures. The significant difference between the composition changes in the near-Earth region and the mid-tail region indicates that during non-storm times, the auroral source feeds the inner plasma sheet, but does not affect the mid-tail region where the reconnection is taking place. During storm times, the $\mathrm{O}^{+}$density is significantly higher, but the increase does not appear to be generally substorm related. There are cases when a substorm leads to a significant $\mathrm{O}^{+}$increase, but on average the composition change at substorm onset is modest and more related to the dynamics of the reconnection region than to an enhancement of the auroral source.

\subsubsection{LSK Simulations of Isolated and Storm-Time Substorms}

An isolated substorm that occurred during a major conjunction of the THEMIS SC was investigated by Ashour-Abdalla et al. (2009) using LSK simulations. They first ran a global MHD simulation using as input the solar wind conditions as measured by the WIND SC upstream of Earth, and carried out a detailed comparison with observations from the Geotail SC both in the magnetosphere and magnetosheath, with GOES-11 and GOES-12, and with four of the THEMIS SC to validate the MHD simulation results (detailed in El-Alaoui et al. 2009). Ashour-Abdalla et al. (2009) then launched solar wind $\mathrm{H}^{+}$ions from a continuous ring just inside the magnetopause current layer, and launched ionospheric $\mathrm{O}^{+}$ions by using the Strangeway et al. (2005) formulae associating $\mathrm{O}^{+}$outflow with electron precipitation and with downward Poynting flux in the ionosphere. Using combination of $\mathrm{O}^{+}$and $\mathrm{H}^{+}$they 
reproduced enhanced energy fluxes of both thermal and energetic particles with energetic ions recorded up to $500 \mathrm{keV}$ observed by THEMIS-E, and showed that the energetic ions arriving at this SC did so from a region just earthward of the X-line on the dawn side, gaining energy rapidly in a region of high total and inductive electric fields and traversed the CS to reach the SC. The ions' behavior in this region is highly nonadiabatic, and the rapid acceleration and cross-tail motion of the ions is consistent with the "wall" region first reported by Ashour-Abdalla et al. (1992a, 1992b). The simulations show that prior to the substorm onset the ionospheric ions significantly contributed to the cross-tail current but after the onset the solar wind ions became dominant.

More recently, ion injection into the inner magnetosphere during a substorm that occurred during the recovery phase of the 17 April 2002 storm was investigated by Peroomian et al. (2011a). The rapid increase in the energy density of $\mathrm{H}^{+}$and $\mathrm{O}^{+}$ions observed in ENA images obtained from the High-Energy Neutral Atom (HENA) instrument on the IMAGE SC was successfully reproduced. The magnetic field topology in the near-Earth tail responsible for the energization and injection of ions during the substorm was delineated.

\subsubsection{Self-consistent Model Simulations of Substorms}

Consistent with the findings that inclusion of heavy ion populations can affect reconnection dynamics in global models, it has been demonstrated that such populations affect the triggering of substorms and their subsequent development. An idealized case study was presented in Wiltberger et al. (2010) using a specified slow $(20 \mathrm{~km} / \mathrm{s})$ and dense $\left(500 \mathrm{~cm}^{-3}\right)$ outflow source relegated to the cusp. The heavy ion fluid played a dual role upon arrival at the near-equator plasma sheet: it altered the reconnection rate of the $\mathrm{X}$-line and mass loaded the plasma sheet Earthward of the X-line. The tail response to these changes was the release of a plasmoid. This result contrasts with the magnetospheric response when a faster outflowing population was used; this population was deposited tailward of the reconnection line and did not trigger large scale tail reconfiguration. Winglee and Harnett (2011), again leveraging their global multi-fluid model, investigated two sequential non-storm substorms that occurred on 13 August, 2001. The Cluster and IMAGE missions observed both events. It was shown that, consistent with results from Kistler et al. (2006), the $\mathrm{O}^{+}$to $\mathrm{H}^{+}$density ratio does not appear to play a role in substorm development. Alternatively, the onset of each event appears correlated to an increase of the ratio of $\mathrm{O}^{+}$to $\mathrm{H}^{+}$energy density to near unity. The authors conclude that even for non-storm time events, heavy ions play a crucial role in substorm development.

Though not truly self consistent, Fok et al. (2006) used an idealized substorm event from the single fluid LFM code to examine the fate of $\mathrm{O}^{+}$, kinetically traced through the MHD fields. In the particle tracing model (Delcourt 1993), it was found that the $\mathrm{O}^{+}$undergoes significant non-adiabatic acceleration during the growth phase while $\mathrm{H}^{+}$did not. When these results were used as an outer boundary condition for the CRCM model, the substormdriven fluxes resulted in a sudden increase in the $\mathrm{O}^{+}$energy density to levels far above the previously-dominant $\mathrm{H}^{+}$energy density. These model results were used to create synthetic ENA images which qualitatively agreed with observations from IMAGE.

\subsection{Sawtooth Events}

A sawtooth event is defined as a periodic substorm with strong and global responses over an extended magnetic local time (MLT). The injections, observed predominantly in protons with energies between 50 and $400 \mathrm{keV}$, have a fast rise, and a slow decay that resembles 
a "sawtooth" shape. During, sawtooth events, significant amounts of energy are pumped earthward periodically, leading to an even more dramatic disturbance near the Earth. Hence, it is important to study the mechanism that triggers the sawtooth events, and how it differs from the triggers of non-sawtooth substorms.

Brambles et al. (2011) suggest that enhanced ionospheric outflow plays a significant role in generating sawtooth events. They showed that when $\mathrm{O}^{+}$outflow fluence, predominantly from the nightside auroral region, is above a threshold, the magnetosphere moves into a sawtooth convection mode. Moreover, the duration of period of single tooth decreases as the outflow fluence of $\mathrm{O}^{+}$increases. Ouellette et al. (2013), further investigating these results, clearly characterized the plasmoid-outflow feedback loop. For each plasmoid release, precipitating Poynting flux triggers the release of $\mathrm{O}^{+}$from the low latitude simulation boundary. Similar to the results of Wiltberger et al. (2010), this heavy population massloads the tail and drives the formation of a NENL. The resulting plasmoid deposits more energy into the ionosphere, and the cycle continues. These studies, for the first time, provided evidence for a non-linear feedback mechanism between heavy ion acceleration at ionospheric/magnetospheric altitudes and global magnetospheric convection modes.

Observations show that $\sim 94 \%$ of sawtooth events occur during geomagnetic storm times (Cai et al. 2011). It is also known that the $\mathrm{O}^{+}$concentration inside the magnetosphere is highly correlated with geomagnetic storms. This provides initial support for the notion that $\mathrm{O}^{+}$outflows are responsible for sawtooth oscillations, but leaves open the possibility that other aspects of geomagnetic storms, other than enhanced $\mathrm{O}^{+}$are in fact responsible for sawtooth development.

A statistical study of the $\mathrm{O}^{+}$concentration inside the near-Earth plasma sheet during sawtooth events and substorms using Cluster/CODIF data was performed by Liao et al. (2014). The sawtooth and substorm event lists are based on the Los Alamos National Lab (LANL) observations at geosynchronous orbit. Figure 19, reproduced from Liao et al. (2014) shows the superposed epoch analysis result of $\mathrm{O}^{+} / \mathrm{H}^{+}$density ratio during sawtooth events and substorms. The grey shade at the background shows the data from non-events times, during which no activity is found. The 0 hour on the superposed epoch analysis scale marks the onset of sawtooth/substorm, -2 hour to 0 hour shows the growth phase and 0 hour to 1 hour shows the recovery phase. The result is sorted into different geomagnetic storm phases and non-storm times distinguish the effect of storms from the effects of $\mathrm{O}^{+}$. In all panels, at the start of the growth phase, sawtooth and substorm events share a similar level of $\mathrm{O}^{+} / \mathrm{H}^{+}$density ratio, which indicates that sawtooth events and substorms do not have a different pre-event condition. The density ratio then increases during most of the growth phase of the sawtooth events, regardless of the storm phase, and reaches $20 \%$ around the onset of dipolarization. This indicates a strong and consistent input of $\mathrm{O}^{+}$into the plasma sheet during the sawtooth events growth phase while the $\mathrm{O}^{+}$content remains about constant, or even decreases during substorms. This also supports the idea that for sawtooth events, there is a threshold for $\mathrm{O}^{+}$concentration to trigger sawtooth onset in the magnetotail. The $\mathrm{O}^{+} / \mathrm{H}^{+}$density ratio, on average, reaches higher levels during sawtooth events than that during substorm events or non-event times. However, the difference between event types is relatively smaller for storm main phase than non-storm times and recovery phase. This confirms the positive correlation between high $\mathrm{O}^{+}$content in the plasma sheet and sawtooth events.

However, this investigation also found that the density ratio is not a necessary or sufficient condition for generating sawtooth events. When the $\mathrm{O}^{+} / \mathrm{H}^{+}$density ratio in the plasma sheet is high, there are often no events. And there are sawtooth events that occur during low $\mathrm{O}^{+}$ time periods. Hence, enhanced $\mathrm{O}^{+}$is likely one of many storm-related factors that play a role in triggering sawtooth events. 
Fig. 19 Superposed epoch study of $\mathrm{O}^{+} / \mathrm{H}^{+}$density ratio in the plasma sheet for sawtooth events (green) and substorms (red) during nonstorm time, storm main phase and recovery phase. Grey belt shows interquartile range of the non-events data. Lines give the median values. Error bars give the 1st and 3rd quartile. The superposed epoch analysis binsize is 0.5 hour. $\mathrm{O}^{+} / \mathrm{H}^{+}$density ratio is plotted in logarithm scale. The epoch of the two groups shifted slightly for better visualization. From Liao et al. (2014)
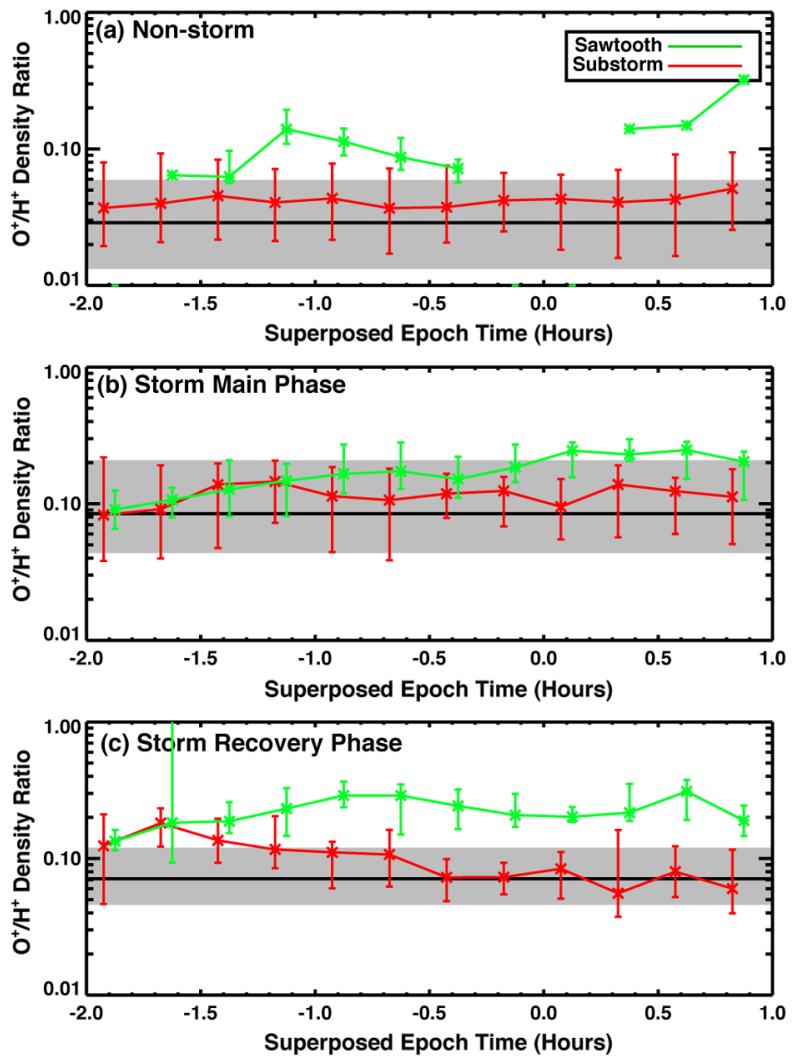

\subsection{Impact of Heavy Ions on the Ring Current}

The first composition measurements of the storm time ring current showed that for major storms, $\mathrm{O}^{+}$can be the dominant species during the main phase (Hamilton et al. 1988). The importance of ionospheric heavy ions for the ring current dynamics may be related to the high $\mathrm{O}^{+} / \mathrm{H}^{+}$ratio in the near-Earth plasma sheet $\left(6-9 \mathrm{R}_{\mathrm{E}}\right)$, due to both the massspectrometer effect, discussed in Sect. 3, and the direct injection of the nightside auroral outflow. This population is then injected into the inner magnetosphere due to enhanced convection during storm times. These heavy ions influence the plasma pressure and, therefore, affect the local dynamics. Additionally, as shown by a model of Xie et al. 2006 (threedimensional test particle trajectory calculations), $\mathrm{O}^{+}$ions are more easily trapped on closed drift trajectories than protons. Therefore, these $\mathrm{O}^{+}$ions help in maintaining the ring current bulk population.

The composition of the low energy $(<10 \mathrm{keV})$ quiet-time ring current becomes heavy ion dominant at low L-values (Lundin et al. 1980). Kistler et al. 1998, showed that this is due to charge exchange with the neutral hydrogen geocorona. As an $\mathrm{H}^{+}$dominant population drifts in from the plasma sheet on a long, slow drift paths, the $\mathrm{H}^{+}$ions are lost at a much faster rate than the $\mathrm{He}^{+}$and $\mathrm{O}^{+}$ions, due to their larger cross section for charge exchange at these energies.

Heavy ions also affect the decay of the ring current. Several loss processes mentioned in Sect. 5, have been proposed. These include charge exchange, precipitation into 
the atmosphere due to wave-particle interactions, and drift losses (e.g. Hamilton et al. 1988; Kistler et al. 1989; Daglis et al. 1999; Ebihara and Ejiri 2002; Keika et al. 2011; Ilie et al. 2012). Coulomb interactions may also play a role at low energies (Fok et al. 1993). Compositional changes in the ring current influence the ring current decay, due to the energy and mass dependence of the charge exchange cross sections. Hamilton et al. (1988), showed that the fast initial decay of the ring current often observed for large storms was consistent with the time scales for $\mathrm{O}^{+}$charge exchange, while the later slow decay of the ring current was consistent with the charge exchange rates for $\mathrm{H}^{+}$. However, Liemohn et al. (1999) suggested that the fast initial decay is due to loss of ions at the frontside magnetopause. The study by Fu et al. (2001) suggests that the ring current is asymmetric due to the strong asymmetry of the ring current $\mathrm{O}^{+}$population. A similar loss of $\mathrm{O}^{+}$ions on the day side (about $60-70 \%$ ) is seen in Fig. 14. Keika et al. (2011) have proposed that ion precipitation through pitch angle scattering (e.g. Electromagnetic Ion Cyclotron (EMIC) waves) is a significant loss mechanism during the storm recovery phase.

\subsection{Scattering and Heating of Particles by EMIC Waves in the Presence of Heavy Ions}

A number of studies showed the evidence that the loss of relativistic electrons in the radiation belts is caused by EMIC wave scattering (e.g., Millan et al. 2007; Sandanger et al. 2007; Rodger et al. 2008; Miyoshi et al. 2008; Blum et al. 2012; Carson et al. 2013). Shprits et al. (2013) demonstrated that EMIC waves play a crucial role for the dynamics of the ultrarelativistic populations in the radiation belts. Detached proton subauroral arcs are caused by the precipitation of ring current protons into the atmosphere produced by EMIC waves (e.g., Jordanova et al. 2007; Spasojevic and Fuselier 2009; Usanova et al. 2010; Yuan et al. 2010). As EMIC waves play an important role in the dynamics of the inner magnetosphere, in this section, we consider how heavy ions regulate EMIC wave scattering, their impact on ion heating by these waves and the minimum resonant energy during wave-particle interactions.

\subsubsection{Electromagnetic Ion Cyclotron Waves}

EMIC waves are often observed in plumes and along the dusk side plasmapause inside or outside the plasmasphere (e.g., Meredith et al. 2003). EMIC waves are excited by a ring current temperature anisotropy with characteristic amplitudes of up to $10 \mathrm{nT}$ during geomagnetically active conditions (e.g., Cornwall 1965; Søraas et al. 1980; Usanova et al. 2008, 2012; McCollough et al. 2010). Such large amplitudes make EMIC waves a viable candidate for the scattering of electrons and ions.

The dispersion relation for L-mode EMIC waves is very sensitive to the inclusion of heavy ions (e.g. Stix 1992; Summers et al. 2007). In a hydrogen plasma there is one frequency band (hydrogen band) where waves can be observed, while in a multi-ion plasma EMIC waves are observed in three separate bands. A number of modeling studies explored the role of $\mathrm{H}^{+}, \mathrm{He}^{+}$, and $\mathrm{O}^{+}$ions on the excitation and propagation properties of EMIC waves (e.g., Gamayunov and Khazanov 2008; Hu et al. 2010; Chen et al. 2011; Omidi et al. 2013, and references therein). Omidi et al. (2013) using hybrid simulations (kinetic for ions and fluid for electrons) showed that EMIC waves are generated in the near equatorial region and propagate parallel or anti-parallel to the magnetic field directly towards the ionosphere where they are absorbed when the $\mathrm{O}^{+}$concentration is lower than $7 \%$. When $\mathrm{O}^{+}$concentration increases to moderate levels $(\sim 15 \%)$ EMIC waves begin to reflect. For high $\mathrm{O}^{+}$concentrations $\geq 30 \%$ EMIC waves are strongly damped. 


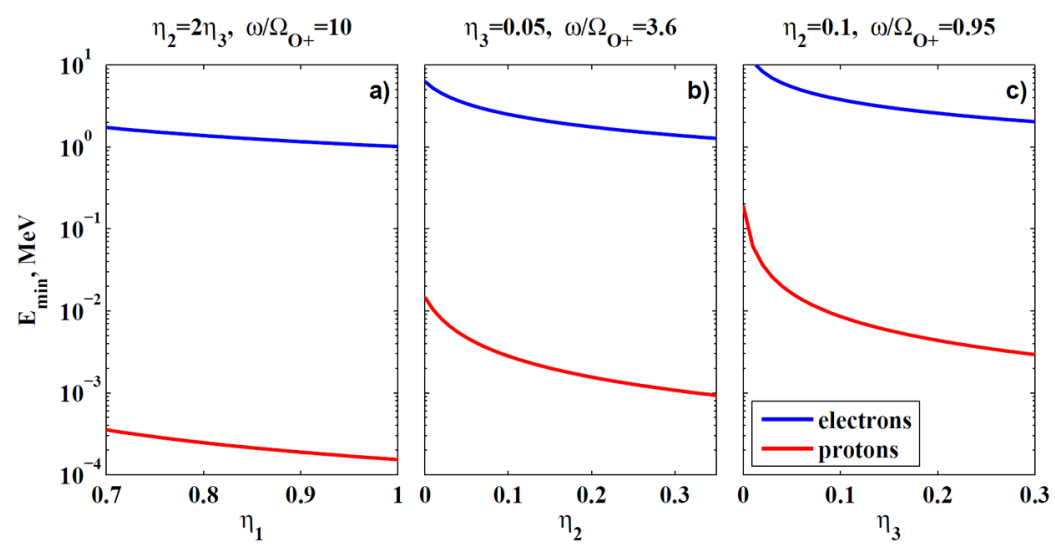

Fig. $20 E_{\min }$ for resonant interaction of electrons and protons (blue and red lines, respectively) with EMIC waves. Panels (a)-(c) show the dependence of $E_{\min }$ on the $\mathrm{H}^{+}, \mathrm{He}^{+}$, and $\mathrm{O}^{+}$fractional ion compositions, respectively, for three L-mode EMIC frequency bands

\subsubsection{Ion Heating by EMIC Waves}

EMIC waves become strongly oblique when they propagate from the source region to higher latitudes and can be damped close to the reflection point near the bi-ion frequency. This absorption of waves causes thermal ion heating perpendicularly to the magnetic field through the cyclotron resonant interaction (e.g., Thorne and Horne 1993; Horne and Thorne 1997; Fuselier and Anderson 1996; Shoji et al. 2011). Observations near geosynchronous orbit (e.g. Mauk et al. 1981; Young et al. 1981) originally revealed the presence of $\mathrm{He}^{+}$heated to $\sim 200 \mathrm{eV}$ by EMIC waves. Anderson and Fuselier (1994) showed that the $\mathrm{He}^{+}$distribution functions were consistent with an off-equatorial gyroresonant interaction which heated the $\mathrm{He}^{+}$ions up to an average of $\sim 35 \mathrm{eV}$. Mouikis (2002), using data from Equator-S, showed an example in which the heating occurred at the inner edge of the plasma sheet, where the slow drift of ions led to a strong proton temperature anisotropy that provided the free energy to drive the waves. In his example, ion heating up to $2 \mathrm{keV}$ was observed. Zhang et al. (2010) and (2011a) showed that long time periods of heating (1-5 hours) are observed predominantly on the dusk side in the outer magnetosphere during quiet times. $\mathrm{The}_{\mathrm{He}}^{+}$heating events were associated with a proton temperature anisotropy and with an increase of the cold plasma density. The conditions favorable to EMIC wave generation and $\mathrm{He}^{+}$heating likely occur in the dusk local time sector because of the long slow drift paths that produce the temperature anisotropy, and the extension of the plasmaspheric plume to high L-values, both of which are expected during quiet geomagnetic conditions.

\subsubsection{Influence of Heavy Ions on the Minimum Resonant Energy}

The EMIC waves excited during active conditions can resonantly interact with electrons and protons causing their strong precipitation to the atmosphere due to pitch angle scattering (Thorne and Kennel 1971; Summers and Thorne 2003; Albert 2003). For each L-mode EMIC band the minimum energy is strongly dependent on the fractional density of the ion that specifies the band and weakly dependent on the other two fractional ion densities (Summers and Thorne 2003; Summers et al. 2007). Figure 20 shows the sensitivity of the mini- 
mum resonant kinetic energy $E_{\min }$ of electrons and protons on reasonable fractional ion composition in each L-mode EMIC frequency band. We used expressions from Summers et al. (2007) to compute $E_{\min }$ and took the ratio of the electron plasma frequency to the electron gyrofrequency equal to $15 . \eta_{1}, \eta_{2}, \eta_{3}$ are the ratios of the $\mathrm{H}^{+}, \mathrm{He}^{+}$, and $\mathrm{O}^{+}$ion number densities, respectively, to the electron number density satisfying the condition $\eta_{1}+\eta_{2}+\eta_{3}=1$. Panel (a) presents the dependence of the minimum energy on $\eta_{1}$ for $\mathrm{H}^{+}$band $\omega / \Omega_{\mathrm{O}^{+}}=10$, where $\Omega_{\mathrm{O}^{+}}$is oxygen ion gyrofrequency and assuming that $\eta_{2}=2 \eta_{3}$. The dependence of $E_{\min }$ on $\eta_{2}$ for $\mathrm{He}^{+}$band is illustrated on Panel (b) considering $\omega / \Omega_{\mathrm{O}^{+}}=3.6$ and $\eta_{3}=0.05$. Panel (c) shows $E_{\min }$ as a function of $\eta_{3}$ for $\mathrm{O}^{+}$band $\omega / \Omega_{\mathrm{O}^{+}}=0.95$ for $\eta_{2}=0.1$. For each frequency band the minimum kinetic energy is decreasing with increasing the fractional density of the ion that specifies the band. For electrons $E_{\text {min }}$ can fall below $2 \mathrm{MeV}$ for EMIC waves with the $\mathrm{H}^{+}$frequency band and $\mathrm{He}^{+}$frequency band with rather large $\eta_{2} \geq 0.15$. Note that Loto'aniu et al. (2006) and Ukhorskiy et al. (2010) showed that EMIC waves right below the $\mathrm{He}^{+}$gyrofrequency can interact with electrons having energies as low as $400 \mathrm{keV}$.

In summary, EMIC waves play an important role in ion heating and strong pitch-angle scattering of both protons and electrons into the loss cone. Excitation of waves, and details of wave-particle interactions depend on the heavy ion composition which provides an additional link between the dynamics of heavy ions and electron/ ion populations of the ring current and the radiation belts.

\section{Open Questions}

During the last decade substantial progress has been made towards understanding the influence of heavy ionospheric ions on the dynamics of the terrestrial magnetosphere. However, there are still many unanswered questions and unexplored avenues of research.

At the beginning of the heavy ion circulation we have not yet quantified the heating and acceleration mechanisms responsible for ions to escape from the ionosphere. While the main processes have been identified, they are not understood well enough to be accurately implemented in physical models. The further acceleration of ionospheric ions in the high altitude cusp and lobes should also be studied in more detail. While ions that exit the cusp relatively low, are observed in the lobes as cold beams and show only little or no acceleration, ions that make it to the high altitudes are strongly heated. The mechanism for this heating is not understood.

Better modeling of the ion transport is also required. Extensive observations have allowed us to explore how the spatial dependence of ionospheric ions in the lobes varies with solar and geomagnetic activity. The next step would be to verify this information with theoretical models. For example models and observations do not agree on how ion outflow paths are controlled by the azimuthal IMF. The velocity filter effect, which is fundamental to the ion transport, is inherently not included in MHD models, so a move to more kinetic models is required.

In an effort to make simulations compatible with observations, we should also establish the relative contributions of different ion sources for different solar and geomagnetic conditions. For instance, the relation between ions outflowing from the dayside cusp region versus nightside auroral region should be explored, as observational and simulation results differ in this case.

That the heavy ion population increases with solar and geomagnetic activity is clear, but how these ions impact the micro scales of reconnection and macro scales of substorm 
triggering and unloading is not understood. Studies of the macro-scale effects of $\mathrm{O}^{+}$on loading and unloading lead to results that are counter to what is expected, based on the current micro-scale understanding. Kinetic simulations that include heavy ions are only now being performed, and careful data-model comparison needs to be done to understand the physical processes that explain these unintuitive results.

In the plasma sheet, the statistical averages of the ion densities, intensities and composition have been determined in detail. However, there is a large scatter in the data, and the reason for this large variability is not known. It would also be useful to know where, depending on their energy, ions reach the plasma sheet. Models could then be used to determine the dominant energization mechanisms depending on location. One highly controversial topic on ion acceleration in the plasma sheet is how heavy ions are accelerated at dipolarization fronts and X-lines. Also the current non-adiabatic picture of ion acceleration is incomplete without waves.

The major source of $\mathrm{O}^{+}$in the ring current is the near-earth plasma sheet, but some internal sources and acceleration mechanisms have also been identified, and their importance is unclear. It is shown by observations that the fast early decay of the ring current is associated with $\mathrm{O}^{+}$ions, but drift loss is also important. We do not know which physical process is most important.

On the global scale, there is still a need for observational confirmation of several largescale processes that are found in simulations, including the changed location of the X-line when $\mathrm{O}^{+}$is enchanced, and the driving of sawtooth events. Also, quantitative and qualitative validations of the physical properties (e.g. density distributions) predicted by models are required. The different models need not only be reconciled with observations, but also with each other. Despite the recent progress in coupling ionospheric outflow models to global magnetospheric models, this work is still in its infancy. Balancing a complete description of ionospheric outflow with the limitations of global models remains an outstanding challenge.

The impact of the heavy ion outflow is complex and nonlinear. On the one hand, including ionospheric outflow in global MHD simulations results in greater ring current energy densities and, therefore, lower Dst index values and better agreement with observations. On the other hand, it leads to a reduction in the cross polar cap potential, resulting in slower convection speeds in the plasma sheet and ring current regions, and therefore weaker ring current. The mechanisms responsible for outflow-related CPCP reduction are poorly understood.

This review was mainly focused on $\mathrm{O}^{+}$observations and theory. However, there is reason to believe that nitrogen ions may have an even stronger dependence on geomagnetic activity. Future investigations of nitrogen ions could thus profoundly improve our understanding of the ion dynamics in the magnetosphere.

Missions currently being planned, including Magnetosphere-Ionosphere-Thermosphere Coupling Constellation Mission (Liu 2014) and Nitrogen Ion Tracing Orbitor/Observatory (NITRO) could help to answer many of the open questions.

\section{Summary}

In this review, we have collected observational and theoretical findings concerning the entire cycle of the heavy ion circulation in the terrestrial magnetosphere focusing on recent results.

The heavy ion content of the magnetosphere depends on the strength and composition of the ionospheric outflow, on its mixing with solar wind plasma at a particular time and on the loss rate. The energy which powers the ionospheric outflow comes from three sources: 
solar EUV, electromagnetic energy from reconnection at the magnetopause and in the tail, and electron precipitation. At higher altitudes, wave-particle interactions further accelerate ions, driving them into the magnetosphere.

It is now well established that a significant amount of $\mathrm{O}^{+}$and $\mathrm{H}^{+}$ions transits from the ionosphere to the magnetosphere. The heavy ions originate from the polar region and low/middle latitudes, as shown in Sketch 1. The polar region includes the polar cap (the polar wind and the polar cap ion beams) and the auroral region which supply the magnetosphere with ions. The auroral region consists of two main sources: the dayside cusp and the nightside auroral region which are the most significant $\mathrm{O}^{+}$outflow sources.

Ions escaping from the dayside ionosphere are accelerated over the cusp towards high altitudes and form beams that move along open field lines simultaneously convecting towards the central plasma sheet. These ions are subjected to a velocity filter effect: slower ions enter the plasma sheet closer to Earth and faster ions travel further out into the tail. Fast cusp ions are more likely to be lost downtail than slow moving populations. During transport in the lobes ionospheric ions undergo centrifugal acceleration. There is also evidence that they are additionally accelerated in the PSBL during active times. The transport path and occurrence rate of ionospheric $\mathrm{O}^{+}$ions are highly dependent upon the solar cycle, IMF conditions and convection patterns. $\mathrm{O}^{+}$that is transiting the lobes can enter the plasma sheet when the magnetic field in the tail reconnects. During active periods, the increased large-scale convection in the magnetospheric lobes brings more energetic ions directly to the near-Earth plasma sheet. This leads to a significant increase in the $\mathrm{O}^{+}$content of the plasma sheet, and later on, of the ring current. A fraction of the $\mathrm{O}^{+}$ions do not enter the plasma sheet. These ions remain on open field lines and are subsequently lost from the magnetosphere.

Nightside auroral outflows occur on closed field lines. This source mainly feeds the inner plasma sheet which then feeds the ring current. There are sources of low-energy heavy ions in the inner magnetosphere at low and middle latitudes including the plasmasphere and ionospheric field-aligned beams. They are more easily trapped on closed drift trajectories, helping to maintain the bulk ion population.

In the mid-tail plasma sheet region the $\mathrm{O}^{+}$density is more dependent on geomagnetic activity than on solar EUV flux. The increase of the $\mathrm{O}^{+}$density with increasing geomagnetic activity appears to be modulated by the solar activity level. Closer to Earth variations of the $\mathrm{O}^{+}$density due to changes in solar EUV flux and geomagnetic activity are comparable in amplitude, and both effects are independent from one another. However, these dependencies are not straightforward as large standard deviations are observed. Simulations confirm this complexity.

Heavy ions in the plasma sheet can be preferentially energized during substorms. The effective acceleration mechanisms during substorms are impulsive nonadiabatic heating, wave heating, and acceleration in the vicinity of an X-line or reconnection region. The contribution of the different acceleration mechanisms to the net energization of heavy ions is position-dependent.

An important aspect of this review is to summarize how heavy ions influence the magnetospheric dynamics. The main effects are outlined in Sketch 3.

Observations and simulations definitively show that the $\mathrm{O}^{+}$ions significantly contribute to the structure and dynamics of Earth's magnetotail CS. Most likely TCS play a very special role in the development of storm/substorm/sawtooth disturbances, and can play the role of a trigger that switches the magnetic energy storage during relatively slow magnetotail thinning to the fast energy release that occurs at the onset and expansion phases of these disturbances. On one hand, the ion outflow fills the plasma sheet, leading to an increase in the inner magnetospheric pressure and to stretching of the tail. Heavy ions noticeably contribute to 
Sketch 3 Effects of heavy ions on the magnetospheric dynamics

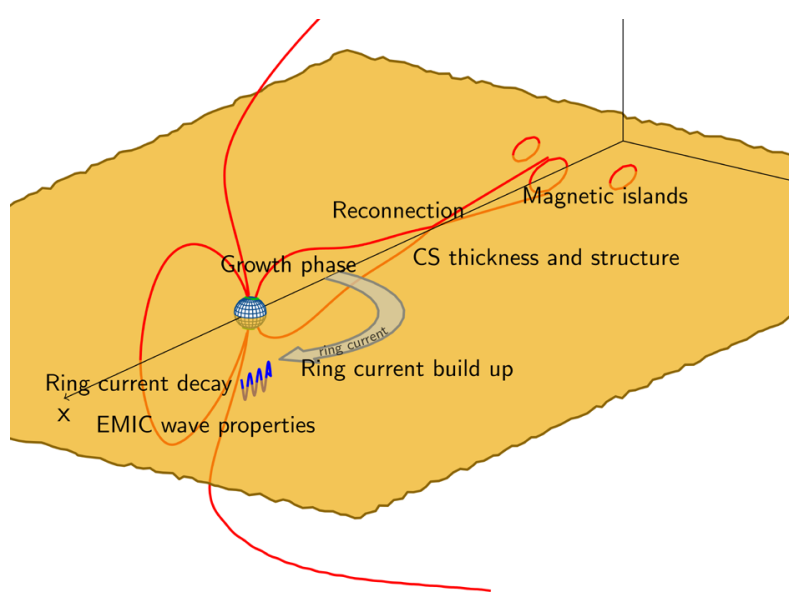

the cross-tail current. On the other hand, they cause a thickening and bifurcation of the TCS. They reduce the number and repetition frequency of secondary magnetic islands, they broaden and intensify the quadrupole out-of-plane magnetic field structure and they slow down the coalescence process of magnetic islands. Simulations of storms and substorms agree noticably better with observations if ionospheric ions are taken into account.

Depending on the IMF conditions, the $\mathrm{O}^{+}$ions follow different paths in the plasma sheet and therefore they differently access and influence the ring current in different ways. The $\mathrm{O}^{+}$ ions have rapid access to the plasma sheet during disturbed times and are able to significantly affect the ring current dynamics. Most likely, the enchanced $\mathrm{O}^{+}$affects not only the ring current magnitude but also the ring current decay. They are lost through charge exchange, scattering, and through drift to the magnetopause.

Finally, heavy ions affect the generation and propagation of EMIC waves. In plasmas with a high $\mathrm{O}^{+}$content, EMIC waves are strongly damped. The scattering of relativistic radiation belt electrons by EMIC waves that leads to strong electron precipitation onto the atmosphere is strongly influenced by the ion composition in the ring current. Scattering of relativistic electrons in the presence of heavy ions plays a crucial role in the dynamics of the radiation belts.

Acknowledgements We thank the International Space Science Institute (ISSI) for their hospitality, and, for giving us the opportunity to gather the team on "Heavy ions: their dynamical impact on the magnetosphere" which allowed us to conceive this work.

Open Access This article is distributed under the terms of the Creative Commons Attribution License which permits any use, distribution, and reproduction in any medium, provided the original author(s) and the source are credited.

\section{References}

T. Abe, B.A. Whalen, A.W. Yau, R.E. Horita, S. Watanabe, E. Sagawa, EXOS D (Akebono) suprathermal mass spectrometer observations of the polar wind. J. Geophys. Res. 98, 11191 (1993). doi:10.1029/ 92JA01971

M.R. Aellig, A.J. Lazarus, J.T. Steinberg, The solar wind helium abundance: variation with wind speed and the solar cycle. Geophys. Res. Lett. 28(1), 2767-2770 (2001). doi:10.1029/2000GL012771

J.M. Albert, Evaluation of quasi-linear diffusion coefficients for EMIC waves in a multispecies plasma. J. Geophys. Res. 108(A6), 1249 (2003). doi:10.1029/2002JA009792 
B.J. Anderson, S.A. Fuselier, Response of thermal ions to electromagnetic ion cyclotron waves. J. Geophys. Res. 99(19), 413 (1994)

L. Andersson, W.K. Peterson, K.M. McBryde, Dynamic coordinates for auroral ion outflow. J. Geophys. Res. 109(A8), A08201 (2004). doi:10.1029/2004JA010424

M. Andre, A. Yau, Theories and observations of ion energization and outflow in the high latitude magnetosphere. Space Sci. Rev. 80(1), 27-48 (1997). doi:10.1023/A:1004921619885

A.V. Artemyev, L.M. Zelenyi, H.V. Malova, G. Zimbardo, D. Delcourt, Acceleration and transport of ions in turbulent current sheets: formation of non-Maxwellian energy distribution. Nonlinear Process. Geophys. 16, 631-639 (2009)

M. Ashour-Abdalla, L.M. Zelenyi, J.M. Bosqued, V. Peroomian, Z. Wang, D. Schriver, R. Richard, Effects of near-Earth stochastic acceleration and reflections of magnetotail ions on the formation of auroral arcs, in Proceedings of the International Conference on Substorms (ICS-1). Eur. Space Agency Spec. Publ., ESA, vol. SP-335 (1992a), p. 545.

M. Ashour-Abdalla, L.M. Zelenyi, J.M. Bosqued, V. Peroomian, Z. Wang, D. Schriver, R.L. Richard, The formation of the wall region: consequences in the near-Earth magnetotail. Geophys. Res. Lett. 19, 1739 (1992b)

M. Ashour-Abdalla, L.M. Zelenyi, V. Peroomian, R.L. Richard, Consequences of magnetotail ion dynamics. J. Geophys. Res. 99(A8), 14891-14916 (1994)

M. Ashour-Abdalla, J.-M. Bosqued, M. El-Alaoui, V. Peroomian, M. Zhou, R.L. Richard, R. Walker, A. Runov, V. Angelopoulos, A simulation study of particle energization observed by THEMIS spacecraft during a substorm. J. Geophys. Res. 114(A9), A09204 (2009). doi:10.1029/2009JA014126

W.I. Axford, Magnetospheric convection. Rev. Geophys. 7(1-2), 421-459 (1969)

W.I. Axford, The polar wind and the terrestrial helium budget. J. Geophys. Res. 73(21), 6855-6859 (1968). doi:10.1029/JA073i021p06855

D.N. Baker, E.W. Hones Jr., D.T. Young, J. Birn, The possible role of ionospheric oxygen in the initiation and development of plasma sheet instabilities. Geophys. Res. Lett. 9, 1337-1340 (1982)

D.N. Baker, T.I. Pulkkinen, P. Toivanen, M. Hesse, R.L. McPherron, A possible interpretation of cold ion beams in the earth's tail lobe. J. Geomagn. Geoelectr. 8, 699-710 (1996a)

D.N. Baker, T.I. Pulkinen, V. Angelopoulos, W. Baumjohann, R.L. McPherron, Neutral line model of substorms: past results and present view. J. Geophys. Res. 101(A6), 12975-13010 (1996b)

T.F. Bell, R.A. Helliwell, U.S. Inan, D.S. Lauben, The heating of suprathermal ions above thunderstorm cells. Geophys. Res. Lett. 20, 1991-1994 (1993). doi:10.1029/93GL02242

J. Birn, M.F. Thomsen, M. Hesse, Acceleration of oxygen ions in the dynamic magnetotail. Ann. Geophys. 22, 1305-1315 (2004). doi:10.5194/angeo-22-1305-2004

L.W. Blum, E.A. MacDonald, L.B.N. Clausen, X. Li, A comparison of magnetic field measurements and a plasma-based proxy to infer EMIC wave distributions at geosynchronous orbit. J. Geophys. Res. 117, A05220 (2012). doi:10.1029/2011JA017474

J.E. Borovsky, M.H. Denton, Effect of plasmaspheric drainage plumes on solar-wind/magnetosphere coupling. Geophys. Res. Lett. 33(20), L20101 (2006). doi:10.1029/2006GL026519

J.E. Borovsky, M. Hesse, J. Birn, M.M. Kuznetsova, What determines the reconnection rate at the dayside magnetosphere? J. Geophys. Res. 113(A7), A07210 (2008). doi:10.1029/2007JA012645

G.G. Borrini, J.T. Gosling, S.J. Bame, W.C. Feldman, Helium abundance enhancements in the solar wind. J. Geophys. Res. 87, 7370-7378 (1982). doi:10.1029/JA087iA09p07370

M. Bouhram, B. Klecker, W. Miyake, H. Rème, J.A. Sauvaud, M. Malingre, L.M. Kistler, A. Blagau, On the altitude dependence of transversely heated $\mathrm{O}$ distributions in the cusp/cleft. Ann. Geophys. 22, 17871798 (2004). doi:10.5194/angeo-22-1787-2004

M. Bouhram, B. Klecker, G. Paschmann, S. Haaland, H. Hasegawa, A. Blagau, H. Rème, J.-A. Sauvaud, L.M. Kistler, A. Balogh, Survey of energetic $\mathrm{O}^{+}$near the dayside mid-latitude magnetopause with Cluster. Ann. Geophys. 23, 1281-1294 (2005). doi:10.5194/angeo-23-1281-2005

O.J. Brambles, W. Lotko, P.A. Damiano, B. Zhang, M. Wiltberger, J. Lyon, Effects of causally driven cusp $\mathrm{O}^{+}$outflow on the storm time magnetosphere-ionosphere system using a multifluid global simulation. J. Geophys. Res. 115, A00J04 (2010). doi:10.1029/2010JA015469

O.J. Brambles, W. Lotko, B. Zhang, M. Wiltberger, J. Lyon, R.J. Strangeway, Magnetosphere sawtooth oscillations induced by ionospheric outflow. Science 332(6034), 1183 (2011). doi:10.1126/science.1202869

W.J. Burke, D.R. Weimer, N.C. Maynard, Geoeffective interplanetary scale sizes derived from regression analysis of polar cap potentials. J. Geophys. Res. 104(A5), 9989-9994 (1999). doi:10.1029/1999JA900031

J. Büchner, L.M. Zelenyi, Regular and chaotic charged particle motion in magnetotaillike field reversals: 1 . Basic theory of trapped motion. J. Geophys. Res. 94, 11821-11842 (1989)

C.L. Cai, I. Dandouras, H. Rème, J.B. Cao, G.C. Zhou, G.K. Parks, Cluster observations on the thin current sheet in the magnetotail. Ann. Geophys. 26, 929-940 (2008) 
X. Cai, J.C. Zhang, C.R. Clauer, M.W. Liemohn, Relationship between sawtooth events and magnetic storms. J. Geophys. Res. 116, A07208 (2011). doi:10.1029/2010JA016310

M. Candidi, S. Orsini, V. Formisano, The properties of ionospheric $\mathrm{O}^{+}$ions as observed in the magnetotail boundary layer and northern plasma lobe. J. Geophys. Res. 87, 9097-9106 (1982). doi:10.1029/JA087iA11p09097

M. Candidi, S. Orsini, A.G. Ghielmetti, Observations of multiple ion beams in the magnetotail evidence for a double proton population. J. Geophys. Res. 89, 2180-2184 (1984). doi:10.1029/JA089iA04p02180

B.R. Carson, C.J. Rodger, M.A. Clilverd, POES satellite observations of EMIC-wave driven relativistic electron precipitation during 1998-2010. J. Geophys. Res. 118, 232-243 (2013). doi:10.1029/ 2012JA017998

P.A. Cassak, M.A. Shay, Scaling of asymmetric magnetic reconnection: general theory and collisional simulations. Phys. Plasmas 14(10), 102114 (2007). doi:10.1063/1.2795630

M.O. Chandler, Observations of downward moving $\mathrm{O}^{+}$in the polar topside ionosphere. J. Geophys. Res. 100(A4), 5795-5800 (1995). doi:10.1029/94JA03236

L. Chen, R.M. Thorne, J. Bortnik, The controlling effect of ion temperature on EMIC wave excitation and scattering. Geophys. Res. Lett. 38, L16109 (2011). doi:10.1029/2011GL048653

S.P. Christon, G. Gloeckler, D.J. Williams, T. Mukai, R.W. McEntire, C. Jacquey, V. Angelopoulos, A.T.Y. Lui, S. Kokubun, D.H. Fairfield, M. Hirahara, T. Yamamoto, Energetic atomic and molecular ions of ionospheric origin observed in distant magnetotail flow-reversal events. Geophys. Res. Lett. 21, 3023 (1994)

J.B. Cladis, W.E. Francis, Distribution in magnetotail of $\mathrm{O}^{+}$ions from cusp/cleft ionosphere-a possible substorm trigger. J. Geophys. Res. 97(A1), 123-130 (1992)

B. Coppi, G. Laval, R. Pellat, Dynamics of the geomagnetic tail. Phys. Rev. Lett. 16(26), 1207-1210 (1966)

J.M. Cornwall, Cyclotron instabilities and electromagnetic emissions in the ultra low frequency and very low frequency ranges. J. Geophys. Res. 70(1), 61-69 (1965)

F.V. Coroniti, Explosive tail reconnection-the growth and expansion phases of magnetospheric substorms. J. Geophys. Res. 90, 7427-7447 (1985). doi:10.1029/JA090iA08p07427

C.M. Cully, E.F. Donovan, Å.W. Yau, G.G. Arkos, Akebono/suprathermal mass spectrometer observations of low-energy ion outflow: dependence on magnetic activity and solar wind conditions. J. Geophys. Res. 108, 1093-1103 (2003). doi:10.1029/2002JA009587

I.A. Daglis, W.I. Axford, Fast ionospheric response to enhanced activity in geospace: ion feeding of the inner magnetotail. J. Geophys. Res. 101, 5691-5703 (1994)

I.A. Daglis, W.I. Axford, Fast ionospheric response to enhanced activity in geospace: ion feeding of the inner magnetotail. J. Geophys. Res. 101(A3), 5047-5066 (1996). doi:10.1029/95JA02592

I.A. Daglis, E. Sarris, B. Wilken, AMPTE/CCE CHEM observations of the energetic ion population at geosynchronous altitudes. Ann. Geophys. 11, 685-696 (1993)

I.A. Daglis, R.M. Thorne, W. Baumjohann, S. Orsini, The terrestrial ring current: origin, formation, and decay. Rev. Geophys. 37(4), 407-438 (1999)

S. Dalena, A. Greco, G. Zimbardo, P. Veltri, Role of oxygen ions in the formation of a bifurcated current sheet in the magnetotail. J. Geophys. Res. 115, A03213 (2010)

P.A. Damiano, O.J. Brambles, W. Lotko, B. Zhang, M. Wiltberger, J. Lyon, Effects of solar wind dynamic pressure on the ionospheric $\mathrm{O}^{+}$fluence during the 31 August 2005 storm. J. Geophys. Res. 115, A00J07 (2010). doi:10.1029/2010JA015583

I. Dandouras, J. Cao, C. Vallat, Energetic ion dynamics of the inner magnetosphere revealed in coordinated Cluster-Double Star observations. J. Geophys. Res. 114, A01S90 (2009). doi:10.1029/2007JA012757

I. Dandouras, Detection of a plasmaspheric wind in the Earth's magnetosphere by Cluster spacecraft. Ann. Geophys. 31, 1143-1153 (2013). doi:10.5194/angeo-31-1143-2013

D.C. Delcourt, The motion of near-Earth (10-15 $\mathrm{R}_{\mathrm{E}}$ ) plasma sheet particles during substorms. Adv. Space Res. 13(4), 237-243 (1993). doi:10.1016/0273-1177(93)90339-D

D.C. Delcourt, C.R. Chappell, T.E. Moore, J.H. Waite, A three-dimensional numerical model of ionospheric plasma in the magnetosphere. J. Geophys. Res. 94(A9), 11893 (1989). doi:10.1029/JA094iA09p11893

D. Delcourt, J.-A. Sauvaud, A. Pedersen, Dynamics of single particle orbits during substorm expansion phase. J. Geophys. Res. 95(A12), 20853-20865 (1990). doi:10.1029/JA095iA12p20853

D.C. Delcourt, J.A. Sauvaud, Plasma sheet ion energization during dipolarization events. J. Geophys. Res. 99, 97 (1994)

D.C. Delcourt, Particle acceleration by inductive electric fields in the inner magnetosphere. J. Atmos. Sol.Terr. Phys. 64(5-6), 551-559 (2002)

M.H. Denton, M.F. Thomsen, H. Korth, S. Lynch, J.C. Zhang, M.W. Liemohn, Bulk plasma properties at geosynchronous orbit. J. Geophys. Res. 110, A07223 (2005). doi:10.1029/2004JA010861

J.W. Dungey, The structure of the exosphere or adventures in velocity space. Geophysics, in The Earth's Environment, ed. by C. DeWitt, J. Hieblot, A. Lebeau (Gordon and Breach, New York, 1963) 
Y. Ebihara, M. Yamauchi, H. Nilsson, R. Lundin, M. Ejiri, Wedge-like dispersion of sub-keV ions in the dayside magnetosphere: particle simulation and Viking observation. J. Geophys. Res. 106, A12 (2001)

Y. Ebihara, M. Ejiri, Numerical simulation of the ring current: review. Space Sci. Rev. 105, 377-452 (2002). doi:10.1023/A:1023905607888

Y. Ebihara, M. Yamada, S. Watanabe, M. Ejiri, Fate of outflowing suprathermal oxygen ions that originate in the polar ionosphere. J. Geophys. Res. 111, A04219 (2006). doi:10.1029/2005JA011403

E. Echer, A. Korth, Q.-G. Zong, M. Fränz, W.D. Gonzalez, F.L. Guarnieri, S.Y. Fu, H. Reme, Cluster observations of $\mathrm{O}^{+}$escape in the magnetotail due to shock compression effects during the initial phase of the magnetic storm on 17 August 2001. J. Geophys. Res. 113, A05209 (2008). doi:10.1029/2007JA012624

M. El-Alaoui, M. Ashour-Abdalla, R.J. Walker, V. Peroomian, R.L. Richard, V. Angelopoulos, A. Runov, Substorm evolution as revealed by THEMIS satellites and a global MHD simulation. J. Geophys. Res. 114, A08221 (2009). doi:10.1029/2009JA014133

H.A. Elliott, R.H. Comfort, P.D. Craven, M.O. Chandler, T.E. Moore, Solar wind influence on the oxygen content of ion outflow in the high-altitude polar cap during solar minimum conditions. J. Geophys. Res. 106(A4), 6067-6084 (2001). doi:10.1029/2000JA003022

E. Engwall, A.I. Eriksson, C.M. Cully, M. André, P.A. Puhl-Quinn, H. Vaith, R. Torbert, Survey of cold ionospheric outflows in the magnetotail. Ann. Geophys. 27, 3185-3201 (2009a). doi:10.5194/ angeo-27-3185-2009

E. Engwall, A.I. Eriksson, C.M. Cully, M. André, R. Torbert, H. Vaith, Earth's ionospheric outflow dominated by hidden cold plasma. Nat. Geosci. 2, 24-27 (2009b). doi:10.1038/ngeo387

R.E. Ergun, C.W. Carlson, J.P. McFadden, F.S. Mozer, G.T. Delory, W. Peria, C.C. Chaston, M. Temerin, R. Elphic, R. Strangeway, R. Pfaff, C.A. Cattell, D. Klumpar, E. Shelley, W. Peterson, E. Moebius, L. Kistler, FAST satellite observations of electric field structures in the auroral zone. Geophys. Res. Lett. 25(12), 2025-2028 (1998). doi:10.1029/98GL00635

D.H. Fairfield, Magnetotail energy storage and the variability of the magnetotail current sheet, in Magnetic Reconnection in Space and Laboratory Plasmas, ed. by E.W. Hones. Geophys. Monogr. Ser., vol. 30 (AGU, Washington, 1984), p. 168

M.-C. Fok, J.U. Kozyra, A.F. Nagy, C.E. Rasmussen, G.V. Khazanov, Decay of equatorial ring current ions and associated aeronomical consequences. J. Geophys. Res. 98, 19381 (1993). doi:10.1029/93JA01848

M.-C. Fok, R.A. Wolf, R.W. Spiro, T.E. Moore, Comprehensive computational model of Earth's ring current. J. Geophys. Res. 106, A5 (2001)

M.-C. Fok, T.E. Moore, P.C. Brandt, D.C. Delcourt, S.P. Slinker, J.A. Fedder, Impulsive enhancements of oxygen ions during substorms. J. Geophys. Res. 111, A10222 (2006). doi:10.1029/2006JA011839

M.-C. Fok, T.E. Moore, S.P. Slinker, J.A. Fedder, D. Delcourt, M. Nosé, S.-H. Chen, J. Geophys. Res. 116, A00J17 (2011)

H.U. Frey, S.B. Mende, V. Angelopoulos, E.F. Donovan, Substorm onset observations by IMAGE-FUV. J. Geophys. Res. 109, A10304 (2004). doi:10.1029/2004JA010607

S.Y. Fu, Q.G. Zong, B. Wilken, Z.Y. Pu, Temporal and spatial variation of the ion composition in the ring current. Space Sci. Rev. 95, 539-554 (2001)

S.A. Fuselier, B.J. Anderson, Low energy $\mathrm{He}^{+}$and $\mathrm{H}^{+}$distributions and proton cyclotron waves in the afternoon equatorial magnetosphere. J. Geophys. Res. 101, 13,255 (1996)

K.V. Gamayunov, G.V. Khazanov, Crucial role of ring current $\mathrm{H}^{+}$in electromagnetic ion cyclotron wave dispersion relation: results from global simulations. J. Geophys. Res. 113, A11220 (2008). doi: 10.1029/2008JA013494

N.Y. Ganushkina, T.I. Pulkkinen, T. Fritz, Role of substorm associated impulsive electric fields in the ring current development during storms. Ann. Geophys. 23, 579-591 (2005). doi:10.5194/angeo-23-579-2005

K.S. Garcia, V.G. Merkin, W.J. Hughes, Effects of nightside $\mathrm{O}^{+}$outflow on magnetospheric dynamics: results of multifluid MHD modeling. J. Geophys. Res. 115, A00J09 (2010). doi:10.1029/2010JA015730

T.T. Giang, M. Hamrin, Y. Yamauchi, R. Lundin, H. Nilsson, Y. Ebihara, H. Reme, I. Dandouras, C. Vallat, M.B. Bavassano-Cattaneo, B. Klecker, A. Korth, L.M. Kistler, M. McCarthy, Outflowing protons and heavy ions as a source for the sub-keV ring current. Ann. Geophys. 27, 839-849 (2009). doi:10.5194/angeo-27-839-2009

A. Glocer, G. Tóth, T. Gombosi, D. Welling, Modeling ionospheric outflows and their impact on the magnetosphere, initial results. J. Geophys. Res. 114(A5), 1-16 (2009a). doi:10.1029/2009JA014053

A. Glocer, G. Tóth, Y. Ma, T. Gombosi, J.-C. Zhang, L.M. Kistler, Multifluid block-adaptive-tree solar wind roe-type upwind scheme: magnetospheric composition and dynamics during geomagnetic stormsinitial results. J. Geophys. Res. 114(A12), A12203 (2009b). doi:10.1029/2009JA014418

G. Gloeckler, J. Geiss, The abundances of elements and isotopes in the solar wind. AIP Conf. Proc. 183, 49-71 (1989)

E.E. Grigorenko, T.M. Burinskaya, M. Shevelev, J.-A. Sauvaud, L.M. Zelenyi, Large-scale fluctuations of PSBL magnetic flux tubes induced by the field-aligned motion of highly accelerated ions. Ann. Geophys. 28, 1273-1288 (2010) 
J.L. Green, J.L. Horwitz, Destiny of earthward streaming plasma in the plasmasheet boundary layer. Geophys. Res. Lett. 13, 76-79 (1986). doi:10.1029/GL013i001p00076

M.E. Greenspan, D.C. Hamilton, Relative contributions of $\mathrm{H}^{+}$and $\mathrm{O}^{+}$to the ring current energy near magnetic storm maximum. J. Geophys. Res. 107 (2002). doi:10.1029/2001JA000155

D.A. Gurnett, N.M. Brice, Ion temperature in the ionosphere obtained from cyclotron damping of proton whistlers. J. Geophys. Res. 71(15), 3639-3652 (1966). doi:10.1029/JZ071i015p03639

S. Haaland, G. Paschmann, M. Förster, J. Quinn, R. Torbert, H. Vaith, P. Puhl-Quinn, C. Kletzing, Plasma convection in the magnetotail lobes: statistical results from Cluster EDI measurements. Ann. Geophys. 26, 2371-2382 (2008). doi:10.5194/angeo-26-2371-2009

S. Haaland, B. Lybekk, K. Svenes, A. Pedersen, M. Förster, H. Vaith, R. Torbert, Plasma transport in the magnetotail lobes. Ann. Geophys. 27, 3577-3590 (2009). doi:10.5194/angeo-27-3577-2009

S. Haaland, A. Eriksson, E. Engwall, B. Lybekk, H. Nilsson, A. Pedersen, K. Svenes, M. André, M. Förster, K. Li, C. Johnsen, N. Østgaard, Estimating the capture and loss of cold plasma from ionospheric outflow. J. Geophys. Res. 117(A7) (2012). doi:10.1029/2012JA017679

D.C. Hamilton, G. Gloeckler, F.M. Ipavich, W. Stüdemann, B. Wilken, G. Kremser, Ring current development during the great geomagnetic storm of February 1986. J. Geophys. Res. 93, 14343-14355 (1988)

M. Hesse, J. Birn, On the cessation of magnetic reconnection. Ann. Geophys. 22(2), 603-612 (2004)

M. Hirahara, T. Mukai, T. Terasawa, S. Machida, Y. Saito, T. Yamamoto, S. Kokubun, Cold dense ion flows with multiple components observed in the distant tail lobe by Geotail. J. Geophys. Res. 101, 7769 (1996)

R.B. Horne, R.M. Thorne, Wave heating of $\mathrm{He}^{+}$by electromagnetic ion cyclotron waves in the magnetosphere: heating near the $\mathrm{H}^{+}$bi-ion resonance frequency. J. Geophys. Res. 102(A6), 11457-11471 (1997)

M. Hoshino, A. Nishida, T. Mukai, Y. Saito, T. Yamamoto, Structure of plasma sheet in magnetotail: doublepeaked electric current sheet. J. Geophys. Res. 101, 24775-24786 (1996)

J.L. Horwitz, Features of ion trajectories in the polar magnetosphere. Geophys. Res. Lett. 11(11), 1111-1114 (1984). doi:10.1029/GL011i011p01111

J.L. Horwitz, R.H. Comfort, P.G. Richards, M.O. Chandler, C.R. Chappell, P. Anderson, W.B. Hanson, L.H. Brace, Plasmasphere-ionosphere coupling. II-Ion composition measurements at plasmaspheric and ionospheric altitudes and comparison with modeling results. J. Geophys. Res. 95, 7949-7959 (1990). doi:10.1029/JA095iA06p07949

Y. Hu, R.E. Denton, J.R. Johnson, Two-dimensional hybrid code simulation of electromagnetic ion cyclotron waves of multi-ion plasmas in a dipole magnetic field. J. Geophys. Res. 115, A09218 (2010). doi:10.1029/2009JA015158

M.M. Huddleston, C.R. Chappell, D.C. Delcourt, T.E. Moore, B.L. Giles, M.O. Chandler, An examination of the process and magnitude of ionospheric plasma supply to the magnetosphere. J. Geophys. Res. 110(A12), A12202 (2005). doi:10.1029/2004JA010401

R. Ilie, R.M. Skouga, H.O. Funstena, M.W. Liemohn, J.J. Baileyc, M. Gruntman, The impact of geocoronal density on ring current development. J. Atmos. Sol.-Terr. Phys. 99, 92-103 (2012). doi:10.1016/ j.jastp.2012.03.010

F.M. Ipavich, A.B. Galvin, G. Gloeckler, D. Hovestadt, B. Klecker, M. Scholer, Energetic $(>100 \mathrm{keV}) \mathrm{O}^{+}$ ions in the plasma sheet. Geophys. Res. Lett. 11, 504 (1984)

C.D. Jacquey, D.J. Williams, R.W. McEntire, A.T.Y. Lui, V. Angelopoulos, S.P. Christon, S. Kokubun, T. Yamamoto, G.D. Reeves, R.D. Belian, Tailward energetic ion streams observed at $\sim 100 \mathrm{R}_{\mathrm{E}}$ by geotailepic associated with geomagnetic activity intensification. Geophys. Res. Lett. 21, 3015 (1994)

S.T. Jones, M.C. Fok, P.C. Brandt, Modeling global $\mathrm{O}^{+}$substorm injection using analytic magnetic field model. J. Geophys. Res. 111, A11S07 (2006). doi:10.1029/2006JA011607

V.K. Jordanova, L.M. Kistler, J.U. Kozyra, G.V. Khasanov, A.F. Nagy, Collisional losses of ring current ions. J. Geophys. Res. 101, 111-126 (1996)

V.K. Jordanova, M. Spasojevic, M.F. Thomsen, Modeling the electromagnetic ion cyclotron waveinduced formation of detached subauroral proton arcs. J. Geophys. Res. 112, A08209 (2007). doi:10.1029/2006JA012215

V.K. Jordanova, S. Zaharia, D.T. Welling, Comparative study of ring current development using empirical, dipolar, and self-consistent magnetic field simulations. J. Geophys. Res. 115, A00J11 (2010). doi:10.1029/2010JA015671

H. Karimabadi, V. Roytershteyn, C.G. Mouikis, L.M. Kistler, W. Daughton, Flushing effect in reconnection: effects of minority species of oxygen ions. Planet. Space Sci. 59, 526-536 (2011)

S. Kasahara, H. Hasegawa, K. Keika, Y. Miyashita, M.N. Nishino, T. Sotirelis, Y. Saito, T. Mukai, Escape of high-energy oxygen ions through magnetopause reconnection under northward IMF. Ann. Geophys. 26, 3955-3966 (2008). doi:10.5194/angeo-26-3955-2008 
J.C. Kasper, M.L. Stevens, A.J. Lazarus, J.T. Steinberg, K.W. Ogilvie, Solar wind helium abundance as a function of speed and heliographic latitude: variation through a solar cycle. Astrophys. J. 660(1), 901910 (2007). doi:10.1086/510842

K. Keika, P.C. Brandt, S. Ohtani, D.G. Mitchell, K. Min, M. Nosé, T. Obara, H. Koshiishi, H. Matsumoto, Mass-dependent evolution of energetic neutral atoms energy spectra during storm time substorms: implication for $\mathrm{O}^{+}$nonadiabatic acceleration. J. Geophys. Res. 115, A00I12 (2010). doi: 10.1029/2010JA015889

K. Keika, P.C. Brandt, M. Nosé, D.G. Mitchell, Evolution of ring current ion energy spectra during the storm recovery phase: implication for dominant ion loss processes. J. Geophys. Res. 116, A00J20 (2011). doi:10.1029/2010JA015628

A. Keiling, G.K. Parks, H. Reme, I. Dandouras, M. Wilber, L. Kistler, C. Owen, A.N. Fazakerley, E. Lucek, M. Maksimovic, N. Cornilleau-Wehrlin, Energy-dispersed ions in the plasma sheet boundary layer and associated phenomena: ion heating, electron acceleration, Alfvén waves, broadband waves, perpendicular electric field spikes and auroral emissions. Ann. Geophys. 24, 2685-2707 (2006)

L.M. Kistler, F.M. Ipavich, D.C. Hamilton, G. Gloeckler, B. Wilken, Energy spectra of the major ion species in the ring current during geomagnetic storms. J. Geophys. Res. 94, 3579-3599 (1989). doi:10.1029/JA094iA04p03579

L.M. Kistler, E. Möbius, B. Klecker, G. Gloeckler, F.M. Ipavich, D.C. Hamilton, Spatial variations in the suprathermal ion distributions during substorms in the plasma sheet. J. Geophys. Res. 95, 18871-18885 (1990). doi:10.1029/JA095iA11p18871

L.M. Kistler et al., FAST/TEAMS observations of charge exchange signatures in ions mirroring at low altitudes. Geophys. Res. Lett. 25(1), 2085-2088 (1998). doi:10.1029/98GL00331

L.M. Kistler, C. Mouikis, E. Möbius, B. Klecker, J.A. Sauvaud, H. Rème, A. Korth, M.F. Marcucci, R. Lundin, G.K. Parks, A. Balogh, Contribution of nonadiabatic ions to the cross-tail current in an $\mathrm{O}^{+}$ dominated thin current sheet. J. Geophys. Res. 110, A06213 (2005). doi:10.1029/2004JA010653

L.M. Kistler, C.G. Mouikis, X. Cao, H. Frey, B. Klecker, I. Dandouras, A. Korth, M.F. Marcucci, R. Lundin, M. McCarthy, R. Friedel, E. Lucek, Ion composition and pressure changes in storm time and nonstorm substorms in the vicinity of the near-Earth neutral line. J. Geophys. Res. 111, A11222 (2006). doi:10.1029/2006JA011939

L.M. Kistler, C.G. Mouikis, B. Klecker, I. Dandouras, Cusp as a source for oxygen in the plasma sheet during geomagnetic storms. J. Geophys. Res. 115(A), 03209 (2010a). doi:10.1029/2009JA014838

L.M. Kistler et al., Escape of $\mathrm{O}^{+}$through the distant tail plasma sheet. Geophys. Res. Lett. 37, L21101 (2010b). doi:10.1029/2010GL045075

B. Klecker, E. Möbius, D. Hovestadt, M. Scholer, G. Gloeckler, Discovery of energetic molecular ions $\left(\mathrm{NO}^{+}\right.$and $\left.{ }^{2}{ }^{+}\right)$in the storm time ring current. Geophys. Res. Lett. 13, 632-635 (1986). doi:10.1029/ GL013i007p00632

E.A. Kronberg, R. Bucik, S. Haaland, B. Klecker, K. Keika, M.I. Desai, P.W. Daly, M. Yamauchi, R. Gómez-Herrero, A.T.Y. Lui, On the origin of the energetic ion events measured upstream of the Earth's bow shock by STEREO, Cluster, and Geotail. J. Geophys. Res. 116(A2) A02210 (2011). doi:10.1029/2010JA015561

E.A. Kronberg, S.E. Haaland, P.W. Daly, E.E. Grigorenko, L.M. Kistler, M. Fränz, I. Dandouras, Oxygen and hydrogen ion abundance in the near-Earth magnetosphere: statistical results on the response to the geomagnetic and solar wind activity conditions. J. Geophys. Res. 117(A12), A12208 (2012). doi:10.1029/2012JA018071

B. Lembege, R. Pellat, Stability of a thick two-dimensional quasineutral sheet. Phys. Fluids 25(11), 19952004 (1982)

W. Lennartsson, E.G. Shelley, Survey of 0.1- to 16-keV/e plasma sheet ion composition. J. Geophys. Res. 91, 3061-3076 (1986). doi:10.1029/JA091iA03p03061

W. Lennartsson, Energetic (0.1- to 16-keV/e) magnetospheric ion composition at different levels of solar F10.7. J. Geophys. Res. 94(A4), 3600-3610 (1989). doi:10.1029/JA094iA04p03600

W. Lennartsson, H.L. Collin, W.K. Peterson, Solar wind control of Earth's $\mathrm{H}^{+}$and $\mathrm{O}^{+}$outflow rates in the 15-eV to 33-keV energy range. J. Geophys. Res. 109(A), 12212 (2004). doi:10.1029/2004JA010690

X. Li, M. Hudson, A. Chan, I. Roth, Loss of ring current $\mathrm{O}^{+}$ions due to interaction with Pc 5 waves. J. Geophys. Res. 98(A1), 215-231 (1993). doi:10.1029/92JA01540

J. Liao, L.M. Kistler, C.G. Mouikis, B. Klecker, I. Dandouras, J.-C. Zhang, Statistical study of $\mathrm{O}^{+}$trans- $^{-}$ port from the cusp to the lobes with Cluster CODIF data. J. Geophys. Res. 115, A00J15 (2010). doi:10.1029/2010JA015613

J. Liao, L.M. Kistler, C.G. Mouikis, B. Klecker, I. Dandouras, Solar cycle dependence of the cusp O ${ }^{+}$access to the near-Earth magnetotail. J. Geophys. Res. 117, A10220 (2012). doi:10.1029/2012JA017819

J. Liao, Statistical study of $\mathrm{O}^{+}$transport from cusp to the plasmasheet. PhD thesis, Department of Physics and Space Science Center, University of New Hampshire, Durham, N.H. (2011) 
J. Liao, J. Cai, L.M. Kistler, C.R. Clauer, C.G. Mouikis, B. Klecker, I. Dandouras, The relationship between sawtooth events and $\mathrm{O}^{+}$in the plasma sheet. J. Geophys. Res. 119, 1572-1586 (2014). doi:10.1002/2013JA019084

M.W. Liemohn, J.U. Kozyra, V.K. Jordanova, G.V. Khazanov, M.F. Thomsen, T.E. Cayton, Analysis of early phase ring current recovery mechanisms during geomagnetic storms. Geophys. Res. Lett. 26(1), 28452848 (1999). doi:10.1029/1999GL900611

Y. Liu, Magnetosphere-ionosphere-thermosphere coupling. TAIKONG, ISSI-BJ Magazine 3 (2014)

Y. Liu, L.M. Kistler, C.G. Mouikis, B. Klecker, I. Dandouras, Heavy ion effects on substorm loading and unloading in the Earth's magnetotail. J. Geophys. Res. 118, 2101-2112 (2013). doi:10.1002/jgra.50240

Y.H. Liu, L.M. Kistler, C.G. Mouikis, V. Roytershteyn, H. Karimabadi, The scale of the magnetotail reconnecting current sheet in the presence of $\mathrm{O}^{+}$. Geophys. Res. Lett. 41(1), 4819-4827 (2014). doi:10.1002/2014GL060440

R.E. Lopez, R. Bruntz, E.J. Mitchell, M. Wiltberger, J.G. Lyon, V.G. Merkin, Role of magnetosheath force balance in regulating the dayside reconnection potential. J. Geophys. Res. 115(A12), A12216 (2010). doi:10.1029/2009JA014597

W. Lotko, The magnetosphere ionosphere system from the perspective of plasma circulation: a tutorial. J. Atmos. Sol.-Terr. Phys. 69, 191-211 (2007). doi:10.1016/j.jastp.2006.08.011

T.M. Loto'aniu, R.M. Thorne, B.J. Fraser, D. Summers, Estimating relativistic electron pitch angle scattering rates using properties of the electromagnetic ion cyclotron wave spectrum. J. Geophys. Res. 111, A04220 (2006). doi:10.1029/2005JA011452

G. Lu, B.A. Emery, A.S. Rodger, M. Lester, J.R. Taylor, D.S. Evans, D.L. Chenette, High-latitude ionospheric electrodynamics as determined by the assimilative mapping of ionospheric electrodynamics procedure for the conjunctive SUNDIAL/ATLAS 1/GEM period of March 28-29, 1992. J. Geophys. Res. 101(A12), 26697 (1996). doi:10.1029/96JA00513

A.T.Y. Lui, R.E. Lopez, B.J. Anderson, K. Takahashi, L.Z. Zanetti, R.W. McEntire, T.A. Potemra, D.M. Klumpar, E.M. Greene, R. Strangeway, Current disruptions in the near-Earth neutral sheet region. J. Geophys. Res. 97, 1461-1480 (1992)

R. Lundin, L.R. Lyons, N. Pisarenko, Observations of the ring current composition at L less than 4. Geophys. Res. Lett. 7, 425-428 (1980). doi:10.1029/GL007i006p00425

H. Luo, E.A. Kronberg, E.E. Grigorenko, M. Fränz, P.W. Daly, G.X. Chen, A.M. Du, L.M. Kistler, Y. Wie, Evidence of strong ion acceleration in the near-Earth magnetotail. Geophys. Res. Lett. 41, 1-5 (2014). doi:10.1002/2014GL060252

L.R. Lyons, T.W. Speiser, Evidence for current sheet acceleration in the geomagnetic tail. J. Geophys. Res. 87(1), 2276-2286 (1982)

R. Maggiolo, J.-A. Sauvaud, D. Fontaine, A. Teste, G. Paschmann, A. Balogh, P. Newell, A. Fazakerley, H. Reme, Ionospheric ion beam acceleration above the polar cap. Ann. Geophys. 24, 1-20 (2006)

R. Maggiolo, M. Echim, J. De Keyser, D. Fontaine, C. Jacquey, I. Dandouras, Polar cap ion beams during periods of northward IMF: cluster statistical results. Ann. Geophys. 29, 771-787 (2011)

R. Maggiolo, M. Echim, C. Wedlund, C. Simon, Y. Zhang, D. Fontaine, G. Lointier, J.-G. Trotignon, Polar cap arcs from the magnetosphere to the ionosphere: kinetic modelling and observations by Cluster and TIMED. Ann. Geophys. 30, 283-302 (2012)

R. Maggiolo, L.M. Kistler, Spatial variation in the plasma sheet composition: dependence on geomagnetic and solar activity. J. Geophys. Res. (2014). doi:10.1002/2013JA019517

H.V. Malova, V.Yu. Popov, D.C. Delcourt, A.A. Petrukovich, L.M. Zelenyi, Antisunward structure of thin current sheets in the Earth's magnetotail: implications of quasi-adiabatic theory. J. Geophys. Res. 118, 4308-4318 (2013). doi:10.1002/jgra.50390

B.H. Mauk, C.E. McIlwain, R.L. McPherron, Helium cyclotron resonance within the Earth's magnetosphere. Geophys. Res. Lett. 8, 103-106 (1981). doi:10.1029/GL008i001p00103

J.P. McCollough, S.R. Elkington, M.E. Usanova, I.R. Mann, D.N. Baker, Z.C. Kale, Physical mechanisms of compressional EMIC wave growth. J. Geophys. Res. 115, A10214 (2010). doi:10.1029/2010JA015393

R.L. McPherron, A. Nishida, C.T. Russell, Is near-Earth current sheet thinning the cause of auroral substorm onset? in Quantitative Modeling of Magnetosphere-Ionosphere Coupling Processes, ed. by Y. Kamide, R.A. Wolf (Kyoto Sangyo University, Kyoto, 1987), pp. 252-265

N.P. Meredith, R.M. Thorne, R.B. Horne, D. Summers, B.J. Fraser, R.R. Anderson, Statistical analysis of relativistic electron energies for cyclotron resonance with EMIC waves observed on CRRES. J. Geophys. Res. 108(A6), 1250 (2003). doi:10.1029/2002JA009700

R.M. Millan, R.P. Lin, D.M. Smith, M.P. McCarthy, Observation of relativistic electron precipitation during a rapid decrease of trapped relativistic electron flux. Geophys. Res. Lett. 34, L10101 (2007). doi:10.1029/2006GL028653

V. Milovanov, L.M. Zelenyi, Nonequilibrium stationary states in the Earth's magnetotail: stochastic acceleration processes and nonthermal distribution functions. Adv. Space Res. 30(12), 2667-2674 (2002) 
D.G. Mitchell, P.C. son Brandt, E.C. Roelof, D.C. Hamilton, K.C. Retterer, S. Mende, Global imaging of O ${ }^{+}$ from IMAGE/HENA. Space Sci. Rev. 109, 63 (2003)

Y. Miyoshi, K. Sakaguchi, K. Shiokawa, D. Evans, J. Albert, M. Connors, V. Jordanova, Precipitation of radiation belt electrons by EMIC waves, observed from ground and space. Geophys. Res. Lett. 35, L23101 (2008). doi:10.1029/2008GL035727

T.E. Moore, D.C. Delcourt, The geopause. Rev. Geophys. 33, 175 (1995). doi:10.1029/95RG00872

T.E. Moore, W.K. Peterson, C.T. Russell, M.O. Chandler, M.R. Collier, H.L. Collin, C.J. Pollock, Ionospheric mass ejection in response to a CME. Geophys. Res. Lett. 26(15), 2339-2342 (1999). doi:10.1029/1999GL900456

T.E. Moore, M.-C. Fok, M.O. Chandler, C.R. Chappell, S.P. Christon, D.C. Delcourt, J. Fedder, M. Huddleston, M. Liemohn, W.K. Peterson, S. Slinker, Plasma sheet and (nonstorm) ring current formation from solar and polar wind sources. J. Geophys. Res. 110 (2005). doi:10.1029/2004JA010563

T.E. Moore, M.-C. Fok, D.C. Delcourt, S. Slinker, J. Fedder, Global aspects of solar wind ionosphere interactions. J. Atmos. Sol.-Terr. Phys. 69, 265-278 (2007). doi:10.1016/j.jastp.2006.08.009

T.E. Moore, J.L. Horwitz, Stellar ablation of planetary atmospheres. Rev. Geophys. 45, RG3002 (2007)

E. Möbius, M. Scholer, B. Klecker, D. Hovestadt, G. Gloeckler, F.M. Ipavich, Acceleration of ions of ionospheric origin in the plasma sheet during substorm activity, in Magnetotail Physics, ed. by A.T.Y. Lui (Johns Hopkins Univ. Press, Baltimore, 1987), pp. 231-234

C.G. Mouikis, Equator-S observations of $\mathrm{He}^{+}$energization by EMIC waves in the dawnside equatorial magnetosphere. Geophys. Res. Lett. 29(1), 1-74 (2002). doi:10.1029/2001GL013899

C.G. Mouikis, L.M. Kistler, Y.H. Liu, B. Klecker, A. Korth, I. Dandouras, $\mathrm{H}^{+}$and $\mathrm{O}^{+}$content of the plasma sheet at $15-19 \mathrm{R}_{\mathrm{E}}$ as a function of geomagnetic and solar activity. J. Geophys. Res. 115 (2010). doi:10.1029/2010JA015978

E.S. Mozer, Origin and effects of electric fields during isolated magnetospheric substorms. J. Geophys. Res. 76(31), 7595-7608 (1971)

T. Mukai, M. Hirahara, S. Machida, Y. Saito, T. Terasawa, A. Nishida, Geotail observation of cold ion streams in the medium distance magnetotail lobe in the course of a substorm. Geophys. Res. Lett. 21, 1023-1026 (1994)

R. Nakamura, W. Baumjohann, A. Runov, Y. Asano, Thin current sheets in the magnetotail observed by Cluster. Space Sci. Rev. 122, 29-38 (2006)

M. Neugebauer, Observations of solar-wind helium. Fundam. Cosm. Phys. 7, 131-199 (1981)

H. Nilsson, M. Waara, S. Arvelius, O. Marghitu, M. Bouhram, Y. Hobara, M. Yamauchi, R. Lundin, H. Rème, J.-A. Sauvaud, I. Dandouras, A. Balogh, L.M. Kistler, B. Klecker, C.W. Carlson, M.B. BavassanoCattaneo, A. Korth, Characteristics of high altitude oxygen ion energization and outflow as observed by Cluster: a statistical study. Ann. Geophys. 24, 1099-1112 (2006). doi:10.5194/angeo-24-1099-2006

H. Nilsson, E. Engwall, A.I. Eriksson, P.A. Puhl-Quinn, S. Arvelius, Centrifugal acceleration in the magnetotail lobes. Ann. Geophys. 28, 569-576 (2010). doi:10.5194/angeo-28-569-2010

H. Nilsson, I.A. Barghouthi, R. Slapak, A.I. Eriksson, M. André, Hot and cold ion outflow: spatial distribution of ion heating. J. Geophys. Res. 117, A11201 (2012). doi:10.1029/2012JA017974

H. Nilsson, I.A. Barghouthi, R. Slapak, A.I. Eriksson, M. André, Hot and cold ion outflow: observations and implications for numerical models. J. Geophys. Res. 118, 105-117 (2013). doi:10.1029/2012JA017975

M. Nosé, A.T.Y. Lui, S. Ohtani, B.H. Mauk, R.W. McEntire, D.J. Williams, T. Mukai, K. Yumoto, Acceleration of oxygen ions of ionospheric origin in the near-Earth magnetotail during substorms. J. Geophys. Res. 105, 7669 (2000). doi:10.1029/1999JA000318

M. Nosé, A. Ieda, S.P. Christon, Geotail observations of plasma sheet ion composition over 16 years: on variations of average plasma ion mass and $\mathrm{O}^{+}$triggering substorm model. J. Geophys. Res. 114, A07223 (2009). doi:10.1029/2009JA014203

M. Nosé, H. Koshiishi, H. Matsumoto, P.C. Brandt, K. Keika, K. Koga, T. Goka, T. Obara, Magnetic field dipolarization in the deep inner magnetosphere and its role in development of $\mathrm{O}^{+}$-rich ring current. $\mathrm{J}$. Geophys. Res. 115, A00J03 (2010). doi:10.1029/2010JA015321

M. Nosé, K. Takahashi, R.R. Anderson, H.J. Singer, Oxygen torus in the deep inner magnetosphere and its contribution to recurrent process of $\mathrm{O}^{+}$-rich ring current formation. J. Geophys. Res. 116, A10 (2011). doi:10.1029/2011JA016651

M. Nosé, K. Takahashi, K. Keika, L.M. Kistler, K. Koga, H. Koshiishi, H. Matsumoto, M. Shoji, Y. Miyashita, R. Nomura, Magnetic fluctuations embedded in dipolarization inside geosynchronous orbit and their associated selective acceleration of $\mathrm{O}^{+}$ions. J. Geophys. Res. 119(6), 4639-4655 (2014). doi:10.1002/2014JA019806

S. Ohtani, P.C. Brandt, D.G. Mitchell, H. Singer, M. Nosé, G.D. Reeves, S.B. Mende, Storm-substorm relationship: variations of the hydrogen and oxygen energetic neutral atom intensities during storm-time substorms. J. Geophys. Res. 110, A07219 (2005). doi:10.1029/2004JA010954 
S. Ohtani, M. Nosé, S.P. Christon, A.T.Y. Lui, Energetic $\mathrm{O}^{+}$and $\mathrm{H}^{+}$ions in the plasma sheet: implications for the transport of ionospheric ions. J. Geophys. Res. 116, A10211 (2011). doi:10.1029/2011JA016532

N. Omidi, J. Bortnik, R. Thorne, L. Chen, Impact of cold $\mathrm{O}^{+}$ions on the generation and evolution of EMIC waves. J. Geophys. Res. 118, 434-445 (2013). doi:10.1029/2012JA018319

Y. Ono, M. Nosé, S.P. Christon, A.T.Y. Lui, The role of magnetic field fluctuations in nonadiabatic acceleration of ions during dipolarization. J. Geophys. Res. 114, A05209 (2009). doi:10.1029/2008JA013918

S. Orsini, M. Candidi, M. Stokholm, H. Balsiger, Injection of ionospheric ions into the plasma sheet. J. Geophys. Res. 95, 7915-7928 (1990)

J.E. Ouellette, O.J. Brambles, J.G. Lyon, W. Lotko, B.N. Rogers, Properties of outflow-driven sawtooth substorms. J. Geophys. Res. 118(6), 3223-3232 (2013). doi:10.1002/jgra.50309

V. Peroomian, Large scale kinetic modeling of magnetospheric plasma. Thesis, UCLA, Volume 55-02. Section B, 0464 (1994)

V. Peroomian, M. Ashour-Abdalla, Relative contribution of the solar wind and the auroral zone to nearEarth plasmas, in Cross-Scale Coupling in Space Plasmas, ed. by J.L. Horwitz, N. Singh, J. Burch. Geophysical Monograph, vol. 93 (1995), p. 213. AGU

V. Peroomian, M. Ashour-Abdalla, Population of the near-Earth magnetotail from the auroral zone. J. Geophys. Res. 101(A7), 15387 (1996). doi:10.1029/96JA00759

V. Peroomian, M. El-Alaoui, M. Ashour-Abdalla, L.M. Zelenyi, Dynamics of ionospheric $\mathrm{O}^{+}$ions in the magnetosphere during the 24-25 September 1998 magnetic storm. J. Geophys. Res. 111(A12), A12203 (2006). doi:10.1029/2006JA011790

V. Peroomian, M. El-Alaoui, M. Ashour-Abdalla, L.M. Zelenyi, A comparison of solar wind and ionospheric plasma contributions to the September 24-25, 1998 magnetic storm. J. Atmos. Sol.-Terr. Phys. 69(3), 212-222 (2007)

V. Peroomian, M. El-Alaoui, P.C. Brandt, The ion population of the magnetotail during the 17 April 2002 magnetic storm: large-scale kinetic simulations and IMAGE/HENA observations. J. Geophys. Res. 116(A5), A05214 (2011a). doi:10.1029/2010JA016253

V. Peroomian, M. El-Alaoui, P.C. Brandt, The storm-time injection of ions into the inner magnetosphere: large-scale kinetic simulations and IMAGE-HENA observations, in Partially Ionized Plasmas Throughout the Cosmos-Proceedings of the 2010 Huntsville Workshop, ed. by V. Florinski, J. Heerikhuisen, G.P. Zank, D.L. Gallagher. AIP Conf. Proc., vol. 1366 (2011b), pp. 22-29. doi:10.1063/1.3625585

W.K. Peterson, R.D. Sharp, E.G. Shelley, R.G. Johnson, H. Balsiger, Energetic ion composition of the plasma sheet. J. Geophys. Res. 86, 761-767 (1981)

W.K. Peterson, H.L. Collin, O.W. Lennartsson, A.W. Yau, Quiet time solar illumination effects on the fluxes and characteristic energies of ionospheric outflow. J. Geophys. Res. 111, A11S05 (2006)

A.A. Petrukovich, A.V. Artemyev, H.V. Malova, V.Y. Popov, R. Nakamura, L.M. Zelenyi, Embedded current sheets in the Earth's magnetotail. J. Geophys. Res. 116, A00I25 (2011)

C.J. Pollock, M.O. Chandler, T.E. Moore, J.H. Waite, C.R. Chappell, D.A. Gurnett, A survey of upwelling ion event characteristics. J. Geophys. Res. 95(A11), 18969 (1990). doi:10.1029/JA095iA11p18969

T.I. Pulkkinen, D.N. Baker, D.G. Mitchell, R.L. McPherron, C.Y. Huang, L.A. Frank, Thin current sheets in the magnetotail during substorms: CDAW 6 revisited. J. Geophys. Res. 99, 5793-5804 (1994)

T.I. Pulkkinen, N.Y. Ganushkina, D.N. Baker, N.E. Turner, J.F. Fennel, J. Roeder, T.A. Fritz, M. Gtande, B. Kellett, G. Kettmann, Ring current ion composition during solar minimum and rising solar activity: Polar/CAMMICE? MICS results. J. Geophys. Res. 106, 19131-19147 (2001). doi:10.1029/2000JA003036

H. Rème et al., First multispacecraft ion measurements in and near the Earth's magnetosphere with the identical Cluster ion spectrometry (CIS) experiment. Ann. Geophys. 19, 1303-1354 (2001). doi:10.5194/angeo-19-1303-2001

W.T.J. Roberts, J.L. Horwitz, R.H. Comfort, C.R. Chappell, J.H.J. Waite, J.L. Green, Heavy ion density enhancements in the outer plasmasphere. J. Geophys. Res. 92, 13499-13512 (1987). doi:10.1029/JA092iA12p13499

C.J. Rodger, T. Raita, M.A. Clilverd, A. Seppälä, S. Dietrich, N.R. Thomson, T. Ulich, Observations of relativistic electron precipitation from the radiation belts driven by EMIC waves. Geophys. Res. Lett. 35, L16106 (2008). doi:10.1029/2008GL034804

A. Runov, V.A. Sergeev, R. Nakamura, W. Baumjohann, S. Apatenkov, Y. Asano, T. Takada, M. Volwerk, Z. Voros, T.L. Zhang, J.-A. Sauvaud, H. Rème, A. Balogh, Local structure of the magnetotail current sheet: 2001 Cluster observations. Ann. Geophys. 23, 1-16 (2005). SRef-ID:1432-0576/ag/2005-23-1

A. Runov, V.A. Sergeev, R. Nakamura, W. Baumjohann, S. Apatenkov, Y. Asano, T. Takada, M. Volwerk, Z. Voros, T.L. Zhang, J.-A. Sauvaud, H. Reme, A. Balogh, Local structure of the magnetotail current sheet: 2001 Cluster observations. Ann. Geophys. 24, 247-262 (2006). doi:10.5194/angeo-24-247-2006

A. Runov, V. Angelopoulos, M.I. Sitnov, V.A. Sergeev, J. Bonnell, J.P. McFadden, D. Larson, K. Glassmeier, U. Auster, THEMIS observations of an earthward-propagating dipolarization front. Geophys. Res. Lett. 36, L14106 (2009). doi:10.1029/2009GL038980 
M. Sandanger, F. Søraas, K. Aarsnes, K. Oksavik, D.S. Evans, Loss of relativistic electrons: evidence for pitch angle scattering by electromagnetic ion cyclotron waves excited by unstable ring current protons. J. Geophys. Res. 112, A12213 (2007). doi:10.1029/2006JA012138

J. Sanny, R.L. McPherron, C.T. Russell, D.N. Baker, T.I. Pulkkinen, A. Nishida, Growth phase thinning of the near-Earth current sheet during the CDAW-6 substorm. J. Geophys. Res. 99, 5805-5816 (1994)

J.-A. Sauvaud, D. Delcourt, A numerical study of suprathermal ionospheric ion trajectories in three-dimensional electric and magnetic field models. J. Geophys. Res. 92(A6), 5873 (1987). doi:10.1029/JA092iA06p05873

J.-A. Sauvaud, P. Louarn, G. Fruit, H. Stenuit, C. Vallat, I. Dandouras, H. Rème, M. André, A. Balogh, M. Dunlop, L. Kistler, E. Möbius, C. Mouikis, B. Klecker, G.K. Parks, J. McFadden, C. Carlson, F. Marcucci, G. Pallocchia, R. Lundin, A. Korth, M. McCarthy, Case studies of the dynamics of ionospheric ions in the Earth's magnetotail. J. Geophys. Res. 109, A01212 (2004). doi:10.1029/2003JA009996

J.-A. Sauvaud, C. Jacquey, M. Oka, L. Palin, G. Fruit, L.M. Kistler, A. Balogh, J.B. Cao, G. Reeves, T. Mukai, I. Shinohara, E. Grigorenko, A study of the changes of the near-Earth plasma sheet and lobe driven by multiple substorms: comparison with a full particle simulation of reconnection. J. Geophys. Res. 117(A1), A01221 (2012). doi:10.1029/2011JA017033

S. Savin, E. Amata, V. Budaev, L. Zelenyi, E.A. Kronberg, J. Buechner, J. Safrankova, Z. Nemecek, J. Blecki, L. Kozak, S. Klimov, A. Skalsky, L. Lezhen, On nonlinear cascades and resonances in the outer magnetosphere. JETP Lett. 99, 16-21 (2014). doi:10.1134/S002136401401010X

K. Schindler, A theory of the substorm mechanism. J. Geophys. Res. 79, 2803 (1974)

R.W. Schunk, J.J. Sojka, A three-dimensional time-dependent model of the polar wind. J. Geophys. Res. 94, 8973-8991 (1989). doi:10.1029/JA094iA07p08973

R.W. Schunk, J.J. Sojka, Global ionosphere-polar wind system during changing magnetic activity. J. Geophys. Res. 102(A6), 11625-11652 (1997). doi:10.1029/97JA00292

R.W. Schunk, Time-dependent simulations of the global polar wind. J. Atmos. Sol.-Terr. Phys. 69(16), 20282047 (2007). doi:10.1016/j.jastp.2007.08.009

K. Seki, M. Hirahara, T. Terasawa, I. Shinohara, T. Mukai, Y. Saito, S. Machida, T. Yamamoto, S. Kokubun, Coexistence of Earth-origin $\mathrm{O}^{+}$and solar wind-origin $\mathrm{H}^{+} / \mathrm{He}^{++}$in the distant magnetotail. Geophys. Res. Lett. 23(9), 985-988 (1996). doi:10.1029/96GL00768

K. Seki, M. Hirahara, T. Terasawa, T. Mukai, Y. Saito, S. Machida, T. Yamamoto, S. Kokubun, Statistical properties and possible supply mechanisms of tailward cold $\mathrm{O}^{+}$beams in the lobe/mantle regions. $\mathrm{J}$. Geophys. Res. 103, 4477-4493 (1998a)

K.T. Seki, T. Terasawa, M. Hirahara, T. Mukai, Quantification of tailward cold $\mathrm{O}^{+}$beams in the lobe/mantle regions with Geotail data: constraints on polar $\mathrm{O}^{+}$outflows. J. Geophys. Res. 103(A12), 29371-29382 (1998b). doi:10.1029/98JA02463

K. Seki, R.C. Elphic, M. Hirahara, T. Terasawa, T. Mukai, On atmospheric loss of oxygen ions from Earth through magnetospheric processes. Science 291(5), 1939-1941 (2001). doi:10.1126/science.1058913

V.A. Sergeev, D.G. Mitchell, C.T. Russell, D.J. Williams, Structure of the tail plasma/current sheet at $11 \mathrm{R}_{\mathrm{E}}$ and its changes in the course of a substorm. J. Geophys. Res. 98, 17345-17365 (1993)

V.P. Shabansky, Some processes in the magnetosphere. Space Sci. Rev. 12(3), 299-418 (1971)

R.D. Sharp, D.L. Carr, W.K. Petersoh, E.G. Shelley, Ion streams in the magnetotail. J. Geophys. Res. 86, 4639-4648 (1981)

R.D. Sharp, W. Lennartsson, W.K. Petersoh, E.G. Shelley, The origins of the plasma in the distant plasma sheet. J. Geophys. Res. 87, 10420-10424 (1982)

M.A. Shay, M. Swisdak, Three-species collisionless reconnection: effect of $\mathrm{O}^{+}$on magnetotail reconnection. Phys. Rev. Lett. 93(17) (2004)

E.G. Shelley, R.G. Johnson, R.D. Sharp, Satellite observations of energetic heavy ions during a geomagnetic storm. J. Geophys. Res. 77, 6104-6110 (1972)

A.S. Sharma, R. Nakamura, A. Runov, E.E. Grigorenko, H. Hasegawa, M. Hoshino, P. Louarn, C.J. Owen, A. Petrukovich, J. Sauvaud, V.S. Semenov, V.A. Sergeev, J.A. Slavin, B.U.Ö. Sonnerup, L.M. Zelenyi, G. Fruit, S. Haaland, H. Malova, K. Snekvik, Transient and localized processes in the magnetotail: a review. Ann. Geophys. 26, 955-1006 (2008)

D.R. Shklyar, L.R.O. Storey, J. Chum, F. Jiř́íček, F. Němec, M. Parrot, O. Santolík, E.E. Titova, Spectral features of lightning-induced ion cyclotron waves at low latitudes: DEMETER observations and simulation. J. Geophys. Res. (Space Phys.) 117(A), 12206 (2012). doi:10.1029/2012JA018016

D.R. Shklyar, I.V. Kuzichev, Ion energization by ELF wave packets formed of lightning-induced emission in the low-altitude magnetosphere. Geophys. Res. Lett. 41 (2014). doi:10.1002/2013GL058692

M. Shoji, Y. Omura, B. Grison, J. Pickett, I. Dandouras, M. Engebretson, Electromagnetic ion cyclotron waves in the helium branch induced by multiple electromagnetic ion cyclotron triggered emissions. Geophys. Res. Lett. 38(17), L17102 (2011). doi:10.1029/2011GL048427 
Y.Y. Shprits, D. Subbotin, A. Drozdov, M.E. Usanova, A. Kellerman, K. Orlova, D.N. Baker, D.L. Turner, K.-C. Kim, Unusual stable trapping of the ultra-relativistic electrons in the Van Allen radiation belts. Nat. Phys. (2013). doi:10.1038/nphys 2760

J.-H. Shue, J.K. Chao, H.C. Fu, C.T. Russell, P. Song, K.K. Khurana, H.J. Singer, A new functional form to study the solar wind control of the magnetopause size and shape. J. Geophys. Res. 102(A5), 9497-9512 (1997). doi:10.1029/97JA00196

G.L. Siscoe, G.M. Erickson, B.U.Ö. Sonnerup, N.C. Maynard, K.D. Siebert, D.R. Weimer, W.W. White, Relation between cusp and mantle in MHD simulation. J. Geophys. Res. 106(A6), 10743 (2001). doi:10.1029/2000JA000385

M.I. Sitnov, L.M. Zelenyi, H.V. Malova, A.S. Sharma, Thin current sheet embedded within a thicker plasma sheet: self-consistent kinetic theory. J. Geophys. Res. 105, 13029-13044 (2000)

R. Slapak, H. Nilsson, L.G. Westerberg, A. Eriksson, Observations of oxygen ions in the dayside magnetosheath associated with southward IMF. J. Geophys. Res. 117, A07218 (2012). doi:10.1029/ 2012JA017754

R. Slapak, H. Nilsson, L.G. Westerberg, A statistical study on $\mathrm{O}^{+}$flux in the dayside magnetosheath. Ann. Geophys. 31, 1005-1010 (2013). doi:10.5194/angeo-31-1005-2013

F. Søraas, J.A. Lundblad, N.F. Maltseva, V. Troitskaya, V. Selivanov, A comparison between simultaneous IPDP ground-based observations and observations of energetic protons obtained by satellites. Planet. Space Sci. 28(4), 387-405 (1980)

M. Spasojevic, S.A. Fuselier, Temporal evolution of proton precipitation associated with the plasmaspheric plume. J. Geophys. Res. 114, A12201 (2009). doi:10.1029/2009JA014530

T.H. Stix, Waves in Plasmas (Am. Inst. of Phys., New York, 1992)

M. Stokholm, H. Balsiger, J. Geiss, H. Rosenbauer, D.T. Young, Variations of the magnetospheric ion number densities near geostationary orbit with solar activity. Ann. Geophys. 7, 69-75 (1989)

R. Strangeway, J.R.E. Ergun, Y.J. Su, C.W. Carlson, R.C. Elphic, Factors controlling ionospheric outflows as observed at intermediate altitudes. J. Geophys. Res. 110(A3), A03221 (2005). doi:10.1029/ 2004JA010829

Y.-J. Su, J.L. Horwitz, T.E. Moore, B.L. Giles, M.O. Chandler, P.D. Craven, M. Hirahara, C.J. Pollock, Polar wind survey with the Thermal Ion Dynamics Experiment/Plasma Source Instrument suite aboard POLAR. J. Geophys. Res. 103(A12), 29305-29338 (1998). doi:10.1029/98JA02662

D. Summers, R.M. Thorne, Relativistic electron pitch-angle scattering by electromagnetic ion cyclotron waves during geomagnetic storms. J. Geophys. Res. 108(A4), SMP2-1 (2003). doi:10.1029/ 2002JA009489

D. Summers, B. Ni, N.P. Meredith, Timescales for radiation belt electron acceleration and loss due to resonant waveparticle interactions: 1. Theory. J. Geophys. Res. 112(A4), A04206 (2007). doi:10.1029/ 2006JA011801

R.M. Thorne, R.B. Horne, Cyclotron absorption of ion-cyclotron waves at the bi-ion frequency. Geophys. Res. Lett. 20(4), 317-320 (1993). doi:10.1029/93GL00089

R.M. Thorne, C.F. Kennel, Relativistic electron precipitation during magnetic storm main phase. J. Geophys. Res. 76(19), 4446 (1971). doi:10.1029/JA076i019p04446

A.V. Timofeev, On the constancy of an adiabatic invariant when the nature of the motion changes. Sov. Phys. JETP 48, 656-659 (1978)

Y.K. Tung, C.W. Carlson, J.P. McFadden, D.M. Klumpar, G.K. Parks, W.J. Peria, K. Liou, Auroral polar cap boundary ion conic outflow observed on FAST. J. Geophys. Res. 106(A), 3603-3614 (2001). doi:10.1029/2000JA900115

A.Y. Ukhorskiy, Y.Y. Shprits, B.J. Anderson, K. Takahashi, R.M. Thorne, Rapid scattering of radiation belt electrons by storm-time EMIC waves. Geophys. Res. Lett. 37, L09101 (2010). doi:10.1029/ 2010GL042906

M.E. Usanova, I.R. Mann, I.J. Rae, Z.C. Kale, V. Angelopoulos, J.W. Bonnell, K.-H. Glassmeier, H.U. Auster, H.J. Singer, Multipoint observations of magnetospheric compression-related EMIC Pc1 waves by THEMIS and CARISMA. Geophys. Res. Lett. 35, L17S25 (2008). doi:10.1029/2008GL034458

M.E. Usanova et al., Conjugate ground and multisatellite observations of compression-related EMIC Pc1 waves and associated proton precipitation. J. Geophys. Res. 115, A07208 (2010). doi:10.1029/ 2009JA014935

M.E. Usanova, I.R. Mann, J. Bortnik, L. Shao, V. Angelopoulos, THEMIS observations of electromagnetic ion cyclotron wave occurrence: dependence on AE, SYMH and solar wind dynamic pressure. J. Geophys. Res. 117, A10218 (2012). doi:10.1029/2012JA018049

C. Vallat, N. Ganushkina, I. Dandouras, C.P. Escoubet, M.G.G.T. Taylor, H. Laakso, A. Masson, J.-A. Sauvaud, H. Reme, P. Daly, Ion multi-nose structures observed by Cluster in the inner magnetosphere. Ann. Geophys. 25, 171-190 (2007). doi:10.5194/angeo-25-171-2007 
R.J. Walker, M. Ashour-Abdalla, T. Ogino, V. Peroomian, R.L. Richard, Modeling Magnetospheric Sources. Geophysical Monograph Series, vol. 133 (2003). doi:10.1029/133GM03

Y. Wei, M. Fraenz, E. Dubinin, J. Woch, H. Lühr, W. Wan, Q.-G. Zong, T.L. Zhang, Z.Y. Pu, S.Y. Fu, S. Barabash, R. Lundin, I. Dandouras, Enhanced atmospheric oxygen outflow on Earth and Mars driven by a corotating interaction region. J. Geophys. Res. 117(A3), A03208 (2012). doi:10.1029/2011JA017340

D.T. Welling, A.J. Ridley, Exploring sources of magnetospheric plasma using multispecies MHD. J. Geophys. Res. 115(A4), A04201 (2010). doi:10.1029/2009JA014596

D.T. Welling, S.G. Zaharia, Ionospheric outflow and cross polar cap potential: what is the role of magnetospheric inflation? Geophys. Res. Lett. 39(23), L23101 (2012). doi:10.1029/2012GL054228

D.T. Welling, V.K. Jordanova, S.G. Zaharia, A. Glocer, G. Toth, The effects of dynamic ionospheric outflow on the ring current. J. Geophys. Res. 116, A00J19 (2011). doi:10.1029/2010JA015642

D.T. Welling, M.W. Liemohn, Outflow in global magnetohydrodynamics as a function of a passive inner boundary source. J. Geophys. Res. 119(4), 2691-2705 (2014). doi:10.1002/2013JA019374

B. Wilken, Q.G. Zong, I.A. Daglis, T. Doke, S. Livi, K. Maezawa, Z.Y. Pu, S. Ullaland, T. Yamamoto, Tailward flowing energetic oxygen ion bursts associated with multiple flux ropes in the distant magnetotail: GEOTAil observations. Geophys. Res. Lett. 22(23), 3267-3270 (1995). doi:10.1029/95GL02980

G.R. Wilson, D.M. Ober, G.A. Germany, E.J. Lund, Nightside auroral zone and polar cap ion outflow as a function of substorm size and phase. J. Geophys. Res. 109(A2), A02206 (2004). doi:10.1029/2003JA009835

M. Wiltberger, W. Lotko, J.G. Lyon, P. Damiano, V. Merkin, Influence of cusp $\mathrm{O}^{+}$outflow on magnetotail dynamics in a multifluid MHD model of the magnetosphere. J. Geophys. Res. 115(A6), A00J05 (2010). doi:10.1029/2010JA015579

R.M. Winglee, Multi-fluid simulations of the magnetosphere: the identification of the geopause and its variation with IMF. Geophys. Res. Lett. 25(24), 4441-4444 (1998). doi:10.1029/1998GL900217

R.M. Winglee, Mapping of ionospheric outflows into the magnetosphere for varying IMF conditions. J. Atmos. Sol.-Terr. Phys. 62, 527-540 (2000)

R.M. Winglee, Global impact of ionospheric outflows on the dynamics of the magnetosphere and cross-polar cap potential. J. Geophys. Res. 107(A9), 1237 (2002). doi:10.1029/2001JA000214

R.M. Winglee, W. Lewis, G. Lu, Mapping of the heavy ion outflows as seen by IMAGE and multifluid global modeling for the 17 April 2002 storm. J. Geophys. Res. 110(A12) A12S24 (2005). doi:10.1029/2004JA010909

R.M. Winglee, W.K. Peterson, A.W. Yau, E. Harnett, A. Stickle, Model/data comparisons of ionospheric outflow as a function of invariant latitude and magnetic local time. J. Geophys. Res. 113(A6), A06220 (2008). doi:10.1029/2007JA012817

R.M. Winglee, E. Harnett, Influence of heavy ionospheric ions on substorm onset. J. Geophys. Res. 116(A11), A11212 (2011). doi:10.1029/2011JA016447

J.R. Wygant, C.A. Cattell, R. Lysak, Y. Song, J. Dombeck, J. McFadden, F.S. Mozer, C.W. Carlson, G. Parks, E.A. Lucek, A. Balogh, M. Andre, H. Reme, M. Hesse, C. Mouikis, Cluster observations of an intense normal component of the electric field at a thin reconnecting current sheet in the tail and its role in the shock-like acceleration of the ion fluid into the separatrix region. J. Geophys. Res. 110(A9), A09206 (2005)

L. Xie, Z.Y. Pu, X.Z. Zhou, S.Y. Fu, Q.-G. Zong, M.H. Hong, Energetic ion injection and formation of the storm-time symmetric ring current. Ann. Geophys. 24, 3547-3556 (2006). doi:10.5194/ angeo-24-3547-2006

M. Yamauchi, I. Dandouras, H. Reme, R. Lundin, L.M. Kistler, Cluster observation of few-hour-scale evolution of structured plasma in the inner magnetosphere. Ann. Geophys. 31, 1569-1578 (2013)

B. Yang, Q.-G. Zong, S.Y. Fu, X. Li, A. Korth, H.S. Fu, C. Yue, H. Reme, The role of ULF waves interacting with oxygen ions at the outer ring current during storm times. J. Geophys. Res. 116, A01203 (2011). doi:10.1029/201JA015683

A.W. Yau, P.H. Beckwith, W.K. Peterson, E.G. Shelley, Long-term (solar cycle) and seasonal variations of upflowing ionospheric ion events at DE 1 altitudes. J. Geophys. Res. 90, 6395-6407 (1985). doi:10.1029/JA090iA07p06395

A.W. Yau, W.K. Peterson, E.G. Shelley, Quantitative parametrization of energetic ionospheric ion outflow, in Modeling Magnetospheric Plasma, ed. by T.E. Moore et al.. Geophys. Monogr. Ser., vol. 44 (AGU, Washington D.C., 1988), pp. 211-217

A.W. Yau, B.A. Whalen, E. Sagawa, Minor ion composition in the polar ionosphere. Geophys. Res. Lett. 18, 345-348 (1991). (ISSN 0094-8276). doi:10.1029/91GL00034

A.W. Yau, M. André, Sources of ion outflow in the high latitude ionosphere. Space Sci. Rev. 80, 1-25 (1997). doi:10.1023/A:1004947203046

A.W. Yau, T. Abe, W.K. Peterson, The polar wind: recent observations. J. Atmos. Sol.-Terr. Phys. 69(16), 1936-1983 (2007). doi:10.1016/j.jastp.2007.08.010 
A.W. Yau, A. Horwarth, W.K. Peterson, T. Abe, Transport of thermal-energy ionospheric oxygen $\left(\mathrm{O}^{+}\right)$ions between the ionosphere and the plasma sheet and ring current at quiet times. J. Geophys. Res. 117(A7), A07215 (2012)

D.T. Young, S. Perraut, A. Roux, C. de Villedary, R. Gendrin, A. Korth, G. Kremser, D. Jones, Wave-particle interactions near Omega/He plus/observed on GEOS 1 and 2. I-Propagation of ion cyclotron waves in He/plus/-rich plasma. J. Geophys. Res. 86(1), 6755-6772 (1981). doi:10.1029/JA086iA08p06755

D.T. Young, H. Balsiger, J. Geiss, Correlations of magnetospheric ion composition with geomagnetic and solar activity. J. Geophys. Res. 87 (1982). doi:10.1029/JA087iA11p09077

Y. Yu, A.J. Ridley, Exploring the influence of ionospheric $\mathrm{O}^{+}$outflow on magnetospheric dynamics: dependence on the source location. J. Geophys. Res. 118(4), 1711-1722 (2013). doi:10.1029/2012JA018411

Z. Yuan, X. Deng, X. Lin, Y. Pang, M. Zhou, P.M.E. Décréau, J.G. Trotignon, E. Lucek, H.U. Frey, J. Wang, Link between EMIC waves in a plasmaspheric plume and a detached sub-auroral proton arc with observations of Cluster and IMAGE satellites. Geophys. Res. Lett. 37, L07108 (2010). doi:10.1029/ 2010GL042711

S. Zaharia, V.K. Jordanova, M.F. Thomsen, G.D. Reeves, Self-consistent modeling of magnetic fields and plasmas in the inner magnetosphere: application to a geomagnetic storm. J. Geophys. Res. 111(A11), A11S14 (2006). doi:10.1029/2006JA011619

L.M. Zelenyi, A.S. Lipatov, D.G. Lominadze, A.L. Taktakishvili, The dynamics of the energetic proton bursts in the course of the magnetic field topology reconstruction in the Earth's magnetotail. Planet. Space Sci. 32, 313-324 (1984)

L.M. Zelenyi, D.V. Zogin, The acceleration of charged particles in the magnetotail. Cosm. Res. 26, 628-631 (1988). (In Russian)

L. Zelenyi, M.I. Sitnov, H.V. Malova, A.S. Sharma, Thin and superthin ion current sheets, quasiadiabatic and nonadiabatic models. Nonlinear Process. Geophys. 7, 127-139 (2000)

L.M. Zelenyi, D.C. Delcourt, H.V. Malova, A.S. Sharma, "Aging" of the magnetotail thin current sheets. Geophys. Res. Lett. 29, 491-494 (2002). doi:10.1029/2001GL013789

L.M. Zelenyi, E.E. Grigorenko, A.O. Fedorov, Spatial-temporal ion structures in the Earth's magnetotail: beamlets as a result of nonadiabatic impulse acceleration of the plasma. JETP Lett. 80(10), 663-673 (2004a)

L.M. Zelenyi, H.V. Malova, V.Yu. Popov, D. Delcourt, A.S. Sharma, Nonlinear equilibrium structure of thin currents sheets: influence of electron pressure anisotropy. Nonlinear Process. Geophys. 11(1), 1-9 (2004b)

L.M. Zelenyi, H.V. Malova, V.Y. Popov, D.C. Delcourt, N.Y. Ganushkina, A.S. Sharma, "Matreshka" model of multilayered current sheet. Geophys. Res. Lett. 33, L05105 (2006). doi:10.1029/2005GL025117

L. Zelenyi, A. Artemiev, H. Malova, V. Popov, Marginal stability of thin current sheets in the Earth's magnetotail. J. Atmos. Sol.-Terr. Phys. 70, 325-333 (2008a). doi:10.1016/j.jastp.2007.08.019

L. Zelenyi, A. Artemyev, H. Malova, A.V. Milovanov, G. Zimbardo, Particle transport and acceleration in a time-varying electromagnetic field with a multi-scale structure. Phys. Lett. A 372, 6284-6287 (2008b)

L.M. Zelenyi, Kh.V. Malova, A.V. Artemyev, V.Yu. Popov, A.A. Petrukovich, Thin current sheets in collisionless plasma: equilibrium structure, plasma instabilities, and particle acceleration. Engl. Transl. Plasma Phys. Rep. 37(2), 118-160 (2011). Pleiades Publishing, Ltd.

J.-C. Zhang, L.M. Kistler, C.G. Mouikis, M.W. Dunlop, B. Klecker, J.A. Sauvaud, A case study of EMIC wave-associated $\mathrm{He}^{+}$energization in the outer magnetosphere: cluster and double star 1 observations. J. Geophys. Res. 115(A), 06212 (2010). doi:10.1029/2009JA014784

J.-C. Zhang, L.M. Kistler, C.G. Mouikis, B. Klecker, J.A. Sauvaud, M.W. Dunlop, A statistical study of EMIC wave-associated $\mathrm{He}^{+}$energization in the outer magnetosphere: Cluster/CODIF observations. J. Geophys. Res. 116(A), 11201 (2011a). doi:10.1029/2011JA016690

J.-C. Zhang, L.M. Kistler, C.G. Mouikis, H. Matsui, B. Klecker, I. Dandouras, M.W. Dunlop, Shock-driven variation in ionospheric outflow during the 11 October 2001 moderate storm. J. Geophys. Res. 116 (2011b). doi:10.1029/2010JA015627

G. Zimbardo, A. Greco, L. Sorriso-Valvo, S. Perri, Z. Vörös, G. Aburjania, K. Chargazia, O. Alexandrova, Magnetic turbulence in the geospace environment. Space Sci. Rev. 156, 89-134 (2010). doi:10.1007/s11214-010-9692-5

Q.-G. Zong, B. Wilken, G.D. Reeves, I.A. Daglis, T. Doke, T. Iyemori, S. Livi, K. Maezawa, T. Mukai, S. Kokubun, Z.-Y. Pu, S. Ullaland, J. Woch, R. Lepping, T. Yamamoto, Geotail observations of energetic ion species and magnetic field in plasmoid-like structures in the course of an isolated substorm event. J. Geophys. Res. 102(A6), 11409-11428 (1997)

Q.-G. Zong, B. Wilken, J. Woch, T. Mukai, T. Yamamoto, G.D. Reeves, T. Doke, K. Maezawa, D.J. Williams, S. Kokubun, S. Ullaland, Energetic oxygen bursts in the distant magnetotail as a product of intense substorms: three case studies. J. Geophys. Res. 103, 20339 (1998) 
Q.-G. Zong, B. Wilken, S.Y. Fu, T.A. Fritz, A. Korth, N. Hasebe, D.J. Williams, Z.Y. Pu, Ring current oxygen ion escaping into the magnetosheath. J. Geophys. Res. 106, 25541-25556 (2001). doi:10.1029/2000JA000127

Q.-G. Zong, T.A. Fritz, Z.Y. Pu, S.Y. Fu, D.N. Baker, H. Zhang, A.T. Lui, I. Vogiatzis, K.H. Glassmeier, A. Korth, P.W. Daly, A. Balogh, H. Rème, Cluster observations of earthward flowing plasmoid in the tail. Geophys. Res. Lett. 31, L18803 (2004). doi:10.1029/2004GL020692 